\title{
UTILIZAÇÃO DE POLÍMEROS E COPOLÍMEROS CONDUTORES NA DETECÇÃO DE COMPOSTOS ORGÂNICOS
}

\author{
Fabiana Moreto
}

Dissertação apresentada ao Instituto de Química de São Carlos, da Universidade de São Paulo para obtenção do título de Mestre em Ciências (Físico-química).

Orientador: Prof. Dr. Artur de Jesus Motheo

São Carlos

2006 
DedicatóRIA

Dedico este trabalho aos meus pais e a Deus, os quais sou grata por minha existência e sobrevivência. 


\section{AgradeCIMENTOS}

- Ao Prof. Dr. Artur de Jesus Motheo pela orientação, compreensão, paciência e amizade.

A todos os profissionais do IQSC-USP que contribuíram para a realização deste trabalho.

A CAPES pela bolsa de estudo.

> Aos amigos do Grupo de eletroquímica Interfacial (Geqi): Álvaro, Douglas, Eveline, Fernando, Karen, Leandro, Luciano, Marciana, Rodrigo e Sandra, pelo apoio, amizade e discussões.

Aos amigos Érica, Fábio, Greves, Jack, Jana, Marli, Pietra, Pri, Rachel, Salame e Val, pela preocupação e incentivo, sempre me dando forças pra continuar quando eu achava que elas não mais existiam.

Aos novos amigos, principalmente Ester e Edson, e aos amigos distantes por nunca deixarem de torcerem por mim.

A minha Vó Carola (in memorian) que sempre será minha estrela guia.

Aos meus familiares, que mesmo distantes sempre me apoiaram.

A todos que direta ou indiretamente contribuíram de algum modo para a realização desta dissertação.

Aos meus pais, minha irmã e a Deus. 


\section{INDICE}

LISTA DE FIGURAS..................................................................... i

LISTA DE TABELAS..................................................................... vi

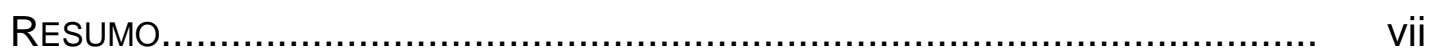

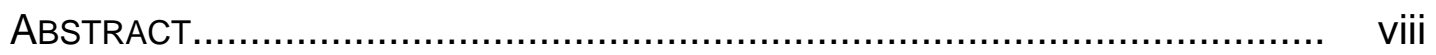

CAPÍTULO I - INTRODUÇÃO..................................................... 1

1.1. Polianilinas Substituídas................................................... 5

1.2. Sensores de Polímeros condutores...................................... 7

1.2.1 Sensores de Polianilinas............................................. 8

1.3 Seletividade de em Sensor Químico........................................... 9

1.4 Tipos de Sensores............................................................. 10

1.4.1 Sensores Potenciométricos (corrente nula)...................... 10

1.4.2 Sensores Amperométricos e Voltamétricos (passagem de

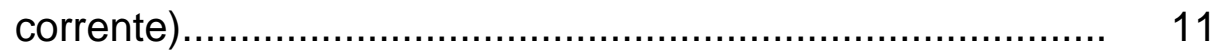

1.5 Modificação de Eletrodos....................................................... 12

1.5.1 Métodos para a Modificação de Eletrodos........................... 12

1.6 Compostos Orgânicos...................................................... 13

1.6.1 Hidroquinona...................................................... 13

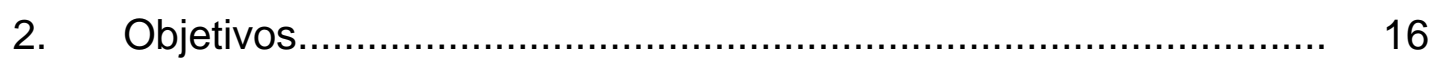

CAPÍTULO II - EXPERIMENTAL .................................................. 17

2.1 Célula eletroquímica.............................................................. 17

2.2 Reagentes e Soluções.......................................................... 18

2.3 Síntese Eletroquímica............................................................. 19

2.3.1 Voltametria Cíclica........................................................... 19

2.4 Caracterização................................................................... 20

2.4.1 Espectroscopia na Região do Infravermelho.................... 20 
2.4.2 Espectroscopia na Região do Ultravioleta e Visível............... 21

2.4.3 Microscopia Eletrônica de Varredura.................................... 22

CAPÍTULO III -RESULTADOS E DISCUSSÕES...................................... 24

3.1. Crescimento Eletroquímico.......................................................... 25

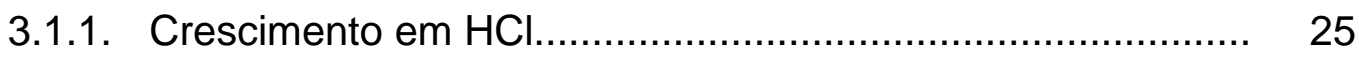

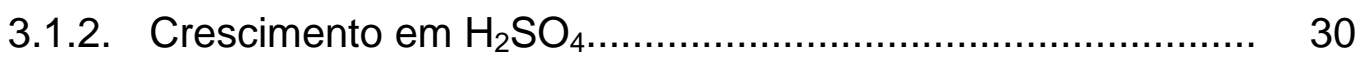

3.2. Espectroscopia na região do infravermelho.................................. 33

3.3. Espectroscopia de ultravioleta e visível....................................... 36

3.4. Microscopia Eletrônica de Varredura........................................... 38

3.5. Respostas Eletroquímicas.................................................... 42

3.6. Comportamento dos filmes poliméricos na presença de soluções contendo hidroquinona............................................................ 44

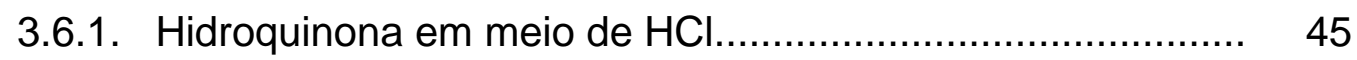

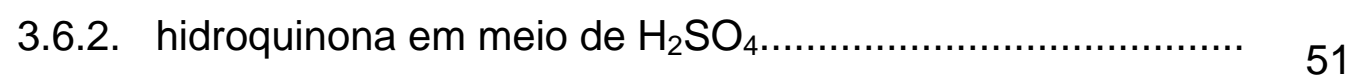

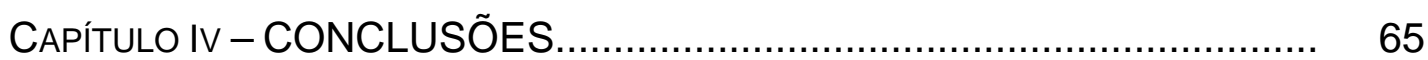

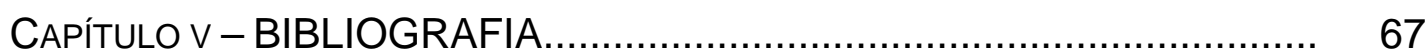




\section{LISTA DE FIGURAS}

Fig.1. Mecanismo simplificado para a reação de polimerização

02 da PAni

Fig. 2 Fórmula Geral da PAni

$\begin{array}{lll}\text { Fig. } 3 & \text { Célula Eletroquímica (a) } & 18\end{array}$

Fig. 4 Voltamograma cíclico do crescimento eletroquímico de PAni em solução de $0,1 \mathrm{~mol} \mathrm{~L}^{-1}$ de anilina e $1 \mathrm{~mol} \mathrm{~L}^{-1}$ $\mathrm{HCl}$ em intervalos de potenciais de $-0,2$ a $0,8 \mathrm{~V}$, velocidade de varredura $50 \mathrm{mV} / \mathrm{s}$.

Fig. 5 Voltamograma cíclico do crescimento eletroquímico de POMA em solução de $0,1 \mathrm{~mol} \mathrm{~L}^{-1}$ de o-anisidina e $1 \mathrm{~mol}$ $\mathrm{L}^{-1} \mathrm{HCl}$ em intervalos de potenciais de $-0,2$ a $0,7 \mathrm{~V}$, velocidade de varredura $50 \mathrm{mV} / \mathrm{s}$.

Fig. 6 Voltamograma cíclico do crescimento eletroquímico de PAOMA em solução de $0,05 \mathrm{~mol} \mathrm{~L}^{-1}$ de anilina e 0,05 mol L-1 de o-anisidina e $1 \mathrm{~mol} \mathrm{~L}^{-1} \mathrm{HCl}$ em intervalos de potenciais de $-0,2$ a $0,7 \mathrm{~V}$, velocidade de varredura 50 $\mathrm{mV} / \mathrm{s}$.

Fig. 7 Voltamograma cíclico do crescimento eletroquímico de PAni em solução de $0,1 \mathrm{~mol} \mathrm{~L}^{-1}$ de anilina e $1 \mathrm{~mol} \mathrm{~L}^{-1}$ $\mathrm{HCl}$ em intervalos de potenciais de $-0,2$ a $0,8 \mathrm{~V}$, velocidade de varredura $50 \mathrm{mV} / \mathrm{s}$.

Fig. 8 Voltamograma cíclico do crescimento eletroquímico de POMA em solução de $0,1 \mathrm{~mol} \mathrm{~L}^{-1}$ de o-anisidina e $1 \mathrm{~mol}$ $\mathrm{L}^{-1} \quad \mathrm{H}_{2} \mathrm{SO}_{4}$ em intervalos de potenciais de $-0,2$ a $0,7 \mathrm{~V}$, velocidade de varredura $50 \mathrm{mV} / \mathrm{s}$. 
Fig. 9 Voltamograma cíclico do crescimento eletroquímico de 33 PAOMA em solução de $0,05 \mathrm{~mol} \mathrm{~L}^{-1}$ de anilina e 0,05 mol L'1 de o-anisidina e $1 \mathrm{~mol} \mathrm{~L}^{-1} \quad \mathrm{H}_{2} \mathrm{SO}_{4}$ em intervalos de potenciais de $-0,2$ a $0,7 \mathrm{~V}$, velocidade de varredura $50 \mathrm{mV} / \mathrm{s}$.

Fig. 10 Espectros de infravermelho dos polímeros dopados: (a) $\operatorname{POMA}(\mathrm{Cl})$, (b) PAOMA(SO 4$)$, (c) PAni(Cl), (d) PAni(SO 4$)$, (e) $\operatorname{PAOMA}(\mathrm{Cl})$, (f) $\operatorname{POMA}\left(\mathrm{SO}_{4}\right)$.

Fig. 11 Espectro de absorção na região do ultravioleta e visível dos filmes poliméricos no estado dopado.

Fig. 12 Espectro de Absorção na região do ultravioleta e visível dos filmes poliméricos no estado desdopado.

Fig. 13 Micrografia obtida para o filme de polianilina em meio de $\mathrm{HCl}$.

Fig. 14 Micrografia obtida para o filme de poli(o-metoxianilina) em meio de $\mathrm{HCl}$.

Fig. 15 Micrografia obtida para o filme de polianilina em meio de $\mathrm{H}_{2} \mathrm{SO}_{4}$.

Fig. 16 Micrografia do filme de poli(o-metoxianilina) em meio de $\mathrm{H}_{2} \mathrm{SO}_{4}$.

Fig. 17 Micrografia obtida para o filme de polianilina e poli(ometoxianilina) em meio de $\mathrm{HCl}$.

Fig. 18 Micrografia obtida para o filme de polianilina e poli(ometoxianilina) em meio de $\mathrm{H}_{2} \mathrm{SO}_{4}$.

Fig. 19 Resposta eletroquímica do filme de PAni em solução de $1 \mathrm{~mol} \mathrm{~L}^{-1}$ a) $\mathrm{HCl}$; b) $\mathrm{H}_{2} \mathrm{SO}_{4}, 5^{\circ}$ ciclo, $\mathrm{v}=50 \mathrm{mV} / \mathrm{s}$.

Fig. 20 Resposta eletroquímica do filme de POMA em solução de $1 \mathrm{~mol} \mathrm{~L}^{-1}$ a) $\mathrm{HCl}$; b) $\mathrm{H}_{2} \mathrm{SO}_{4}, 5^{\circ}$ ciclo, $\mathrm{v}=50 \mathrm{mV} / \mathrm{s}$ 
Fig. 21 Resposta eletroquímica do filme de PAOMA em solução 44 $1 \mathrm{~mol} . \mathrm{L}^{-1} \mathrm{~L}^{-1}$ a) $\mathrm{HCl}$; b) $\mathrm{H}_{2} \mathrm{SO}_{4}, 5^{\circ}$ ciclo, $\mathrm{v}=50 \mathrm{mV} / \mathrm{s}$.

Fig. 22 Resposta eletroquímica de a) POMA; b) PAni e c) 46 PAOMA em $1 \mathrm{~mol} \mathrm{~L}^{-1} \mathrm{HCl}(-)$ sem $\mathrm{HQ}$ e $(-)$ com $5 \mathrm{mM} \mathrm{HQ} . \mathrm{v}=50 \mathrm{mV} / \mathrm{s}$.

Fig. 23 Resposta eletroquímica de a) PAni, b) POMA e c) 47 PAOMA em contato com solução de $1 \mathrm{~mol} \mathrm{~L}^{-1} \mathrm{HCl}$ e 5 a $50 \mathrm{~mol} \mathrm{~L}^{-1} \mathrm{HQ}$.

Fig. 24 Curva do pico de corrente de oxidação da $\mathrm{HQ}$ pela concentração de $\mathrm{HQ}$ em solução de $\mathrm{HCl} 1 \mathrm{~mol} \mathrm{~L}^{-1}$ do filme de PAni(Cl). Coeficiente angular de 1,38142.

Fig. 25 Curva do pico de corrente de oxidação da $\mathrm{HQ}$ pela concentração de $\mathrm{HQ}$ em solução de $\mathrm{HCl} 1 \mathrm{~mol} \mathrm{~L}^{-1}$ do filme de $\mathrm{POMA}(\mathrm{Cl})$. Coeficiente angular de 0,46307.

Fig. 26 Curva do pico de corrente de oxidação da $\mathrm{HQ}$ pela concentração de $\mathrm{HQ}$ em solução de $\mathrm{HCl} 1 \mathrm{~mol} \mathrm{~L}^{-1}$ do filme de PAOMA(Cl). Coeficiente angular de 0,17423.

Fig. 27 Curva de coeficiente angular da reta do pico de corrente de oxidação pela concentração de $H Q$, pela $Q_{\text {picoA }}$ do filme de PAni(Cl).

Fig. 28 Curva de coeficiente angular da reta do pico de corrente de oxidação pela concentração de $H Q$ pela $Q_{\text {picoA }}$ do filme de $\operatorname{POMA}(\mathrm{Cl})$.

Fig. 29 Curva de coeficiente angular da reta do pico de corrente de oxidação pela concentração de $H Q$ pela $Q_{\text {picoA }}$ do filme de $\operatorname{PAOMA}(\mathrm{Cl})$.

Fig. 30 Respostas eletroquímicas dos filmes de a) POMA; b) 52 PAni e c) PAOMA em $1 \mathrm{~mol} \mathrm{~L}^{-1}$ de $\mathrm{H}_{2} \mathrm{SO}_{4}$ ( - ) sem $\mathrm{HQ}$ e com (- ) $5 \mathrm{mM} \mathrm{HQ}$. v $=50 \mathrm{mV} / \mathrm{s}$.

Fig. 31 Resposta eletroquímica de a) PAni, b) POMA e c) 53 PAOMA em contato com solução de $1 \mathrm{~mol} \mathrm{~L}^{-1} \mathrm{H}_{2} \mathrm{SO}_{4}$ e 5 a $50 \mathrm{~mol} . \mathrm{L}^{-1} \mathrm{HQ}$. 
Fig. 32 Curva do pico de corrente de oxidação da $\mathrm{HQ}$ pela 54 concentração de $\mathrm{HQ}$ em solução de $\mathrm{H}_{2} \mathrm{SO}_{4} 1 \mathrm{~mol} \mathrm{~L}^{-1}$ do filme de PAni( $\left.\mathrm{SO}_{4}\right)$. Coeficiente angular de 2,46559.

Fig. 33 Curva do pico de corrente de oxidação da $\mathrm{HQ}$ pela 54 concentração de $\mathrm{HQ}$ em solução de $\mathrm{H}_{2} \mathrm{SO}_{4} 1 \mathrm{~mol} \mathrm{~L}^{-1}$ do filme de $\operatorname{POMA}\left(\mathrm{SO}_{4}\right)$. Coeficiente angular de 0,48005.

Fig. 34 Curva do pico de corrente de oxidação da $\mathrm{HQ}$ pela concentração de $\mathrm{HQ}$ em solução de $\mathrm{H}_{2} \mathrm{SO}_{4} 1 \mathrm{~mol} \mathrm{~L}^{-1}$ do filme de PAOMA(SO $\mathrm{SO}_{4}$. Coeficiente angular de 0,26339.

Fig. 35 Curva de coeficiente angular da reta do pico de corrente de oxidação pela concentração de $H Q$ pela $Q_{\text {picoA }}$ do filme de PAni( $\left.\mathrm{SO}_{4}\right)$.

Fig. 36 Curva de coeficiente angular da reta do pico de corrente 56 de oxidação pela concentração de $H Q$ pela $Q_{\text {picoA }}$ do filme de $\mathrm{POMA}\left(\mathrm{SO}_{4}\right)$.

Fig. 37 Curva de coeficiente angular da reta do pico de corrente de oxidação pela concentração de $H Q$ pela $Q_{\text {picoA }}$ do filme de $\mathrm{PAOMA}\left(\mathrm{SO}_{4}\right)$.

Fig. 38 Diagrama da interação do filme polimérico com a 59 Hidroquinona.

Fig. 39 Efeito da espessura (d) na concentração de $\mathrm{HQ}^{P}$ para o 61 filme de PAni(Cl).

Fig. 40 Efeito da espessura (d) na concentração de $\mathrm{HQ}^{\mathrm{P}}$, para o filme de $\mathrm{POMA}(\mathrm{Cl})$.

Fig. 41 Efeito da espessura (d) na concentração de $\mathrm{HQ}^{\mathrm{P}}$, para o filme de $\mathrm{PAOMA}(\mathrm{Cl})$.

Fig. 42 Efeito da espessura (d) na concentração de $\mathrm{HQ}^{\mathrm{P}}$ para $0 \quad 62$ filme de PAni( $\left.\mathrm{SO}_{4}\right)$.

Fig. 43 Efeito da espessura (d) na concentração de $\mathrm{HQ}^{P}$ para o 62 filme de $\mathrm{POMA}\left(\mathrm{SO}_{4}\right)$.

Fig. 44 Efeito da espessura (d) na concentração de $\mathrm{HQ}^{P}$ para o 62 filme de PAOMA $\left(\mathrm{SO}_{4}\right)$. 
$\begin{array}{llllllll}\text { Fig. } 45 \text { Valores de } \Delta & E_{\mathrm{P}} & \text { para } & 0 & \text { par redox } & 64\end{array}$ Quinona/Benzoquinona para os filmes de polímeros e copolímeros. 


\section{LISTA DE TABELAS}

Tabela 1 Diferentes Formas de Polianilina 03

Tabela 2 Colorações do filme de PAni observadas a diferentes 26 potenciais.

Tabela 3 Colorações do filme de POMA observadas em 28 diferentes potenciais.

Tabela 4 Colorações do filme de PAOMA observadas em 29 diferentes potenciais.

Tabela 5 Concentração Média de $\left[O x^{P}\right] /$ mol.L $^{-1}$., para todos os filmes de polímeros e copolímeros 


\section{Capítulo I}

\section{Introdução}

Os polímeros condutores têm sido alvo de vários estudos nos últimos anos, devido as suas características condutoras muito próximas das dos metais [1]. Um polímero condutor em sua forma desdopada possui características isolantes, ou seja, não conduz eletricidade. Para que esse polímero se torne condutor de elétrons, ele deve ser dopado pela ação de agentes oxidantes ou pela adição de agentes que deslocalizem parcialmente suas próprias cargas no interior do polímero [2,3]. Há algumas décadas, foi observado que compostos com ligações conjugadas, ou seja, ligações simples e duplas alternadas ao longo da cadeia do polímero, permitem um aumento de até 15 ordens de grandeza na condutividade elétrica, quando submetidos a processos de dopagem química ou eletroquímica [4]. Em outras palavras, dependendo do grau de dopagem, os polímeros podem apresentar valores de condutividade elétrica que vão desde isolantes até condutores.

Alguns polímeros condutores podem conduzir corrente elétrica, através do fluxo de partículas carregadas (íons) em seu interior ou ao longo da 

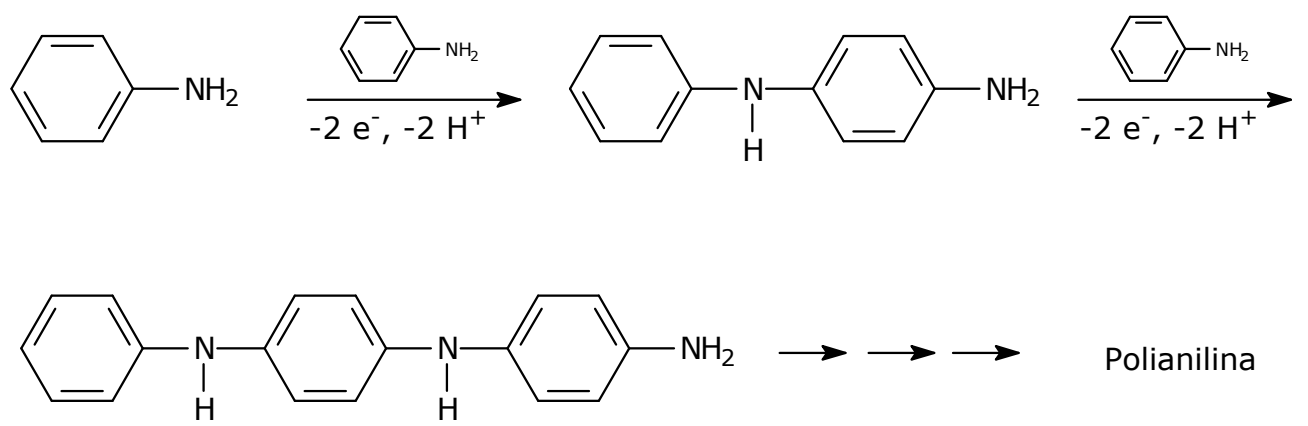

Figura 1. Mecanismo simplificado para a reação de polimerização da PAni.

cadeia do polímero [5,6], estes polímeros são conhecidos como polímeros condutores eletrônicos [4-7]. Devido a essas características, os polímeros condutores possuem uma série de aplicações nas mais diversas áreas tecnológicas tais como proteção à corrosão, baterias, sensores, capacitores eletrolíticos, janelas inteligentes, eletrocatálise, etc. [7-12]

A polianilina (PAni) é um material muito interessante em aplicações tecnológicas e seu destaque é devido a grande estabilidade em condições ambientais e a facilidade com que é sintetizada. A síntese de PAni pode ser feita de duas maneiras: pela oxidação direta da anilina por oxidantes químicos ou pela oxidação aniônica em um eletrodo inerte, na presença de doadores de prótons [3]. Na Figura 1 está representado um mecanismo simplificado para a reação de polimerização da PAni.

A fórmula geral da PAni na sua forma de base não dopada está representada na Figura 2, sendo que y corresponde à fração de unidades repetidas reduzidas e 1-y à fração de unidades repetidas oxidadas. 


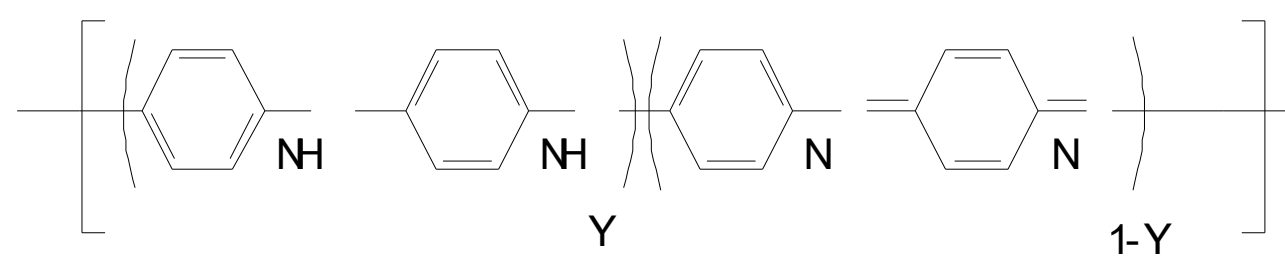

Figura 2: Fórmula Geral da Pani.

Tabela 1: Diferentes formas de polianilina [15].

\begin{tabular}{|c|c|c|c|}
\hline $\begin{array}{l}\text { Valor de } \\
\text { y }\end{array}$ & Nome & Cor & $\begin{array}{c}\text { Condutividade } \\
\left(\mathrm{S} . \mathrm{cm}^{-1}\right)\end{array}$ \\
\hline $\begin{array}{l}1 \text { (forma } \\
\text { reduzida) }\end{array}$ & $\begin{array}{c}\text { Base } \\
\text { Polileucoesmeraldina }\end{array}$ & Transparente & $<10^{-5}$ \\
\hline 0,75 & $\begin{array}{c}\text { Base } \\
\text { Poliprotoesmeraldina }\end{array}$ & & $<10^{-5}$ \\
\hline $\begin{array}{c}0,5 \\
\text { (desdopada) }\end{array}$ & $\begin{array}{c}\text { Base } \\
\text { Poliesmeraldina }\end{array}$ & Azul & $<10^{-5}$ \\
\hline $\begin{array}{c}0,5 \\
\text { (dopada) }\end{array}$ & $\begin{array}{c}\text { Sal } \\
\text { Poliesmeraldina }\end{array}$ & Verde & $\sim 15$ \\
\hline 0,25 & Base polinigranilina & & $<10^{-5}$ \\
\hline $\begin{array}{l}0 \text { (forma } \\
\text { oxidada) }\end{array}$ & $\begin{array}{c}\text { Base } \\
\text { Polipernigranilina }\end{array}$ & Púrpura & $<10^{-5}$ \\
\hline
\end{tabular}

O valor de y pode variar continuamente entre 0 e 1 . Quando y assume o valor 1 , teremos o polímero completamente reduzido apresentando apenas nitrogênio amina, conhecido como leucoesmeraldina. 
Quando $\mathrm{y}=0$, o polímero estará completamente oxidado contendo apenas nitrogênio imina, conhecido como pernigranilina. O estado mais estável e condutor é conhecido como esmeraldina (50\% oxidado).

Os termos que indicam os diferentes graus de oxidação da polianilina estão na Tabela 1 .

Os estados de oxidação da polianilina designados por protoesmeraldina $(y=0,75)$ e nigranilina $(y=0,25)$ não foram sintetizada s até o momento. Observou-se que a base esmeraldina é oxidada para a base pernigranilina de uma vez, sem passar por qualquer estado de oxidação discreto intermediário. Com base nestes resultados suspeita-se que os estados protoesmeraldina e nigranilina sejam uma composição dos outros estados de oxidação do polímero. Assim, os termos leucoesmeraldina, esmeraldina e pernigranilina referem-se aos diferentes estados de oxidação da polianilina.

Cada um desses estados de oxidação pode existir tanto na forma de base (não condutora) como na forma de sal (condutora), através de dopagem da base com um ácido de Brönsted. O estado de oxidação esmeraldina é a forma na qual, após dopagem, alcança-se os maiores valores de condutividade e, portanto, a síntese mais empregada é aquela que a produz nesse estado.

A aplicação de polímeros eletricamente ativos em sensores químicos vem sendo muito estudada devido a dois fatores: a) grande seletividade da superfície do polímero sintetizado a alguns materiais inorgânicos, b) mecanismo pelo qual a interação química é medida como um sinal físico.

A habilidade de modificar significativamente alguns parâmetros físicos 
de uma interação em particular com algumas espécies químicas é uma das características mais importantes para a identificação de um elemento químico. Um fenômeno desse tipo pode ser considerada como um processo de dopagem secundário [10].

Um outro fator importante, do ponto de vista de sensores, é que a PAni e seus derivados têm uma grande estabilidade em seus estados de oxidação. A eletropolimerização dos filmes, produzindo polímeros condutores em seu estado mais oxidado, apresenta um efeito peculiar: o potencial de equilíbrio do polímero decresce mais de $400 \mathrm{mV}$ em um período de algumas horas. Isso mostra que há um aumento na concentração de ânions na superfície do eletrodo. Outro efeito observado é que a função de trabalho do polímero decresce de aproximadamente $800 \mathrm{mV}$, um processo atribuído ao relaxamento das cadeias do filme polimérico. Eletroquimicamente, isto significa que as interações entre os elétrons e o polímero matricial ficaram mais fracas e, portanto, mais suscetíveis a reações [13,14]. A ocorrência desse fenômeno foi observada em politiofeno (PT), polipirrol (PPY) e polianilina (PAni), sendo que espera-se que aconteça em todos os polímeros eletroativos.

Se houver presença de oxigênio, a perda de elétrons é atribuída por sua redução, que pode resultar na formação de radicais aniônicos de oxigênio e na degradação do polímero por oxidação [10]. 


\subsection{Polianilinas Substituídas}

Polianilinas substituídas são obtidas a partir da troca do átomo de hidrogênio no anel aromático da anilina, por grupos funcionais como $-\mathrm{CH}_{3}$, $\mathrm{C}_{2} \mathrm{H}_{5},-\mathrm{OCH}_{3},-\mathrm{OC}_{2} \mathrm{H}_{5}$. As polianilinas modificadas obtidas a partir dos grupos funcionais $-\mathrm{OCH}_{3}$ e $-\mathrm{OC}_{2} \mathrm{H}_{5}$ são solúveis em água e suas condutividades estão entre $10^{-1}-10^{-3} \mathrm{~S} . \mathrm{cm}^{-1}[15]$.

Quando se incorpora um grupo funcional substituinte ao anel aromático, aumenta-se a estabilidade do polímero produzido e diminue-se a sua condutividade, ao contrário do esperado que seria o aumento da localização dos elétrons ou a redução nas ligações $\pi$ conjugadas.

A poli (o-metilanilina) mostra grande localização de elétrons comparada com a polianilina, embora suas estruturas de bandas eletrônicas sejam essencialmente as mesmas. Este aumento na localização de elétrons pode ser devido à diminuição da velocidade de difusão intercadeia e a redução intercadeia como resultado do grupo $-\mathrm{CH}_{3}$ localizado aleatoriamente ao longo dos anéis fenis, o que aumenta a localização de elétrons e diminui a condutividade do polímero em aproximadamente 3 ordens de grandezas.

PAni, poli(o-metilanilina), poli(o-etilanilina) e poli(o-propilanilina) mostraram também aumento na localização dos elétrons ao longo de suas cadeias com o aumento do tamanho do grupo alquil substituinte nos anéis fenis.

A condutividade elétrica da poli(o-etoxianilina) mostra-se similar a das polianilinas alquil-substituídas. Estudos realizados com poli(2,5- 
dialcoxianilinas), mostraram que a condutividade de polímeros disubstituídos como a poli(2,5-dimetoxianilina) e poli(2,5-dietoxianilina) chega a $10^{-1}{\mathrm{~S} . \mathrm{cm}^{-1}}^{-1}$ ,mas para polímeros com grupos alcóxis de cadeia longa (mais de 6 átomos) a condutividade decresce de 3 à 5 ordens de grandeza [16].

\subsection{Sensores de Polímeros Condutores}

Polímeros condutores têm ganhado grande popularidade como material sensível a vários vapores orgânicos, gases tóxicos e umidade [17]. Sensores de polímeros condutores são geralmente fabricados pela deposição dos filmes poliméricos sobre eletrodos interdigitados de configuração prédeterminada, a membrana polimérica atua como matriz suporte imobilizando moléculas específicas. Um exemplo é a PAni, que pode ser usada como sensor para gases devido a sua diferente permeabilidade e seletividade dos íons nos seus estados dopado e não dopado [18].

Muitos dos sensores disponíveis para gases são baseados em dióxido de estanho. Esses sensores operam a altas temperaturas para assegurar uma melhor sensibilidade e seletividade do sensor. Assim na tentativa de aperfeiçoar as características dos sensores, outros materias como polímeros condutores estão sendo estudados.

As vantagens dos polímeros condutores em relação aos materias inorgânicos usados até agora são: a facilidade em sintetizá-los e boa sensibilidade quando operam a temperatura ambiente.

O polipirrol foi o primeiro polímero usado como sensor para gases, mas 
mostrou baixa sensibilidade, alto tempo de resposta e desorção incompleta das moléculas de gás [15]. Alguns estudos foram realizados com o polipirrol (Ppy) e poli-3-metiltiofeno (P3MT), dopados com inclusões metálicas de cobre e paládio na matriz polimérica. Os filmes obtidos mostraram boa sensibilidade para gases como o $\mathrm{NH}_{3}, \mathrm{H}_{2}$ e $\mathrm{CO}$ [19].

Outros sistemas usados como sensores tem sido desenvolvido, como: o nariz eletrônico e a língua eletrônica [18].Três tipos de sensores gustativos foram desenvolvidos, o primeiro composto por oito tipos diferentes de lipídios dispersos sobre matriz polimérica (PVC), usando medidas potenciométricas para a obtenção dos resultados. O segundo tem sua suas medidas baseado no FET e suas medidas não respondem tão bem quanto as medidas realizadas com o método potenciométrico e o terceiro constituído de 6 diferentes eletrodos de trabalho e a resposta baseada em pulsos voltamétricos. Todos os 3 tipos de língua eletrônica também mostraram-se aptos para detecção de poluentes em água [18].

\subsubsection{Sensores de polianilinas}

A Pani e seus derivados substituídos têm sido amplamente estudados como sensores para uma grande gama e substâncias. Athawale et al. [20], realizaram estudos comparativos entre PAni e seus derivados substituídos como sensores para diferentes vapores e álcoois alifáticos. A exposição desses polímeros aos vapores dos álcoois resultou na mudança de condutividade e cristalinidade dos mesmos, que são explicadas pelas 
mudanças estruturais ocorridas nos polímeros devido à adsorção das moléculas de álcool.

Foram também realizados recentemente, estudos sobre polianilinas com inclusões metálicas. Sharma et al. [21], sintetizaram quimicamente uma nanocomposição de polianilina/ $\mathrm{Cu}$. O polímero obtido foi submetido à presença de vapores de clorofórmio $\left(\mathrm{CHCl}_{3}\right)$ em diferentes concentrações $(<$ 100 ppm). Os resultados mostraram que a sensibilidade da nanocomposição PAni/Cu é maior que a sensibilidade da PAni pura, devido a adsorçãodesorção do clorofórmio sobre a superfície do centro metálico. A sensibilidade da nanocomposição pode ser aumentada com o aumento do centro metálico incluso no polímero.

Lindfors e Ivaska [22] observaram que a Pani e seus derivados substituídos são sensíveis ao $\mathrm{pH}$. Seus estudos revelaram que a sensibilidade desses materiais ao $\mathrm{pH}$ é dependente do substituinte do anel aromático da anilina e do tamanho do ânion do ácido usado na eletropolimerização.

Sensores a base de polímeros condutores também são usados para reproduzir e com maior sensibilidade alguns sentidos humanos como o olfato e gustativo. Riul Jr. et al. [23] desenvolveram recentemente uma língua eletrônica, usando polipirrol e polianilina como sensores, com sensibilidade superior a da língua humana e de todos os trabalhos similares encontrados na literatura. Sua capacidade de deteç̧ão é de concentrações abaixo de 5 . $10^{-3} \mathrm{~mol}^{-\mathrm{L}^{-1}}$. 


\subsection{Seletividade de um sensor químico}

A seletividade de um sensor químico é a capacidade que ele tem em detectar a presença de uma espécie química em um meio onde há várias espécies. A relação entre a concentração das espécies na amostra e o sinal externo do sensor é a função de resposta. Essa função pode ser linear (em sensores ópticos e amperométricos) ou logarítmica (em sensores potenciométricos) [10].

Nesses dois casos a seletividade depende da termodinâmica e da cinética das interações químicas entre as espécies da amostra e a superfície do eletrodo. Os polímeros condutores também se destacam nesse aspecto porque são muito previsíveis. A sensibilidade do eletrodo a determinada espécie química é determinada de acordo com o tipo de polímero eletroativo e como ele é preparado. Então, se um determinado polímero for "preparado" de diferentes formas, o sensor será capaz de detectar várias espécies químicas. A modificação de superfícies de metais com polímeros é o aspecto mais relevante para a fabricação de sensores [10]. 


\subsection{Tipos de sensores}

As medidas eletroquímicas efetuadas para fins analíticos podem ser sob condições de equilíbrio (sem passar corrente) utilizando sensores potenciométricos ou sob condições fora de equilíbrio (com passagem de corrente) utilizando sensores amperométricos ou voltamétricos.

Assim pode-se dividir os sensores eletroquímicos em duas classes: sensores com passagem de corrente elétrica e sensores sem passagem de corrente elétrica.

\subsubsection{Sensores Potenciométricos (corrente nula)}

O potencial de equilíbrio de uma medição potenciométrica $\left(E_{e q}\right)$ ocorre quando a soma das correntes parciais anódicas e catódicas for igual a zero. Formando assim o valor de $\mathrm{E}_{\mathrm{eq}}$ útil para uma análise quantitativa.

O funcionamento varia com o tipo de material de que é constituído o eletrodo (sal, vidro, etc) e o seu funcionamento é diferente de um eletrodo metálico ou semicondutor.

\subsubsection{Sensores Amperométricos e Voltamétricos (passagem de} corrente)

Um sensor amperométrico mede uma corrente em resposta a aplicação de um degrau de potencial um potencial aplicado fixo, isto é, para um ponto na curva de corrente-potencial. Já num sensor voltamétrico, registra-se pontos numa região escolhida do perfil de corrente-potencial. Por isso, um 
sensor amperométrico é um sensor voltamétrico para um dado potencial fixo.

Estas são medidas eletroquímicas fora do equilíbrio, e sabe-se que elas permitem a determinação de parâmetros cinéticos e termodinâmicos dos processos do eletrodo, enquanto que medidas no equilíbrio (sensores potenciométricos) fornecem apenas dados termodinâmicos. Então, ao passo que a análise potenciométrica é uma boa ferramenta para a determinação de atividades ou concentrações, a análise amperométrica ou voltamétrica permite a obtenção de outros parâmetros além destes parâmetros cinéticos.

O parâmetro de seletividade mais importante dos eletrodos para sensores voltamétricos é o potencial aplicado.

O aumento da seletividade e sensibilidade e o aumento dos limites de detecção do eletrodo têm sido foco de estudo dos desenvolvimentos mais recentes de sensores voltamétricos e amperométricos. Os eletrodos hidrodinâmicos, além de terem uma maior sensibilidade, permitem uma reprodutibilidade maior e também a possibilidade de serem utilizados em sistemas de fluxo para controle de processo, controle de qualidade e como detetores para cromatografia.

\subsection{Modificação de eletrodos}

Em um eletrodo modificado, a sua superfície é alterada por adsorção, por recobrimento físico, ou pela ligação de espécies específicas. O objetivo desta modificação é inibir alguns processos que ocorrem no eletrodo e promover outros. Dessa maneira a modificação do eletrodo é muito útil para 
a obtenção de eletrodos com maior seletividade.

A camada de modificador é normalmente eletroativa, ela age como mediadora entre a solução e o eletrodo-substrato na transferência de elétrons.

\subsubsection{Métodos para a modificação de eletrodos}

(a) Modificação química: uma espécie eletroativa é imobilizada na superfície do eletrodo por reação química. São formadas ligações químicas.

(b) Adsorção: este método tem sido usado na preparação de eletrodos modificados de polímeros. Pode ser reversível ou irreversível. Neste método o eletrodo pode ser imerso em uma solução do polímero ou pode ser pintado com a solução, seguindo-se então a evaporação do solvente. Exemplos de polímeros utilizados neste caso são alguns que deixam passar carga através do filme (polivinilpiridina (PVP), polivinilferroceno (PVF), porfirinas e ftalocianinas).

(c) Eletroadsorção: a adsorção é efetuada com um potencial aplicado ao eletrodo. A aplicação de potencial na presença de uma molécula susceptível de polimerizar-se pode produzir radicais, iniciando a polimerização e, consequentemente, a modificação do eletrodo, já que a polimerização ocorre em sua superfície. Exemplos desses polímeros condutores são: polipirrol, polianilina e politiofeno.

(d) Plasma: um plasma deixa átomos não ligados na superfície do eletrodo, deixando essa superfície ativada. A descarga do plasma na 
presença de monômeros gera radicais em solução, conduzindo à formação de polímero na superfície. É equivalente à ativação química.

\subsection{Compostos orgânicos}

Dentre os inúmeros compostos orgânicos existentes, em sua maioria utilizados em processos manufaturados, a enfaze é dada a:

\subsubsection{Hidroquinona}

A hidroquinona é também denominada de 1,4-dihidroxibezeno paradifenol, benzeno 1,4-diol-hidroquinol ou quinol. É um sólido cristalino, de fórmula molecular: $\mathrm{C}_{6} \mathrm{H}_{4}(\mathrm{OH})_{2}$, com densidade de $1,33 \mathrm{~g} \mathrm{~cm}^{-3}$, ponto de fusão de $170^{\circ} \mathrm{C}$ e de ebulição de $285^{\circ} \mathrm{C}$. É usualmente empregada no fabrico de tintas e em dermatologia para o tratamento de hipercromias.

Não foi achada nenhuma informação sobre a concentração de hidroquinona ( $\mathrm{HQ})$ no ar, solo, ou água. Entretanto, a $\mathrm{HQ}$ tem sido medida na fumaça de cigarros em quantidades que variam de 110 a 300 mg por cigarro. A HQ foi achada em produtos alimentícios derivados de plantas como café e chás, onde a concentração pode ultrapassar $1 \%$.

Nos países da União Européia, o uso de hidroquinona em cosméticos é restrito a uma concentração de $2 \%$ ou menos. A administração de alimentos e medicamentos dos Estados Unidos (US Food and Drug Administration) publicou uma nota de proposta de lei para o uso de hidroquinona como clareador de pele a concentrações menores que $2 \%$. 
Os estudos sobre a detecção de hidroquinona têm sido inúmeros e, dentre estes podem ser citados os seguintes exemplos:

1) Eletrodo de platina com DeniLiteTM laccase imobilizada foi utilizado para detecção amperométrica de HQ. Neste caso, a sensibilidade

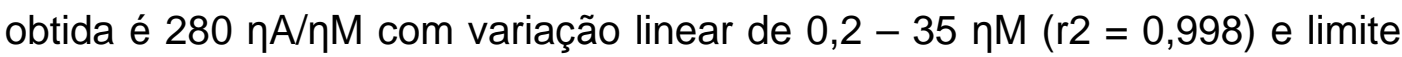
de detecção $(\mathrm{S} / \mathrm{N}=3)$ de 50 ๆM. Essa alta sensibilidade pode ser atribuída à amplificação química relacionada com a ciclização do substrato, causado pela oxidação enzimática e conseqüentes regenerações eletroquímicas. Os tempos de resposta são em torno de 2 segundos para os dois substratos e a sua estabilidade é de 60 dias para HQ. A alta velocidade de resposta e a alta estabilidade são as principais vantagens deste sensor. Estudos de $\mathrm{pH}$ mostram que o pH ótimo para o sensor de HQ é 6,0. [24].

2) Com o intuito de empregar um eletrodo barato como alternativa para a platina para o uso de alunos de graduação, eletrodos de polianilina depositados sobre aço inoxidável são indicados para potenciometria e titulações potenciométricas de algumas reações de oxi-redução. A PAni foi depositada sobre a superfície de um metal comum por polimerização eletroquímica de anilina usando a técnica de voltametria cíclica. Métodos alternativos para produzir eletrodos de PAni também foram levados em conta. Os eletrodos responderam a diferentes concentrações de $H Q$, $\mathrm{Fe}^{2+} / \mathrm{Fe}^{3+}$ e $\left[\mathrm{Fe}(\mathrm{CN})_{6}\right]^{4-} /\left[\mathrm{Fe}(\mathrm{CN})_{6}\right]^{3-}$ em meio de $\mathrm{HCl}$. Os eletrodos podem ser utilizados para várias titulações se forem armazenados em meio ácido por um longo período de tempo. Então, os eletrodos convencionais de $\mathrm{Pt}$ e $\mathrm{Au}$ 
podem ser substituídos por eletrodos de PAni depositados sobre metal comum como sensor potenciométrico para titulações de oxi-redução.[25]. 


\section{Objetivos}

O presente trabalho tem como objetivo geral a preparação de sensores eletroquímicos com PAni e seus derivados, para a detecção de hidroquinona em solução aquosa. Como objetivos parciais deste trabalho estão inclusos:

(a) Preparar sensores eletroquímicos utilizando polianilina, polianilinas substituídas e seus copolímeros;

(b) Detectar diferentes concentrações de hidroquinona em soluções aquosas;

(c) Caracterizar a estrutura e morfologia dos filmes poliméricos;

(d) Analisar a forma de interação da hidroquinona com os filmes poliméricos. 


\section{Capítulo II}

\section{Experimental}

Neste capítulo serão apresentadas técnicas utilizadas para a síntese eletroquímica e caracterização estrutural e morfológica dos filmes produzidos. Além das técnicas envolvidas serão descritos os materiais e reagentes utilizados para a realização dos experimentos.

\subsection{Célula eletroquímica}

A célula eletroquímica utilizada para as sínteses eletroquímica, foi confeccionada em vidro Pyrex com tampa em TEFLON ${ }^{\circledR}$, possuindo várias cavidades onde são alojados:

(a) Eletrodo de referência: eletrodo de calomelanos saturado (ECS);

(b) Eletrodo de Trabalho: placa de platina com área de $0,5 \mathrm{~cm}^{2}$.

(c) Contra-eletrodos: duas placas de platina com área de $4,5 \mathrm{~cm}^{2}$; 


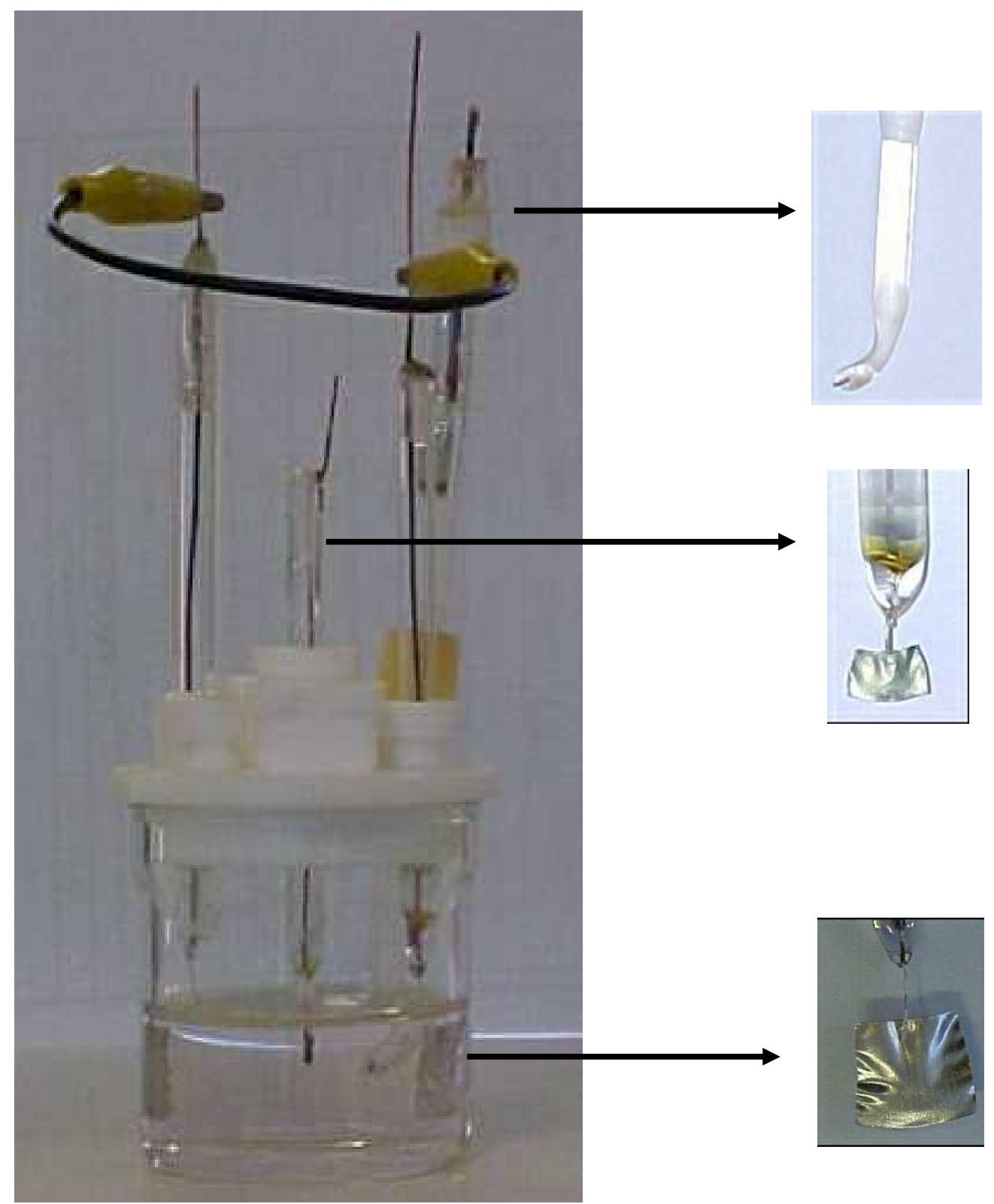

(a)

(b)

(c)

Figura 3: Célula Eletroquímica (a) Eletrodo de referência (ECS); (b) Eletrodo de trabalho; (c) Contra-eletrodos.

\subsection{Reagentes e soluções}

A anilina 99,5\% e o-Anisidina 99\% (Aldrich) foram destiladas sob pressão reduzida na presença de zinco em pó. Todas as sínteses foram realizadas em meio de ácido clorídrico $(\mathrm{HCl})$ diluído a partir de $\mathrm{HCl} 37 \%$ 
(Synth p.a.) e ácido sulfúrico $\left(\mathrm{H}_{2} \mathrm{SO}_{4}\right)$ diluído a partir de 95-98\% (Synth p. a.).

A água utilizada para a lavagem da célula e preparo de soluções foi qualidade ultra pura proveniente de um sistema Mili-Q (Milpore). Tanto a PAni quanto a POMA e a mistura dos dois monômeros, foram eletrossintetizadas a partir de soluções aquosas com 1 mol.L-1 de $\mathrm{HCl}$ ou 1 mol.L ${ }^{-1}$ de $\mathrm{H}_{2} \mathrm{SO}_{4}$ e 0,1 mol.L ${ }^{-1}$ de monômero. As soluções de misturas foram preparadas nas razões de 1:1 de anilina e o-anisidina.

As soluções de hidroquinona foram preparadas a partir da dissolução de hidroquinona nas soluções de $\mathrm{HCl}$ e $\mathrm{H}_{2} \mathrm{SO}_{4} 1$ mol.L $\mathrm{L}^{-1}$, nas concentrações de 5 a $50.10^{-3}$ mol. $\mathrm{L}^{-1}$.

\subsection{Síntese eletroquímica}

\subsubsection{Voltametria Cíclica}

Esta técnica consiste na varredura de um determinado intervalo de potencial no sentido direto e inverso, obedecendo a um padrão linear constante. A partir da aplicação deste potencial programado e controlável é gerada uma resposta de corrente em função do potencial. Voltamograma cíclico é o nome dado ao conjunto de respostas de correntes em função do potencial aplicado.

Sendo uma técnica relativamente simples, a voltametria cíclica nos dá um grande conjunto de informações importantes. É uma técnica muito utilizada para estudos de processos como [26]: reações de transferência de elétrons precedidos ou seguidos de reações químicas relativamente lentas e efeitos de adsorção, reações de transferência de elétrons reversíveis ou 
irreversíveis. Por estar relacionada com experimentos de curta duração, pode-se supor que nas proximidades do eletrodo, ocorram apenas pequenas mudanças nas concentrações dos reagentes e dos produtos.

Neste estudo esta técnica foi utilizada para a realização da síntese eletroquímica dos polímeros e para a análise do comportamento eletroquímico dos polímeros obtidos. A resposta eletroquímica pode fornecer informações importantes a respeito da estabilidade de um material frente à variação de potencial, uma vez que as transferências de cargas no interior do polímero não são totalmente reversíveis.

O equipamento utilizado para os estudos de voltametria cíclica foi um potenciostato/galvanostato EG\&G/PAR, modelo 273A, acoplado a um microcomputador, utilizando o programa Echem270 (EG\&G/PAR).

\subsection{Caracterização}

\subsubsection{Espectroscopia no Infravermelho (FTIR)}

A espectroscopia na região do infravermelho é uma técnica importante para a caracterização de materiais, fornecendo informações detalhadas a respeito da estrutura do material analisado $[27,28,29,30]$.

Esta técnica baseia-se nas transições entre níveis de energia nas moléculas que resultam das vibrações das ligações química destas moléculas, ou seja, quando vibrações moleculares resultam em uma mudança no momento dipolo da ligação, como conseqüência da mudança da distribuição eletrônica na ligação. É então possível estimular a transição entre os níveis de energia através da interação com a radiação eletromagnética apropriada, [31]. Quando a interação ocorre, existe uma 
absorção da radiação pelo material e então a detecção é feita por diferença entre as intensidades inicial e final na amostra. Assim, os diversos grupos funcionais da amostra são identificados através dos diversos modos vibracionais das ligações químicas presente na amostra [32].

As análises por espectroscopia de infravermelho, foram feitas utilizando um espectrômetro de infravermelho Bomem, modelo MB-102 com FTIR e os dados foram obtidos com o auxílio do programa Spectra Calc.

Para as análises de FTIR, foram utilizados filmes dos polímeros nos estados dopado e desdopado. Para a desdopagem do material , o mesmo ficou imerso em solução de $\mathrm{NH}_{4} \mathrm{OH} 0,1 \mathrm{~mol} \mathrm{~L}^{-1}$ por $24 \mathrm{hs}$, e depois foram condicionados a um dessecador para secagem completa. Após esse procedimento os filmes foram retirados dos eletrodos de platina e triturados junto a brometo de potássio $(\mathrm{KBr})$ para a confecção das pastilhas.

\subsubsection{Espectroscopia de Ultravioleta e Visível}

A espectroscopia na região do ultravioleta e visível é utilizada para obter informações sobre o comportamento eletrônico de determinados materiais, uma vez que os níveis de energias empregados correspondem aos níveis de excitação eletrônica do material. Esses níveis são dependentes das ligações químicas da amostra a ser analisada, onde: os elétrons- $\sigma$ absorvem fótons de energias elevadas e os elétrons- $\pi$ absorvem fótons de comprimentos de onda maiores [33].Os espectros de absorção no ultravioleta-visível (UV-Vis) são importantes para caracterizar os polímeros condutores. Espectroscopia nas regiões do ultravioleta visível são utilizadas para a identificação e determinação de uma variedade de materiais 
orgânicos e inorgânicos. A absorção molecular na região ultravioleta-visível depende da estrutura eletrônica da molécula. A seletividade da absorção no ultravioleta é uma vantagem, uma vez que se pode reconhecer grupos característicos em moléculas de complexidade bastante variável. Um espectro de ultravioleta-visível é um gráfico de freqüência ou comprimento de onda de absorção versus a intensidade de absorção (absorbância). Desta forma, a espectroscopia de UV-vis é utilizada para verificar o comportamento das bandas bipolarônicas dos materiais poliméricos, uma vez que são essas bandas que permite ao polímero a passagem de corrente elétrica em nível semicondutor ou metálico.

Foram realizadas espectroscopias de UV-Vis, utilizando um espectrômetro de UV-Vis de marca Varian, modelo Cary 5G, em cubeta de quartzo e o caminho óptico percorrido de $1 \mathrm{~cm}$.

Os eletrodos contendo os filmes poliméricos foram imersos em hidróxido de amônio $\left(\mathrm{NH}_{4} \mathrm{OH} 0,1 \mathrm{~mol} \mathrm{~L} \mathrm{~L}^{-1}\right)$, por $24 \mathrm{~h}$, para a desdopagem, depois foram levados a um dessecador para secagem completa. Após este tratamento os eletrodos contendo os filmes poliméricos, foram dissolvidos em N-metil-pirrolidona (NMP) para a análise no espectrômetro. Cada polímero foi analisado na sua forma desdopada. Após essa análise, foi adicionada uma gota do ácido correspondente ao polímero na forma dopada para que o processo de dopagem ocorresse novamente, e nova análise de UV-Vis foi realizada.

\subsubsection{Microscopia Eletrônica de Varredura (MEV)}

A microscopia eletrônica de varredura é obtida por meio do 
microscópico eletrônico, que possibilita a formação de imagens com o aumento de ate 300.000 vezes e $10 \mathrm{~nm}$ de profundidade, através do bombardeamento de elétrons [34]. A formação da imagem se dá pela varredura de um feixe eletrônico através da amostra em sincronismo com o feixe de varredura dentro do tubo de raios catódicos do monitor de vídeo, por intermédio de um detector de elétrons secundários ou elétrons retroespalhados.

Para realizar as análises de MEV é necessário que a amostra esteja totalmente seca. Além da amostra seca é necessário que ela seja eletricamente condutora, pois o bombardeamento de elétrons torna a amostra carregada, por isso a corrente depositada sobre a amostra deve ter passagem para um aterramento elétrico, assim todas as amostras nãometálicas (não-condutoras), são recobertas com uma camada fina de uma substância condutora (ouro ou carbono), este processo é conhecido como "sputerring".

O equipamento utilizado para a obtenção das imagens de microscopia eletrônica de varredura foi um Microscópio Eletrônico de Varredura modelo 440 da LEO Cambridge. 


\section{Capítulo III}

\section{Resultados e Discussões}

Neste capítulo são apresentados os resultados obtidos no crescimento eletroquímico dos filmes de PAni, POMA e PAOMA, o comportamento eletroquímico dos filmes através das respostas eletroquímicas em meio de $\mathrm{HCl}$ e $\mathrm{H}_{2} \mathrm{SO}_{4}$. Também serão apresentados as respostas eletroquímicas dos filmes poliméricos em diferentes espessuras frente a solução de hidroquinona (HQ) nas concentrações de 5 a $50 \mathrm{~mol} \mathrm{~L}^{-1}$. Tanto os crescimentos como as respostas eletroquímicas foram realizados utilizando a técnica de voltametria cíclica.

Além disso, também são apresentados os resultados das caracterizações morfológicas pela técnica de microscopia eletrônica de varredura, e estrutural, por espectroscopias nas regiões de infravermelho e de ultravioleta, dos filmes obtidos. 


\subsection{Crescimento Eletroquímico}

Como descrito na parte experimental os crescimentos foram realizados em dois meios distintos: $\mathrm{HCl}$ e $\mathrm{H}_{2} \mathrm{SO}_{4}$. A seguir são mostrados os voltamogramas cíclicos relativos a estes crescimentos, de PANI, POMA e PAOMA separando com os meios ácidos utilizados.

\subsubsection{Crescimento em HCl}

A Figura 4 mostra os voltamogramas cíclicos de crescimento do filme de PAni à $50 \mathrm{mV} / \mathrm{s}$ a partir de solução $0,1 \mathrm{~mol} \mathrm{~L}^{-1}$ de anilina e $1 \mathrm{~mol} \mathrm{~L}^{-1} \mathrm{HCl}$.

A partir da Figura 4 é possível observar os pares de picos redox: A/A'; B/B' e C/C', característicos do crescimento eletroquímico do polímero, cujos pares redox são descritos como:

Pico A: $( \pm 0,2 \mathrm{~V})$ este pico corresponde a primeira oxidação do polímero, quando o polímero passa do estado leucoesmeraldina a esmeraldina.

Pico B: $( \pm 0,45$ V) corresponde a efeitos de degradação, ou seja, formação de produtos intermediários que se incorporam ao polímero, estes produtos são formados por reações paralelas, como por exemplo, a formação de quinonas e hidroquinonas $[35,36]$.

Pico C: $( \pm 0,75$ V) é correspondente a segunda oxidação do polímero, quando este passa do estado esmeraldina ao estado pernigranilina.

Outra característica interessante do crescimento eletroquímico do filme de PAni é o comportamento eletrocrômico [37] que também foi observado no presente trabalho. Estes dados se encontram na Tabela 2. 


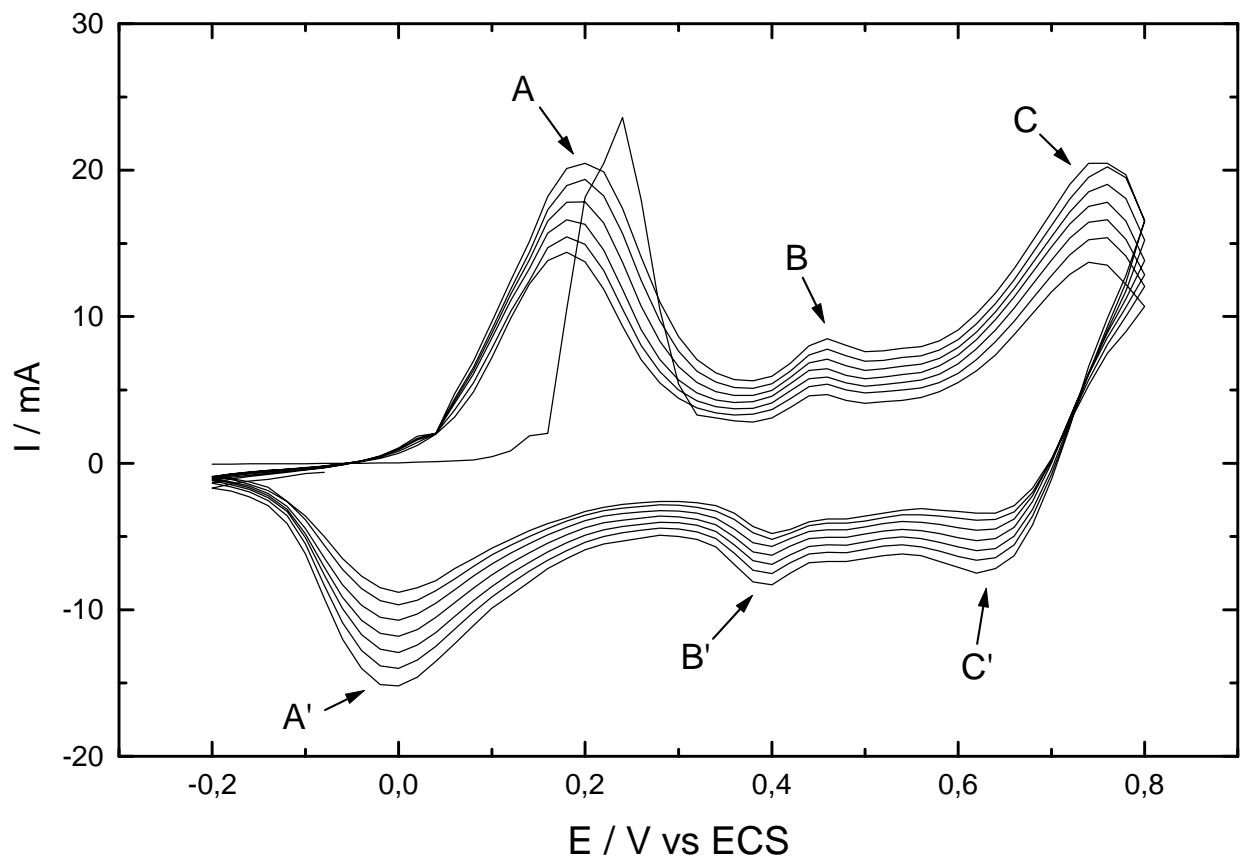

Figura 4: Voltamograma cíclico do crescimento eletroquímico de PAni em solução de $0,1 \mathrm{~mol} \mathrm{~L}^{-1}$ de anilina e $1 \mathrm{~mol} \mathrm{~L}^{-1} \mathrm{HCl}$ em intervalos de potenciais de $-0,2$ a $0,8 \mathrm{~V}$, velocidade de varredura $50 \mathrm{mV} / \mathrm{s}$.

Tabela 2: Colorações do filme de PAni observadas a diferentes potenciais.

\begin{tabular}{|c|c|}
\hline Coloração & Potencial (V) \\
\hline Amarelo Claro & $\pm 0,8$ \\
\hline Verde Claro & Pico A $( \pm 0,2)$ \\
\hline Verde Escuro & Pico B $( \pm 0,45)$ \\
\hline Azul Escuro & Pico C $( \pm 0,75)$ \\
\hline
\end{tabular}


O crescimento eletroquímico do filme de POMA à $50 \mathrm{mV} / \mathrm{s}$ a partir de $0,1 \mathrm{~mol} \mathrm{~L}^{-1}$ de o-anisidina e $1 \mathrm{~mol} \mathrm{~L}^{-1} \mathrm{HCl}$, é apresentado na Figura 5, onde pode ser observado a presença de:

Pico A: $( \pm 0,2 \mathrm{~V})$ este pico corresponde a primeira oxidação do polímero [38].

Pico B: $( \pm 0,45$ V) considerado como efeitos de degradação do polímero, ou incorporação de oligômeros.

Pico C: $( \pm$ 0,65 V) é atribuído a oxidação do monômero, segunda oxidação do polímero.

Durante os experimentos de voltametria cíclica com o crescimento dos filmes de POMA, foi observado o desprendimento de uma substância de coloração castanha, proveniente da formação de oligômeros solúveis de oanisidina na solução. Isto nos mostra o forte efeito de degradação da oanisidina sobre os filmes poliméricos formados.

O comportamento eletrocrômico também foi observado durante o crescimento eletroquímico do polímero, e esta descrito na tabela 3.

A Figura 6 mostra o crescimento eletroquímico do copolímero PAOMA formado na razão 1:1 de monômeros Ani:OMA em $1 \mathrm{~mol} \mathrm{~L}^{-1}$ de $\mathrm{HCl}$ à 50 $\mathrm{mV} / \mathrm{s}$. 


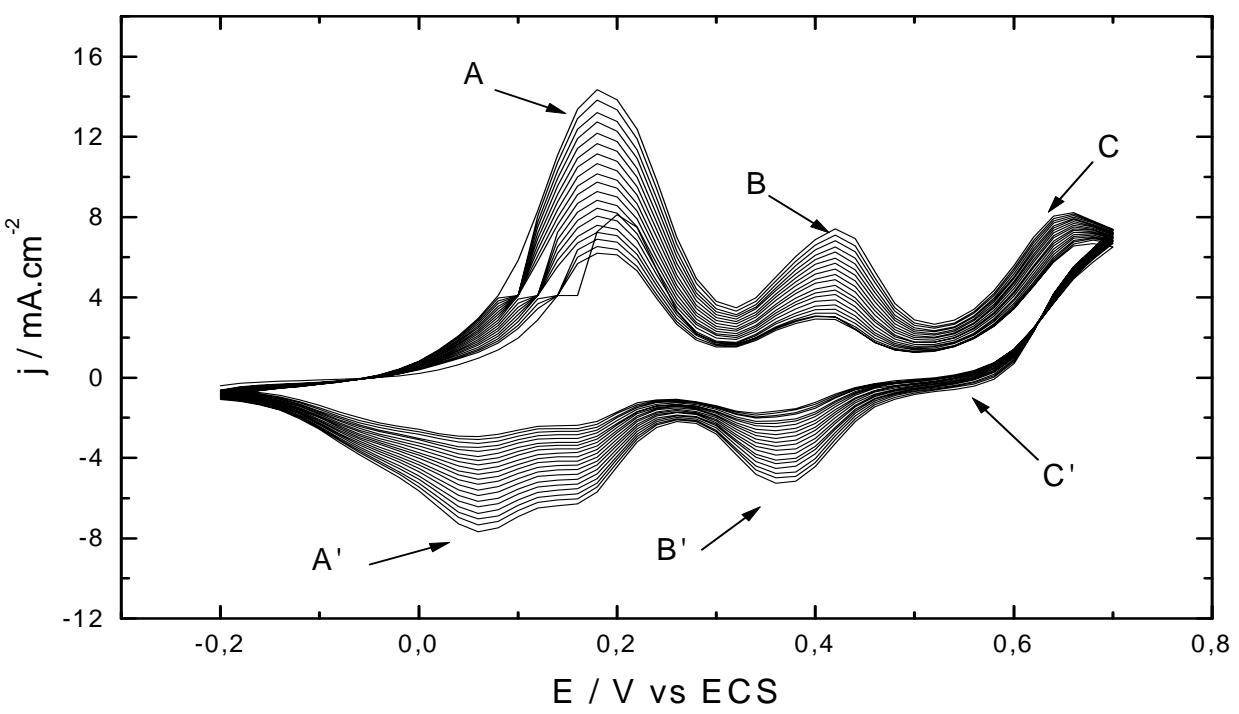

Figura 5: Voltamograma cíclico do crescimento eletroquímico de POMA em solução de $0,1 \mathrm{~mol} \mathrm{~L}^{-1}$ de o-anisidina e $1 \mathrm{~mol} \mathrm{~L}^{-1} \mathrm{HCl}$ em intervalos de potenciais de $-0,2$ a $0,7 \mathrm{~V}$, velocidade de varredura $50 \mathrm{mV} / \mathrm{s}$.

Tabela 3: Colorações do filme de POMA observadas em diferentes potenciais.

\begin{tabular}{|c|c|}
\hline Coloração & Potencial (V) \\
\hline Amarelo Claro & $\pm 0,7$ \\
\hline Amarelo Esverdeado & Pico A $( \pm 0,2)$ \\
\hline Verde & Pico B $( \pm 0,45)$ \\
\hline Azul Escuro & Pico C $( \pm 0,65)$ \\
\hline
\end{tabular}




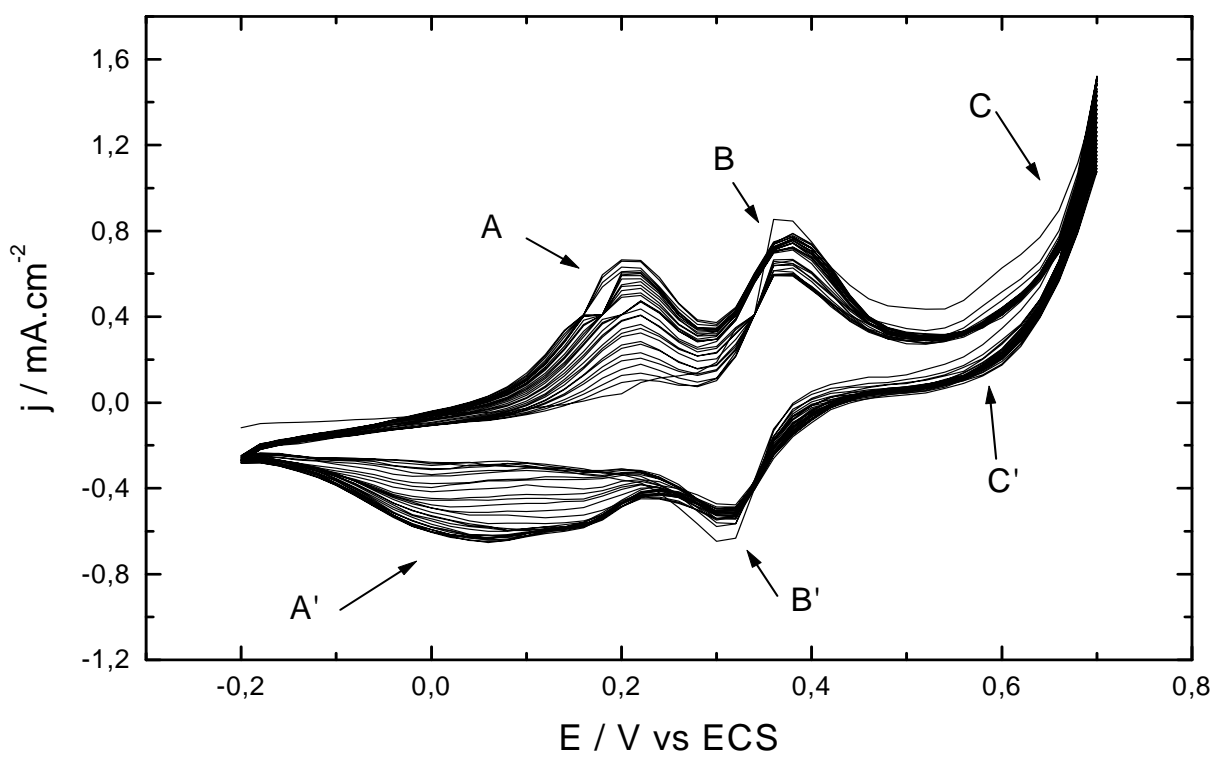

Figura 6: Voltamograma cíclico do crescimento eletroquímico de PAOMA em solução de $0,05 \mathrm{~mol} \mathrm{~L}^{-1}$ de anilina e $0,05 \mathrm{~mol} \mathrm{~L}^{-1} 1$ de o-anisidina e $1 \mathrm{~mol} \mathrm{~L}^{-1} \mathrm{HCl}$ em intervalos de potenciais de $-0,2$ a $0,7 \mathrm{~V}$, velocidade de varredura $50 \mathrm{mV} / \mathrm{s}$.

Tabela 4: Colorações do filme de PAOMA observadas em diferentes potenciais.

\begin{tabular}{|c|c|}
\hline Coloração & Potencial (V) \\
\hline Amarelo Esverdeado & $\pm 0,7$ \\
\hline Verde & Pico A $( \pm 0,2)$ \\
\hline Verde Escuro & Pico B $( \pm 0,4)$ \\
\hline Azul Escuro & Pico C $( \pm 0,65)$ \\
\hline
\end{tabular}

Os picos de oxidação $\mathbf{A}, \mathbf{B}$ e $\mathbf{C}$ nos potenciais $0,2 \mathrm{~V}, 0,4 \mathrm{~V}$ e $0,7 \mathrm{~V}$, respectivamente correspondem a degradação do polímero (pico B), a primeira oxidação do polímero (pico A) e a segunda oxidação do polímero (pico C). Nessa velocidade de varredura $50 \mathrm{mV} / \mathrm{s}$ pode ser observado uma 
estabilização da relação entre as correntes dos picos B e A em função do número de ciclos.

\subsubsection{Crescimento em $\mathrm{H}_{2} \mathrm{SO}_{4}$}

A Figura 7 mostra o voltamograma cíclico do crescimento de PAni à $50 \mathrm{mV} / \mathrm{s}$ nas concentrações de $0,1 \mathrm{~mol} \mathrm{~L}^{-1}$ de anilina e $1 \mathrm{~mol} \mathrm{~L}^{-1}$ de $\mathrm{H}_{2} \mathrm{SO}_{4}$, onde são observados três pares de picos de oxidação característicos da PAni.

O primeiro pico $\mathbf{A}$, que se encontra no potencial de $0,16 \mathrm{~V}$ corresponde ao primeiro estado de oxidação do polímero; o pico B apresenta dois ombros, um no potencial de $0,44 \mathrm{~V}$ e outro em $0,5 \mathrm{~V}$, que difere o filme de PAni $\left(\mathrm{SO}_{4}\right)$ do filme de PAni $(\mathrm{Cl})$, é atribuído aos processos de degradação do polímero [39]; o pico C corresponde ao segundo estado de oxidação do polímero.

Na Figura 8 temos o voltamograma cíclico do crescimento da POMA à $50 \mathrm{mV} / \mathrm{s}$ nas concentrações de $0,1 \mathrm{~mol} \mathrm{~L}^{-1}$ de 0 -anisidina e $1 \mathrm{~mol} \mathrm{~L}^{-1}$ de $\mathrm{H}_{2} \mathrm{SO}_{4}$. 


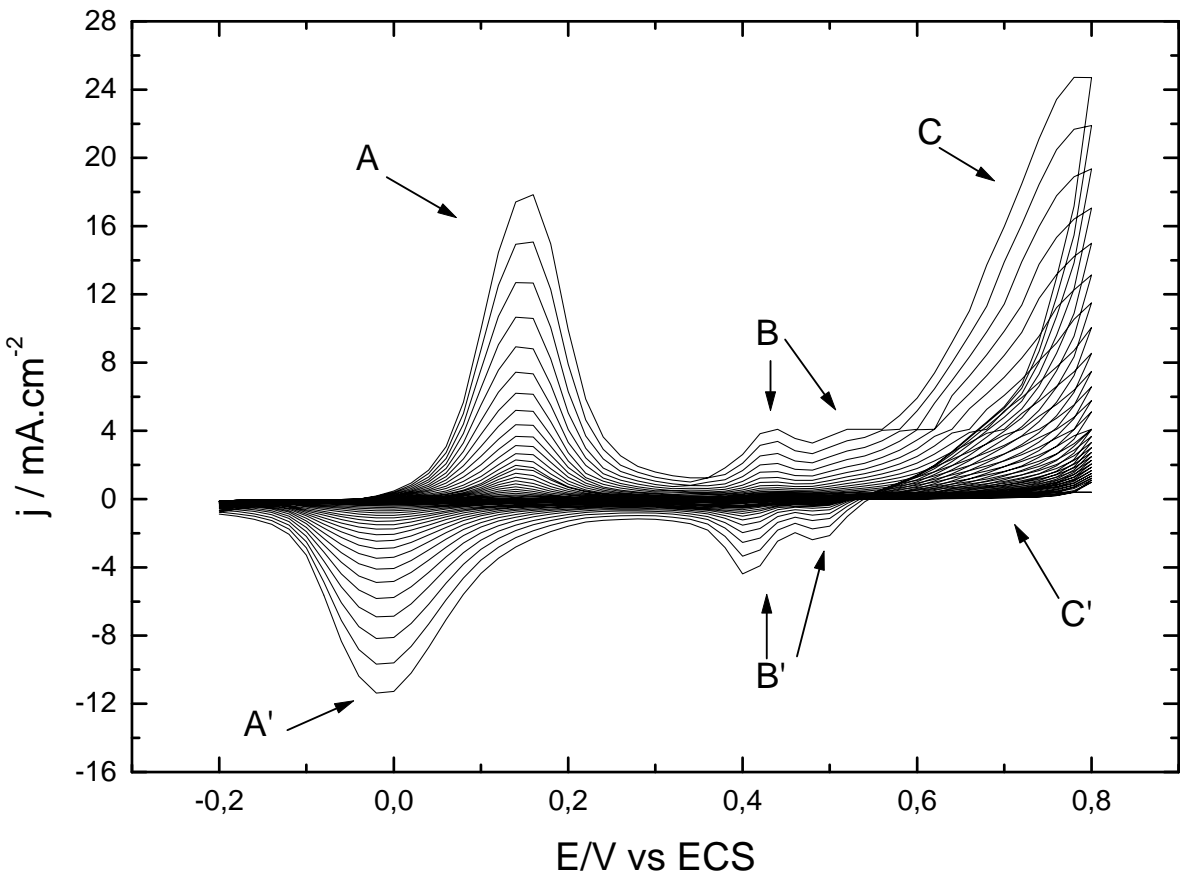

Figura 7: Voltamograma cíclico do crescimento eletroquímico de PAni em solução de $0,1 \mathrm{~mol} \mathrm{~L}^{-1}$ de anilina e $1 \mathrm{~mol} \mathrm{~L}^{-1} \mathrm{HCl}$ em intervalos de potenciais de $-0,2$ a $0,8 \mathrm{~V}$, velocidade de varredura $50 \mathrm{mV} / \mathrm{s}$.

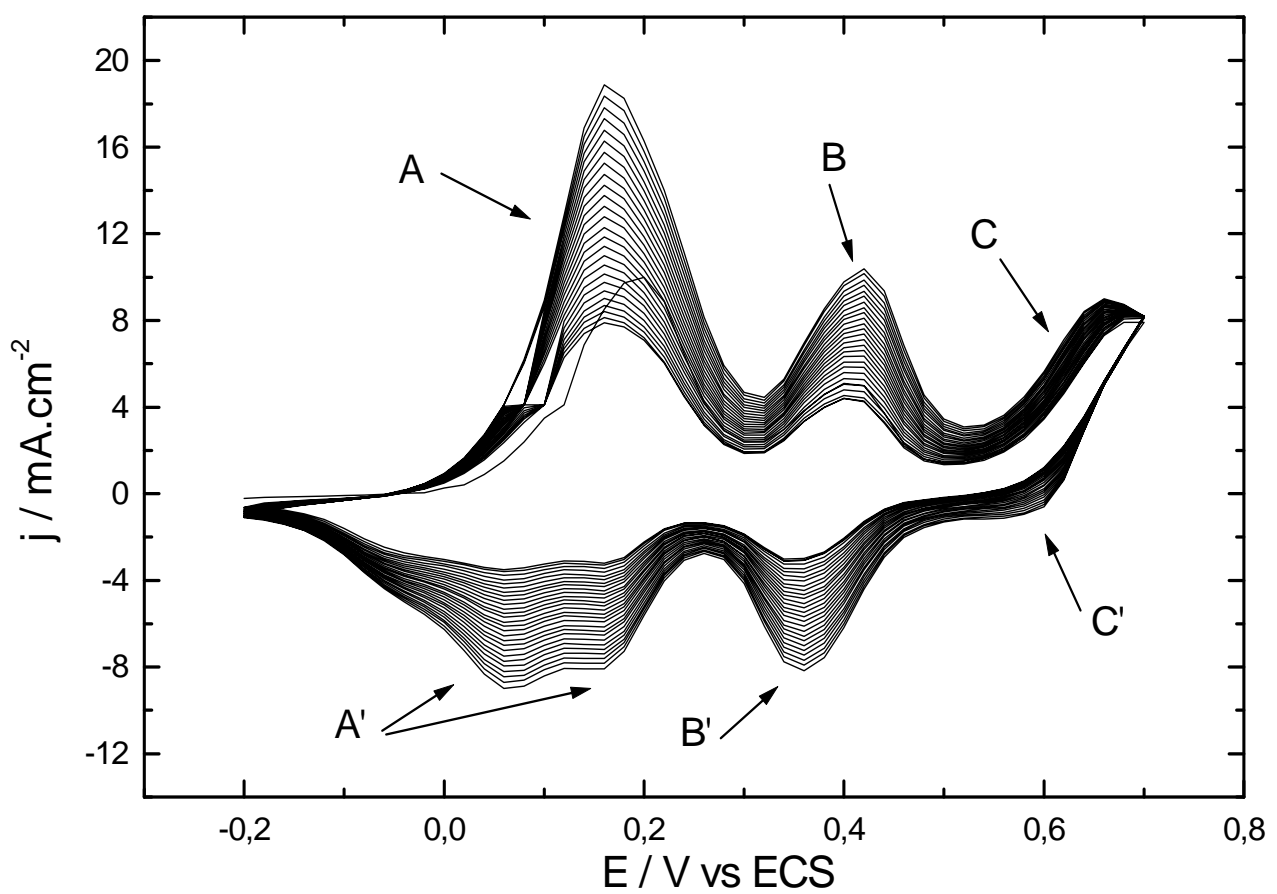

Figura 8: Voltamograma cíclico do crescimento eletroquímico de POMA em solução de $0,1 \mathrm{~mol} \mathrm{~L}^{-1}$ de o-anisidina e $1 \mathrm{~mol} \mathrm{~L}^{-1} \mathrm{H}_{2} \mathrm{SO}_{4}$ em intervalos de potenciais de $-0,2$ a $0,7 \mathrm{~V}$, velocidade de varredura $50 \mathrm{mV} / \mathrm{s}$. 
O voltamograma mostra claramente a formação do polímero eletroativo no eletrólito usado neste estudo. O pico $\mathbf{C}$ é atribuído a oxidação do monômero de o-anisidina e também a sua polimerização. O pico $\mathbf{A}$ é designado a oxidação da POMA depositada na superfície do eletrodo de platina, o que corresponde a conversão das unidades aminas em radicais cátions, já o pico B é atribuído à produtos de degradação por vários autores [40], esse efeito pode ser eliminado controlando o potencial limite e a densidade de corrente durante a síntese eletroquímica. Nesse estudo isso não foi possível, pois o potencial não foi devidamente controlado.

As curvas dos voltamogramas aumentam com o número de ciclos tanto para os polímeros crescidos em meio de $\mathrm{HCl}$ como para em meio de $\mathrm{H}_{2} \mathrm{SO}_{4}$, indicando a formação dos polímeros condutores, isso nos mostra que o potencial de oxidação da o-metoxianilina não depende do tipo nem do tamanho do ânion presente no eletrólito suporte [40].

A Figura 9 mostra o voltamograma cíclico do crescimento da PAOMA à $50 \mathrm{mV} / \mathrm{s}$ nas concentrações de $0,05 \mathrm{~mol} \mathrm{~L}^{-1}$ de anilina e $0,05 \mathrm{~mol} \mathrm{~L}^{-1}$ oanisidina e $1 \mathrm{~mol} \mathrm{~L}^{-1}$ de $\mathrm{H}_{2} \mathrm{SO}_{4}$. 


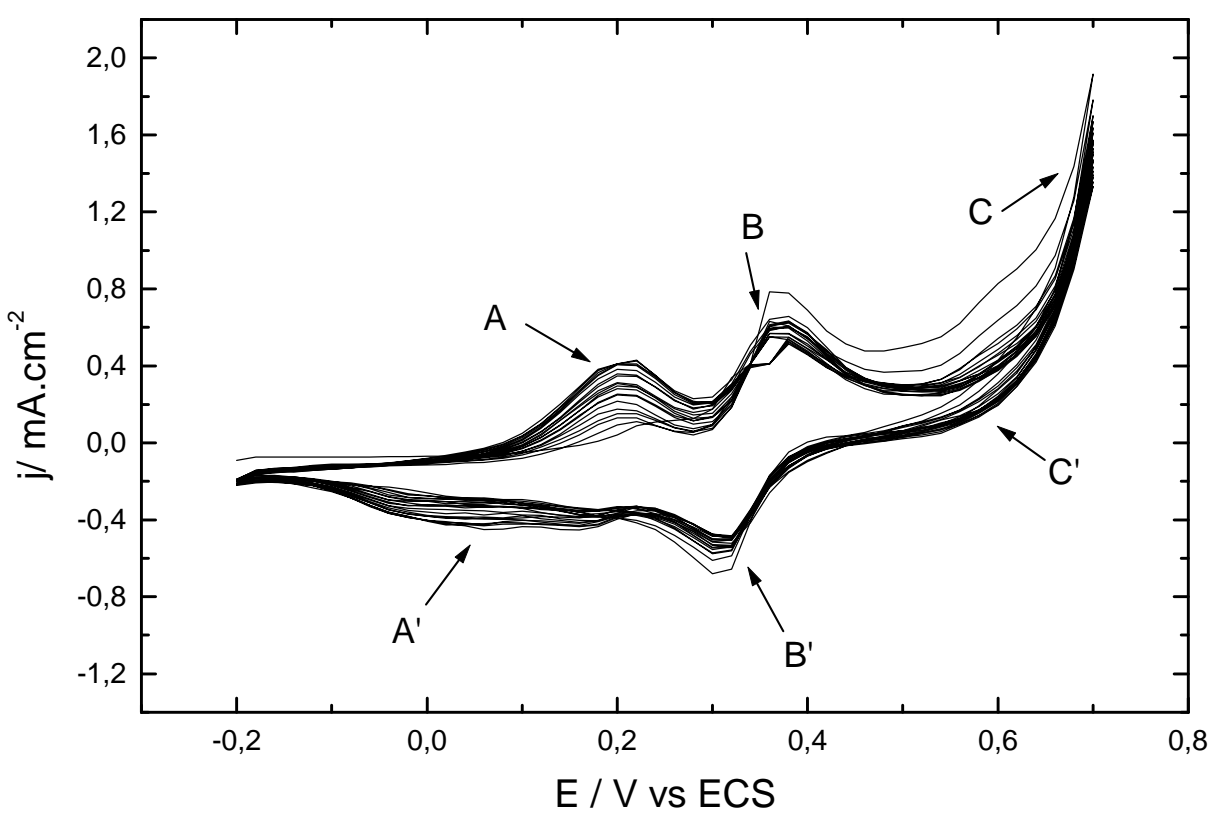

Figura 9: Voltamograma cíclico do crescimento eletroquímico de PAOMA em solução de $0,05 \mathrm{~mol} \mathrm{~L}^{-1}$ de anilina e $0,05 \mathrm{~mol} \mathrm{~L}^{-1}$ de 0 -anisidina e $1 \mathrm{~mol}$ $\mathrm{L}^{-1} \quad \mathrm{H}_{2} \mathrm{SO}_{4}$ em intervalos de potenciais de $-0,2$ a $0,7 \mathrm{~V}$, velocidade de varredura $50 \mathrm{mV} / \mathrm{s}$.

O maior aumento de densidade de corrente correspondente aos três picos anódicos pode ser observado para os filmes crescidos em meio de $\mathrm{H}_{2} \mathrm{SO}_{4}$, como descreve Patil et al. [40].

\subsection{Espectroscopia na região do Infravermelho}

Na Figura 10 são apresentados os espectros de infravermelho de absorção para todos os polímeros sob análise. 


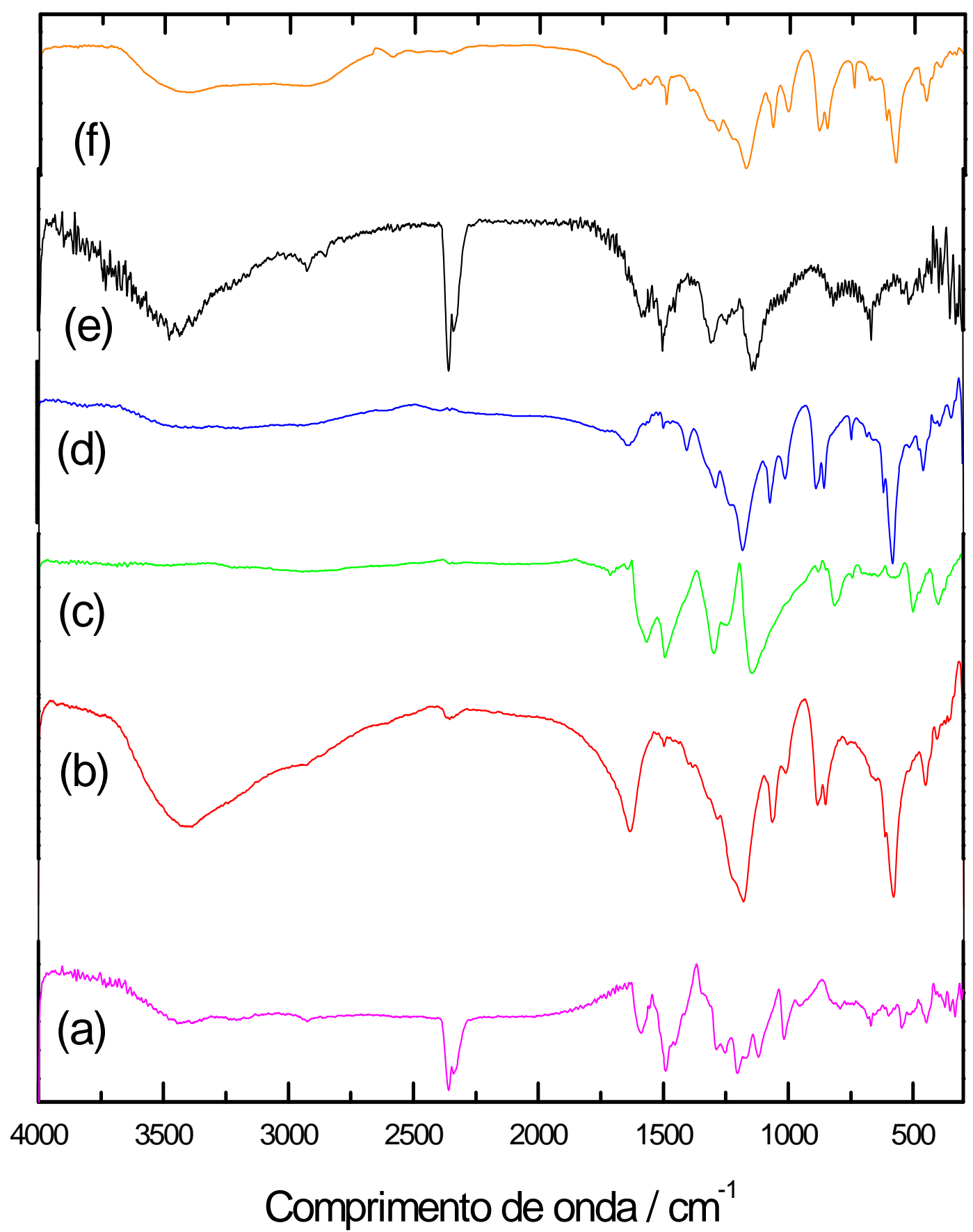

Figura 10: Espectros de infravermelho dos polímeros dopados: (a) POMA(Cl), (b) PAOMA(SO $\mathrm{S}_{4}$ ), (c) PAni(Cl), (d) PAni( $\left.\mathrm{SO}_{4}\right)$, (e) PAOMA(Cl), (f) $\operatorname{POMA}\left(\mathrm{SO}_{4}\right)$. 
Na Figura 10 (c) é apresentado o espectro PAni(Cl), pelo qual pode ser observado suas bandas características: 1579 e 1498 cm$^{-1}$ correspondentes aos grupamentos quinona (Q) e benzoquinona (B), respectivamente [41] ; e em 1294, 1147 e $813 \mathrm{~cm}^{-1}$ relacionados com os modos de vibração, das ligações C-N nos grupamentos quinóides e benzóides, e C-H no plano e fora do plano respectivamente [42].

As bandas localizadas por volta de $1150 \mathrm{~cm}^{-1}$ podem ser relacionadas a eletroatividade dos polímeros, pois a condutividade aumenta quando a cadeia possui mais unidades benzóides e quinóides alternantes quando se utiliza $\mathrm{HCl}$ como agente dopante [43].

O espectro da POMA(Cl) pode ser observado na Figura 10 (a): em 1589 e $1500 \mathrm{~cm}^{-1}$ pode ser notada as bandas relacionadas aos grupamentos quinona $(\mathrm{Q})$ e benzoquinona $(\mathrm{BQ})$ respectivamente [44]; e em 1203 e 1014 $\mathrm{cm}^{-1}$ correspondentes aos modos de estiramentos assimétrico e simétrico das ligações C-O-C dos radicais metoxi ligados ao anel, respectivamente.

A Figura 10 (e) mostra o espectro da PAOMA(Cl), polímero formado por solução de anilina e o-anisidina na razão de 1:1, pode se observar neste espectro que ele se afasta um pouco do espectro da PAni, pois as bandas em 1296, 1145 e $829 \mathrm{~cm}^{-1}$ sofrem um significativa diminuição na sua intensidade o que sugere um menor caráter condutor do polímero [43].

O espectro do filme de PAni $\left(\mathrm{SO}_{4}\right)$ é apresentado na Figura 10 (d), onde observa-se as bandas características dos grupamentos quinonas e benzoquinonas em 1600 e $1496 \mathrm{~cm}^{-1}$, respectivamente; em 1286 e $1168 \mathrm{~cm}^{-}$ 1 encontram-se as bandas atribuídas aos modos de vibrações C-N nos 
grupamentos quinóides e benzóides, respectivamente; em $879 \mathrm{~cm}^{-1}$ a banda correspondente as vibrações de $\mathrm{C}-\mathrm{H}$ dentro e fora do plano.

A Figura 10 (f) apresenta o espectro do filme de $\operatorname{POMA}\left(\mathrm{SO}_{4}\right)$, em 1606 e $1498 \mathrm{~cm}^{-1}$ são encontradas as bandas correspondentes aos grupamentos quinóides e benzóides, respectivamente, em 1280 e $1178 \mathrm{~cm}^{-1}$ corresponde as vibrações C-N dos grupamentos Q e BQ; a banda em 879 corresponde aos modos de vibrações das ligações $\mathrm{C}-\mathrm{H}$ dentro e fora do plano.

O filme de $\mathrm{PAOMA}\left(\mathrm{SO}_{4}\right)$ tem seu espectro apresentado na Figura 10 (b), os picos correspondentes aos grupamentos quinóides e benzoquinóides aparecem nos comprimentos de onda 1623 e $1496 \mathrm{~cm}^{-1}$, em $1294 \mathrm{~cm}^{-1} \mathrm{a}$ banda correspondente ao modo de vibração do C-N no grupamento quinóide é representado por um pequeno pico, e em $1174 \mathrm{~cm}^{-1}$ o pico que corresponde ao modo de vibração $\mathrm{C}-\mathrm{N}$ do grupamento benzóide é muito intenso. A banda atribuída ao modo de vibração do C-H aparece em 852 $\mathrm{cm}^{-1}$.

\subsection{Espectroscopia de Ultravioleta e visível}

Para as análises de espectroscopia de UV-vis foram utilizadas amostras de polímeros diluídas em solução de NMP. Para a observação das variações de absorção dos polímeros na presença dos agentes protonadores, estes foram analisados nas suas formas dopada e desdopada.

Nos espectros de UV-vis que estão apresentados na Figura 11 os filmes poliméricos estão no estado dopado e é visível que a adsorção óptica depende do ânion advindo do eletrólito suporte. Para os filmes polimerizados 


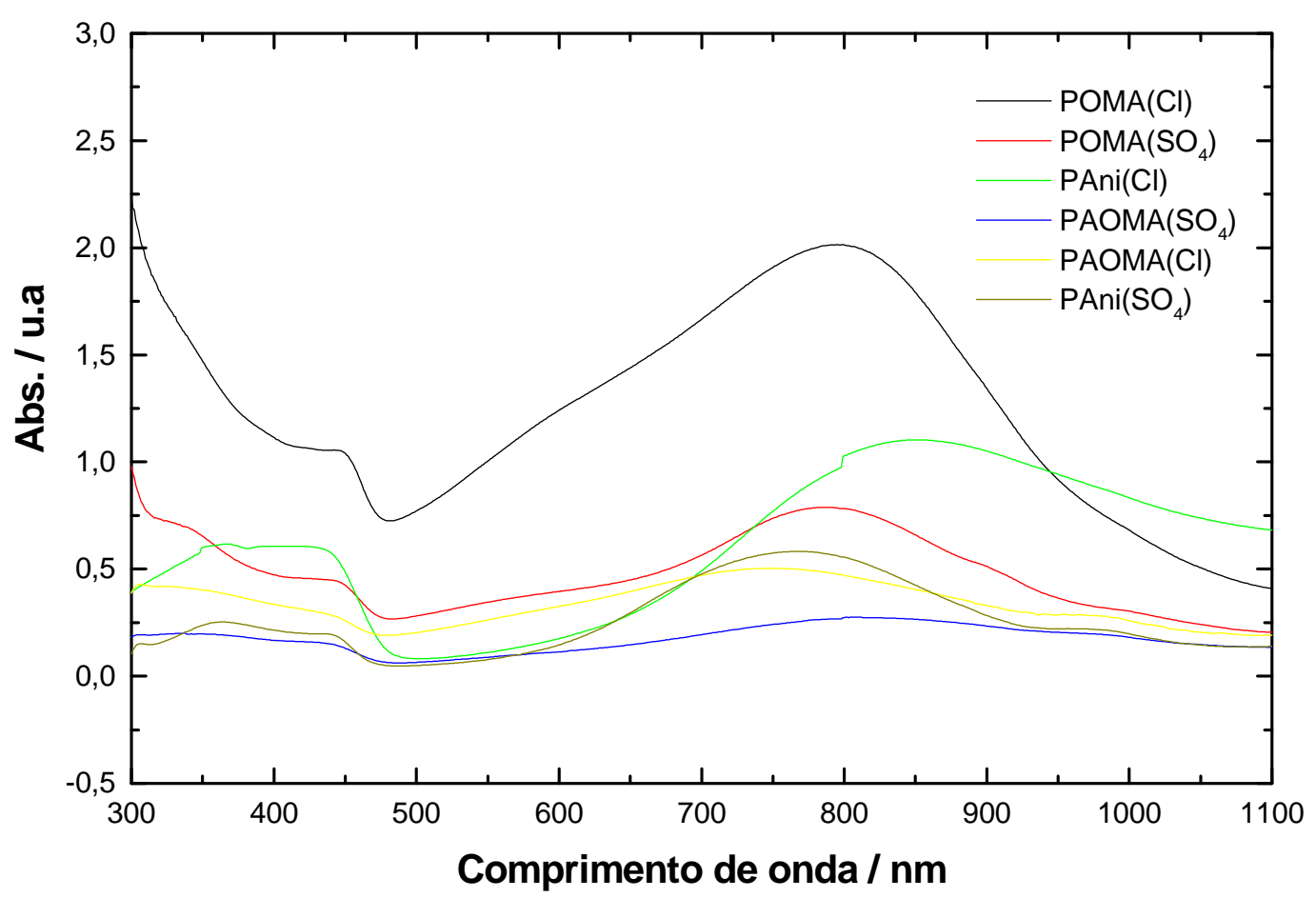

Figura 11: Espectro de absorção na região do ultravioleta e visível dos filmes poliméricos no estado dopado.

em meio de $\mathrm{H}_{2} \mathrm{SO}_{4}$ o pico correspondente ao estado esmeraldina ocorre a 810, 792 e 769 nm para PAOMA, POMA e PAni, respectivamente e os espectros dos filmes polimerizados em meio de $\mathrm{HCl}$, os picos ocorrem por volta de 846 e 800 nm para PAni e POMA respectivamente.

O deslocamento na posição dos picos correspondentes ao estado esmeraldina para comprimentos de onda mais baixos, pode ser atribuído ao tamanho do ânion, sendo o $\mathrm{HSO}_{4}^{-}$maior que o ânion $\mathrm{Cl}^{-}$[40].

Na Figura 12 os picos dos polímeros correspondente ao comprimento de onda por volta de 600-640 nm, corresponde a banda excitônica que se situa em regiões de menores energias $[33,45,46]$. Comparando os polímeros no estado dopado e desdopado, pode ser observado a transição da banda 


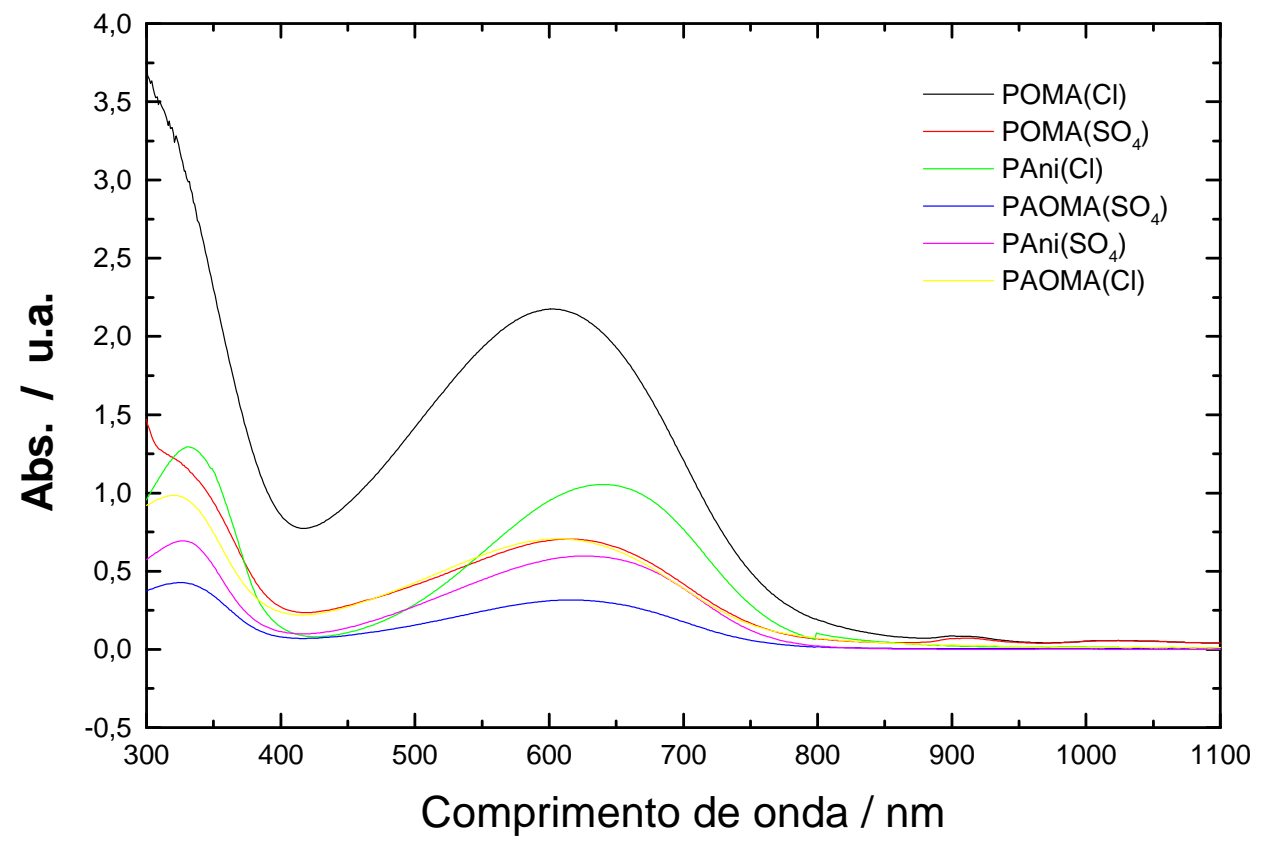

Figura 12: Espectro de Absorção na região do ultravioleta e visível dos filmes poliméricos no estado desdopado.

excitônica para banda polarônica, caracterizando um aumento na mobilidade eletrônica no estado dopado.

\subsection{Microscopia Eletrônica de Varredura}

Na Figura 13 é apresentada a micrografia de PAni(Cl) preparada a partir de solução contendo $0,1 \mathrm{~mol} \mathrm{~L}^{-1}$ de anilina e $1 \mathrm{~mol} \mathrm{~L}^{-1}$ de $\mathrm{HCl}$. Nesta figura pode ser observado que a PAni(Cl) apresenta uma morfologia fibrilar quando o filme não é muito espesso, isto é, a baixa concentrações de monômero [47].

A micrografia de $\mathrm{POMA}(\mathrm{Cl})$ preparada a partir de solução contendo $0,1 \mathrm{~mol} \mathrm{~L}^{-1}$ de o-metoxianilina e $1 \mathrm{~mol} \mathrm{~L}^{-1}$ de $\mathrm{HCl}$ é apresentada na Figura 14, onde pode ser observada a presença de fibrilas com maior distância 
entre si, quando comparadas as do filme de PAni(Cl), que apresenta uma morfologia fibrilar mais compacta.

As Figuras 15 e 16 mostram as micrografias de PAni( $\left.\mathrm{SO}_{4}\right)$ e POMA $\left(\mathrm{SO}_{4}\right)$, respectivamente, preparadas a partir de soluções contendo 0,1 mol L ${ }^{-1}$ do monômero correspondente em $1 \mathrm{~mol} \mathrm{~L}^{-1}$ de ácido.

Nestas figuras pode-se observar que os filmes de PAni $\left(\mathrm{SO}_{4}\right)$ e $\operatorname{POMA}\left(\mathrm{SO}_{4}\right)$ apresentam uma morfologia muito compacta, não sendo possível distinguir se a morfologia é fibrilar ou esponjosa como é descrito para esses polímeros [48]. Este fato pode ser explicado pelo filme não ser muito espesso, tornando as estruturas poliméricas mais agregadas.

Nas Figuras 17 e 18 são apresentadas as micrografias correspondentes à $\mathrm{PAOMA}(\mathrm{Cl})$ e $\mathrm{PAOMA}\left(\mathrm{SO}_{4}\right)$, preparadas a partir de soluções contendo $0,1 \mathrm{~mol} \mathrm{~L}^{-1}$ de anilina e o-metoxianilina, na proporção de 1:1, em meio de $1 \mathrm{~mol} \mathrm{~L}^{-1}$ de $\mathrm{HCl}$ e $1 \mathrm{~mol} \mathrm{~L}^{-1}$ de $\mathrm{H}_{2} \mathrm{SO}_{4}$, respectivamente.

Pode ser observado que a $\operatorname{PAOMA}(\mathrm{Cl})$, apresenta um comportamento mais próximo ao do filme de $\mathrm{PAni}(\mathrm{Cl})$, possuindo uma morfologia fibrilar mais compacta. Esta maior compactação das fibrilas, pode contribuir para o aumento da condutividade desses polímeros. Já o filme de $\operatorname{PAOMA}\left(\mathrm{SO}_{4}\right)$, apresenta um comportamento próximo ao do filme de $\mathrm{PAni}\left(\mathrm{SO}_{4}\right)$, com uma morfogologia esponjosa [48], como se é esperado para esses filmes, mas não pode ser observado no filme de PAni $\left(\mathrm{SO}_{4}\right)$ aqui apresentado. 


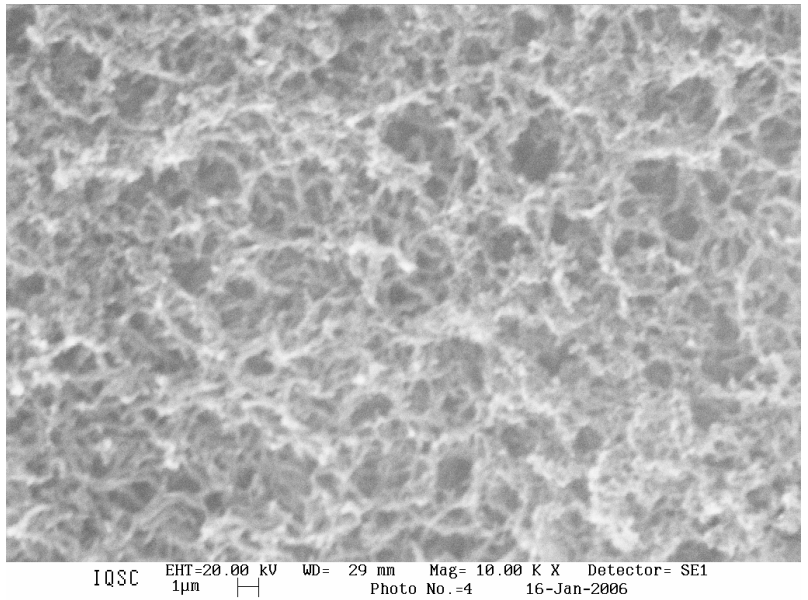

Figura 13: Micrografia obtida para o filme de polianilina em meio de $\mathrm{HCl}$.

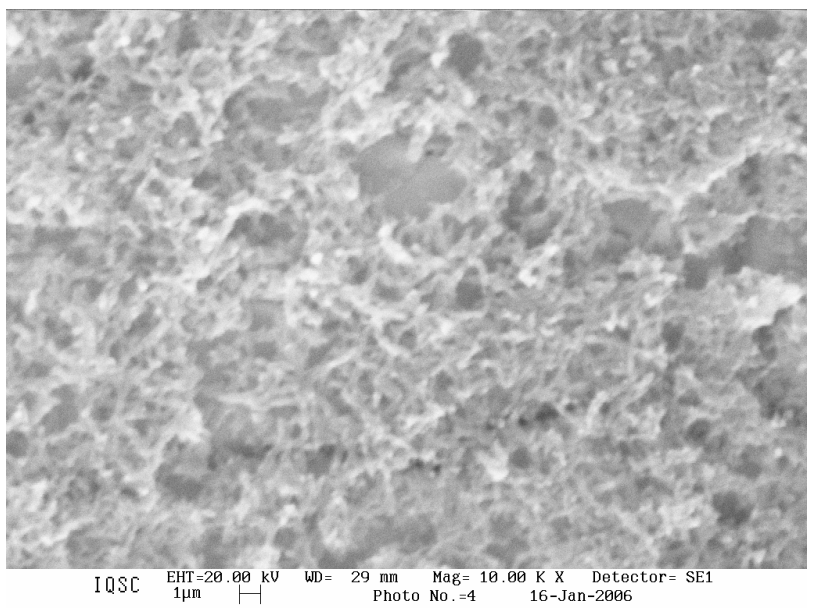

Figura 14: Micrografia obtida para o filme de poli(o-metoxianilina) em meio de $\mathrm{HCl}$.

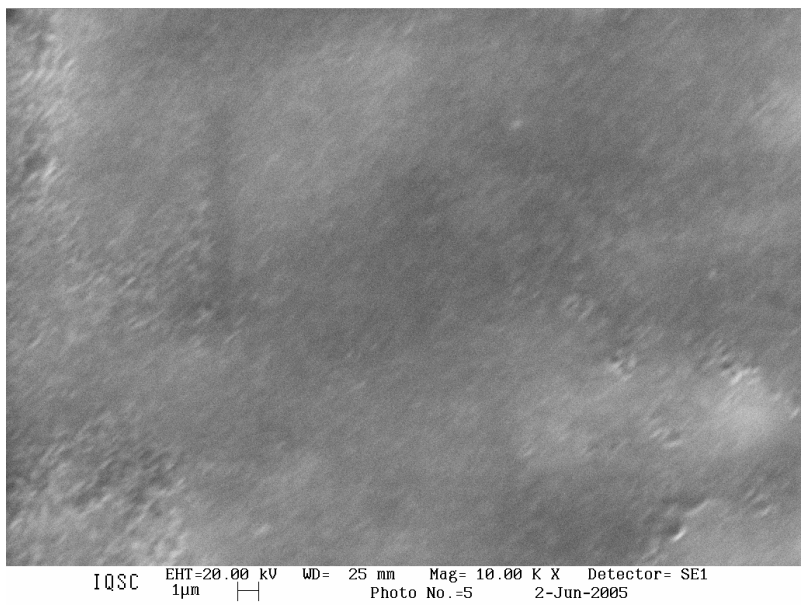

Figura 15: Micrografia obtida para o filme de polianilina em meio de $\mathrm{H}_{2} \mathrm{SO}_{4}$. 


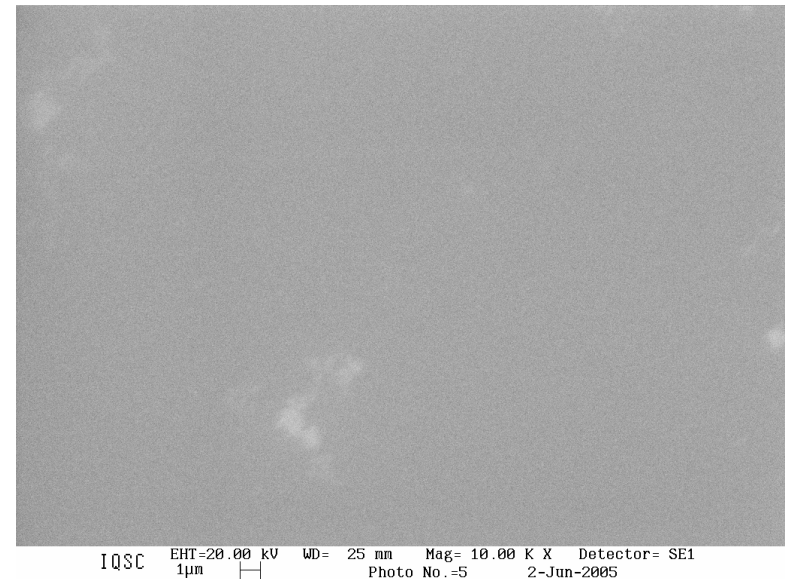

Figura 16: Micrografia do filme de poli(o-metoxianilina) em meio de $\mathrm{H}_{2} \mathrm{SO}_{4}$.

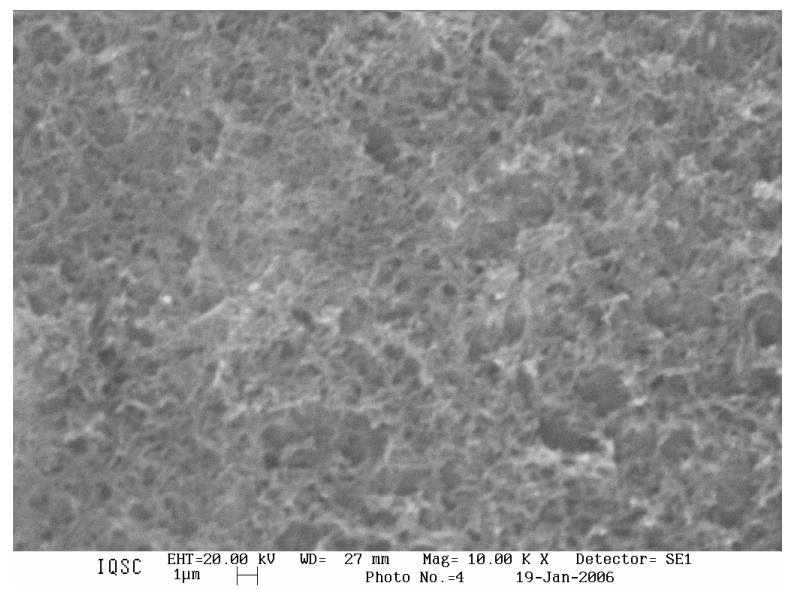

Figura 17: Micrografia obtida para o filme de polianilina e poli(ometoxianilina) em meio de $\mathrm{HCl}$.

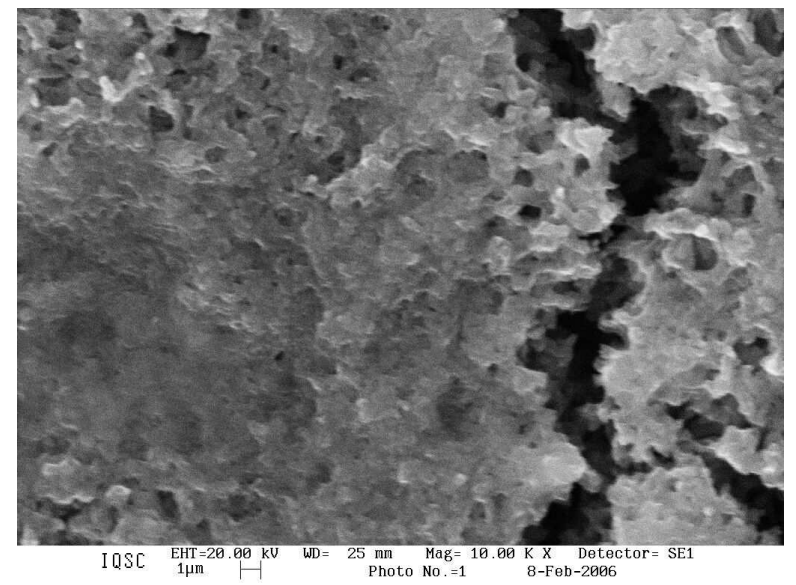

Figura 18: Micrografia obtida para o filme de polianilina e poli(ometoxianilina) em meio de $\mathrm{H}_{2} \mathrm{SO}_{4}$. 


\subsection{Respostas eletroquímicas}

A estabilidade eletroquímica dos filmes de polímeros e copolímeros foi analisada através das respostas eletroquímicas obtidas por voltametria cíclica. Nestes voltamogramas podem ser observados os pares redox dos polímeros e copolímeros aqui analisados, como mostram as Figuras 19, 20 e 21.

Os picos $\mathbf{A}(0,2 \mathrm{~V})$ e $\mathbf{C}(0,75 \mathrm{~V})$ que são atribuídos ao primeiro e ao segundo processo de oxidação do polímero, respectivamente, garantem a eletroatividade do polímero e são acompanhados pelas variações de coloração: amarelo para verde no pico $\mathbf{A}$ e de verde para azul escuro no pico C.

O pico B $(0,45 \mathrm{~V})$, intermediário do processo é atribuído a efeitos degradação, e aparece também na resposta eletroquímica, pois mesmo após a lavagem do eletrodo com o filme, ainda há oligômeros adsorvidos ao polímero que faz com que este apresente ainda esse comportamento.

A POMA e PAOMA possuem um comportamento eletroquímico que difere em alguns aspectos do comportamento eletroquímico da PAni, como observado nos voltamogramas das Figuras 20 e 21, estes polímeros apresentam os mesmos pares redox observados nas respostas eletroquímicas da PAni, com a diferença de estarem mais próximos [7], e o pico $\mathbf{B}$ é mais ressaltado. 

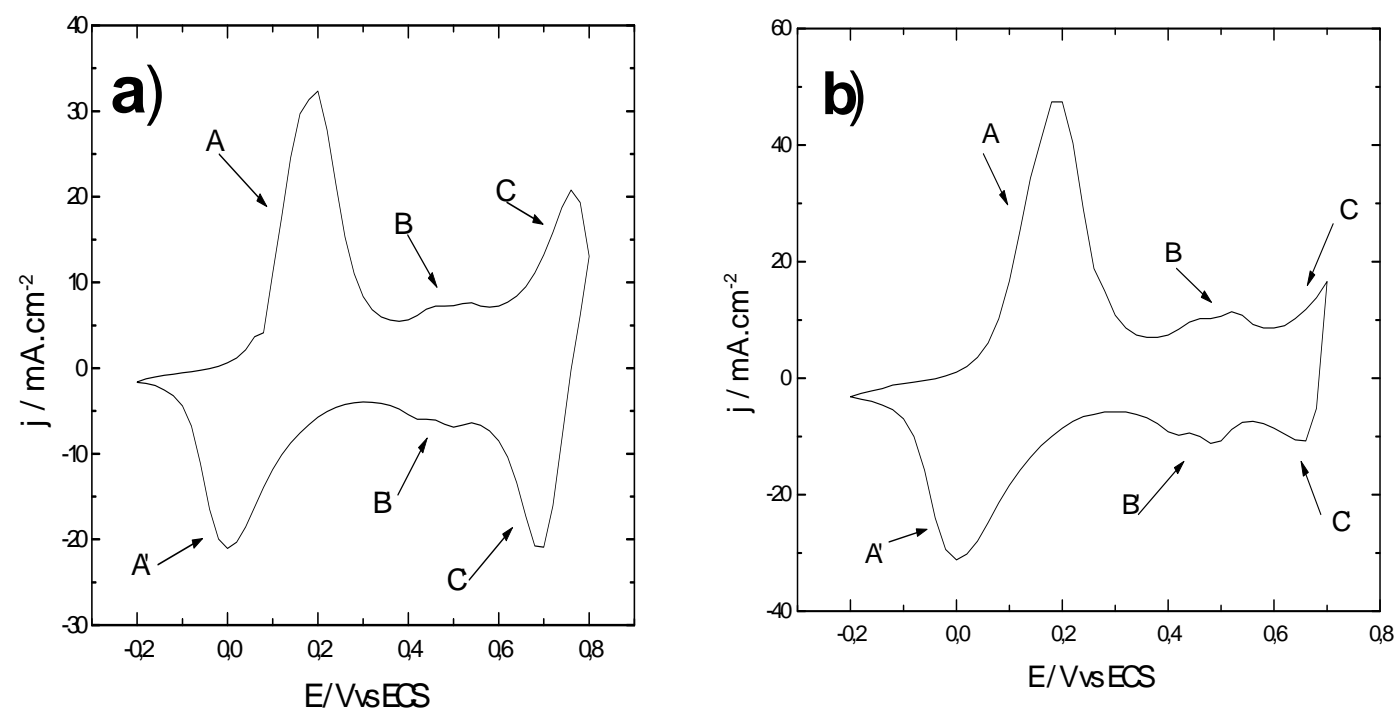

Figura 19: Resposta eletroquímica do filme de PAni em solução de $1 \mathrm{~mol} \mathrm{~L}^{-1}$ a) $\mathrm{HCl}$; b) $\mathrm{H}_{2} \mathrm{SO}_{4}, 5^{\circ}$ ciclo, $\mathrm{v}=50 \mathrm{mV} / \mathrm{s}$.
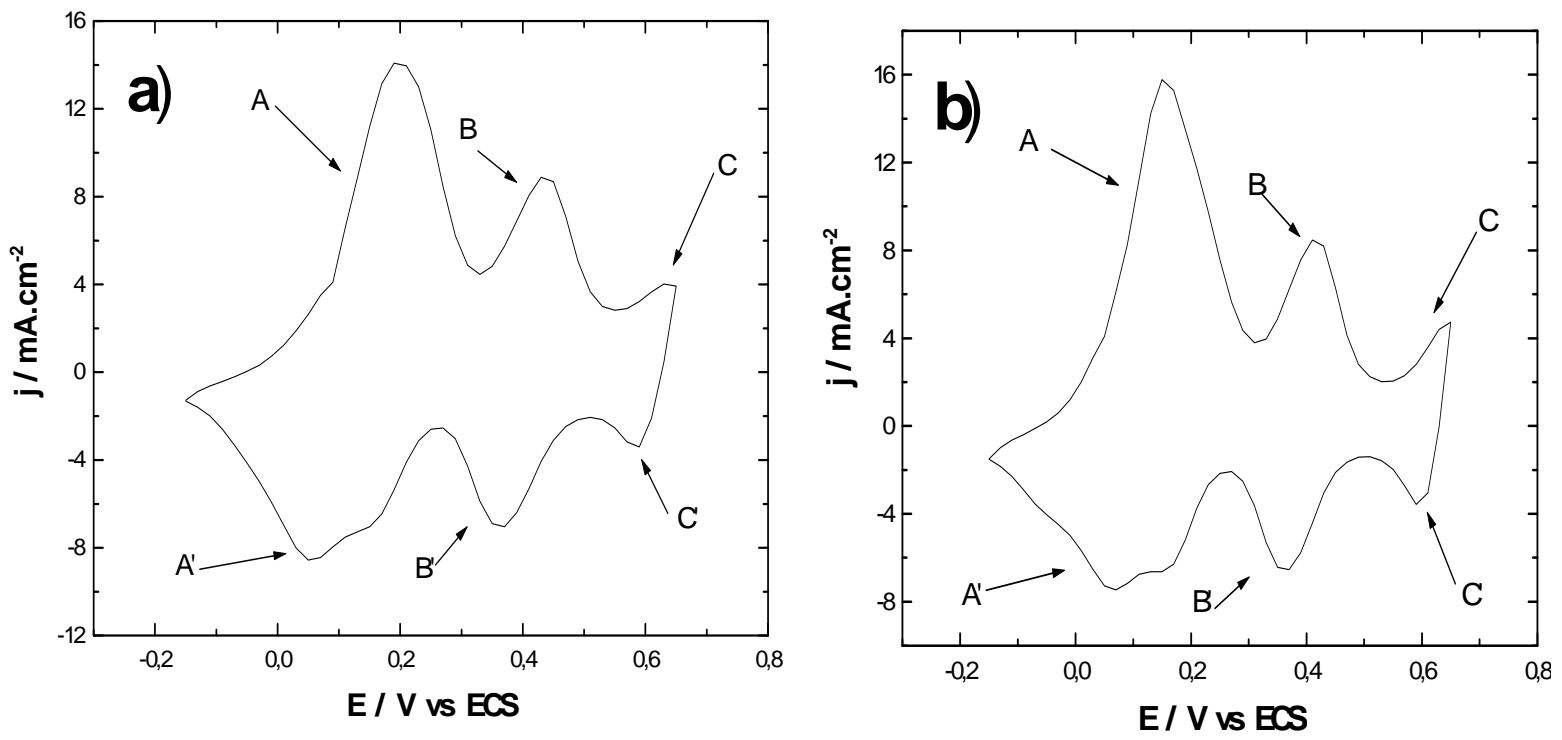

Figura 20: Resposta eletroquímica do filme de POMA em solução de $1 \mathrm{~mol}$ $\mathrm{L}^{-1}$ a) $\mathrm{HCl}$; b) $\mathrm{H}_{2} \mathrm{SO}_{4}, 5^{\circ}$ ciclo, $\mathrm{v}=50 \mathrm{mV} / \mathrm{s}$. 

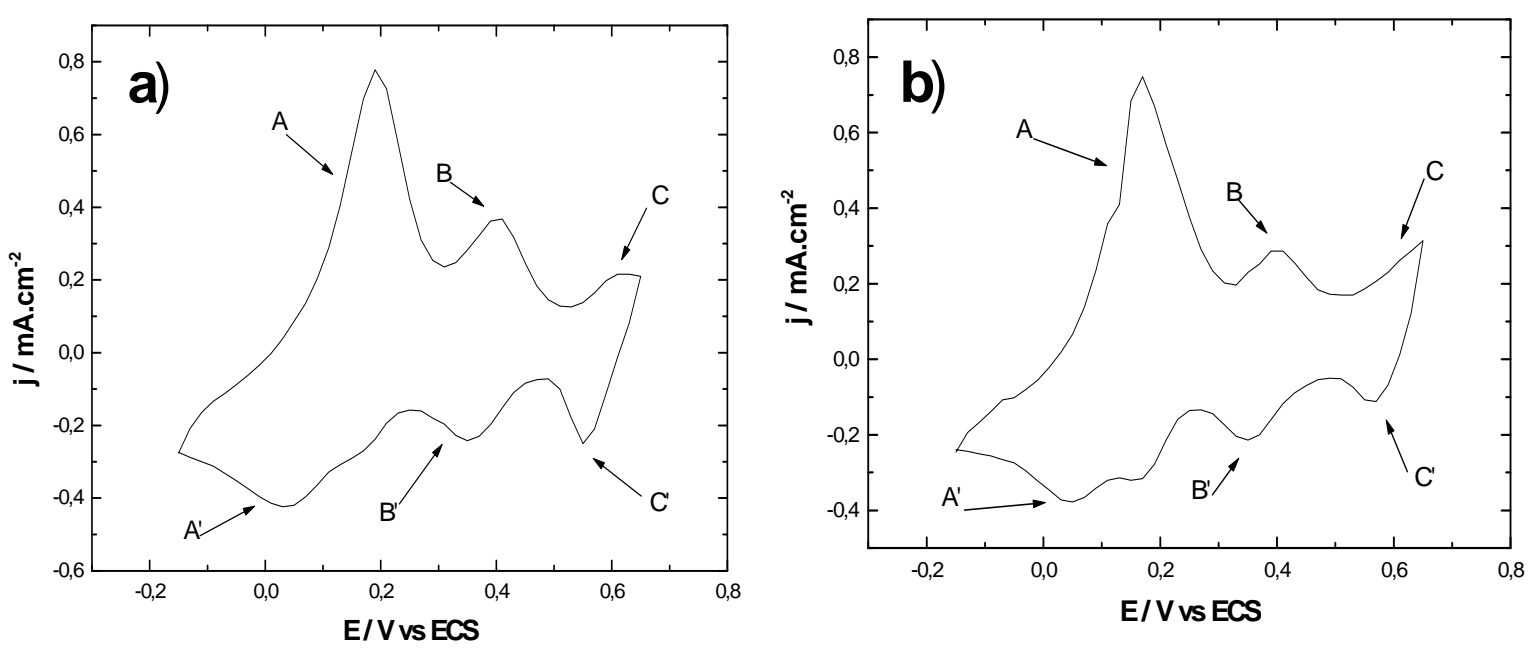

Figura 21: Resposta eletroquímica do filme de PAOMA em solução de $1 \mathrm{~mol} \mathrm{~L}^{-1}$ a) $\mathrm{HCl}$; b) $\mathrm{H}_{2} \mathrm{SO}_{4}, 5^{\circ}$ ciclo, $\mathrm{v}=50 \mathrm{mV} / \mathrm{s}$.

\subsection{Comportamento dos filmes poliméricos na presença de soluções contendo Hidroquinona.}

Os filmes dos polímeros e copolímeros obtidos na síntese eletroquímica em meio de $\mathrm{HCl}$ e $\mathrm{H}_{2} \mathrm{SO}_{4}$, foram testados quanto a sua sensibilidade a um composto orgânico (hidroquinona), também foi estudado qual a melhor espessura desses filmes para a detecção a hidroquinona.

As espessuras dos filmes depositados foram estimadas pela carga $Q_{1}$ necessária para a mudança da forma leucoesmeraldina (LE) para a forma esmeraldina $\left(\mathrm{EM}^{+2}\right)$ da PAni e POMA de acordo com a equação [48]:

$d=\left(Q_{1} M w\right) /(z F A \rho)$

onde,

d = espessura do filme polimérico;

$Q_{I}=$ carga anódica do primeiro pico $(\mathbf{A})$;

Mw = massa molecular do monômero; 
$z$ = número de elétrons por unidade de monômero $(z=0,5)$;

$\mathrm{F}=$ constante de Faraday $(\mathrm{F}=96487 \mathrm{C} / \mathrm{mol})$;

$A=$ área do eletrodo $\left(A=0,5 \mathrm{~cm}^{2}\right)$;

$\rho=$ densidade específica do monômero.

Esta equação não leva em consideração a porosidade do filme nem o volume do contra-íon, ela calcula apenas a quantidade total de polímero depositada sobre o eletrodo.

As reações redox sobre os eletrodos dos polímeros, são explicadas pelas adsorção específica das moléculas de $\mathrm{HQ}$ sobre os centros de $\left(\mathrm{EM}^{+2}\right)$. O pico A é o pico de oxidação que determina a espessura do filme polimérico depositado sobre o eletrodo de platina, sendo que a caga anódica é de valor igual à área baixo deste pico [48].

\subsubsection{Hidroquinona em meio de $\mathrm{HCl}$}

Observando as Figura 22 é possível verificar que os filmes dos polímeros aqui identificados são sensíveis a soluções de hidroquinona em $\mathrm{HCl}$ 1M. A PAni não possui picos de oxidação no intervalo de potencial $(0,35$ a $0,55 \mathrm{~V}$ ), porém quando está em contato com a $\mathrm{HQ}$ pode-se notar o aparecimento do pico de oxidação das quinonas nesse intervalo de potencial, que indica que está ocorrendo a oxidação da HQ. 


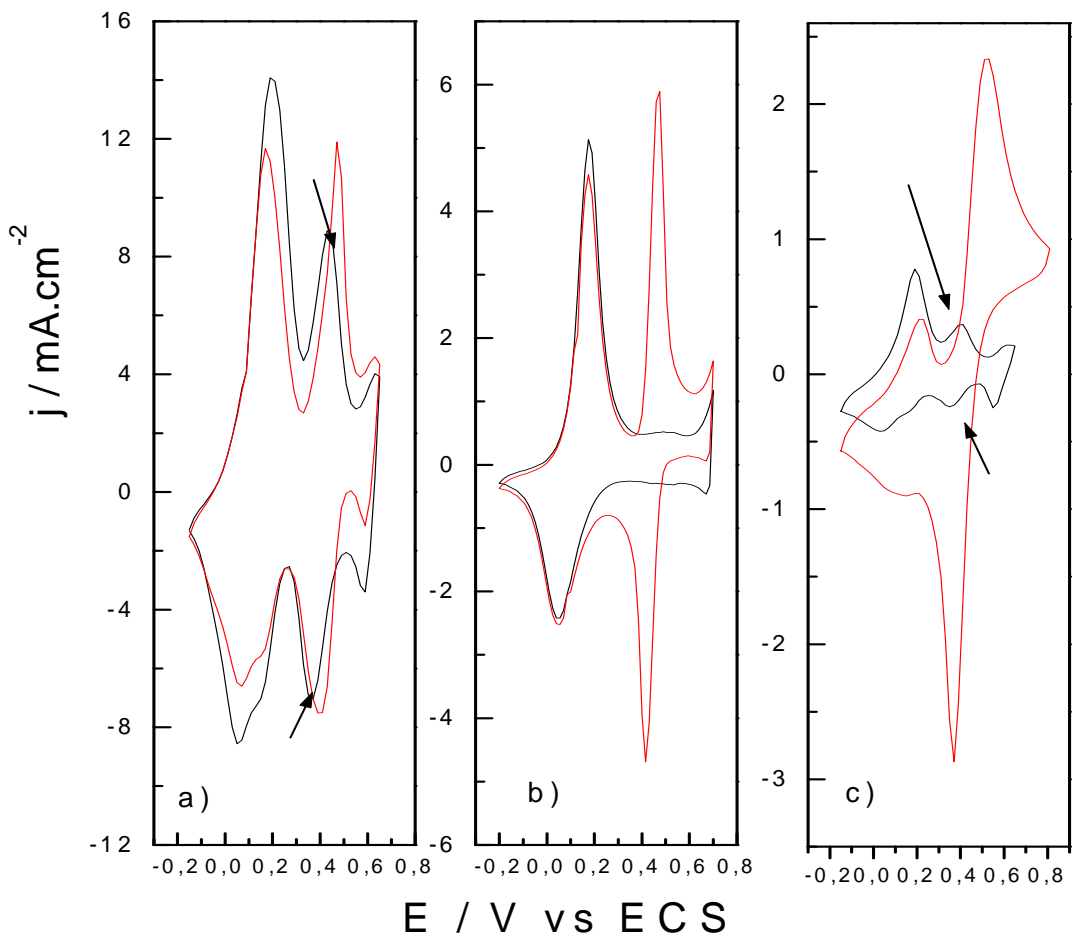

Figura 22: Resposta eletroquímica de a) POMA; b) PAni e c) PAOMA em $1 \mathrm{~mol} \mathrm{~L}^{-1} \mathrm{HCl}(-)$ sem HQ e $(-)$ com $5 \mathrm{mM} \mathrm{HQ}$. v $=50 \mathrm{mV} / \mathrm{s}$.

No entanto a POMA e a PAOMA possuem um pico de oxidação característico neste intervalo de potencial [49], coincidindo com o intervalo de potencial de oxidação da HQ. Pelas respostas eletroquímicas foi observado aumento da corrente de pico nesse intervalo quando os filmes de POMA e PAOMA são colocados em contato com a HQ, sendo que quanto maior a concentração de $\mathrm{HQ}$ maior é a corrente de pico. Este aumento de corrente também é acompanhado pelo alargamento na base do pico, sendo que a integração deste pico fornece a carga envolvida na oxidação da $\mathrm{HQ}$. 

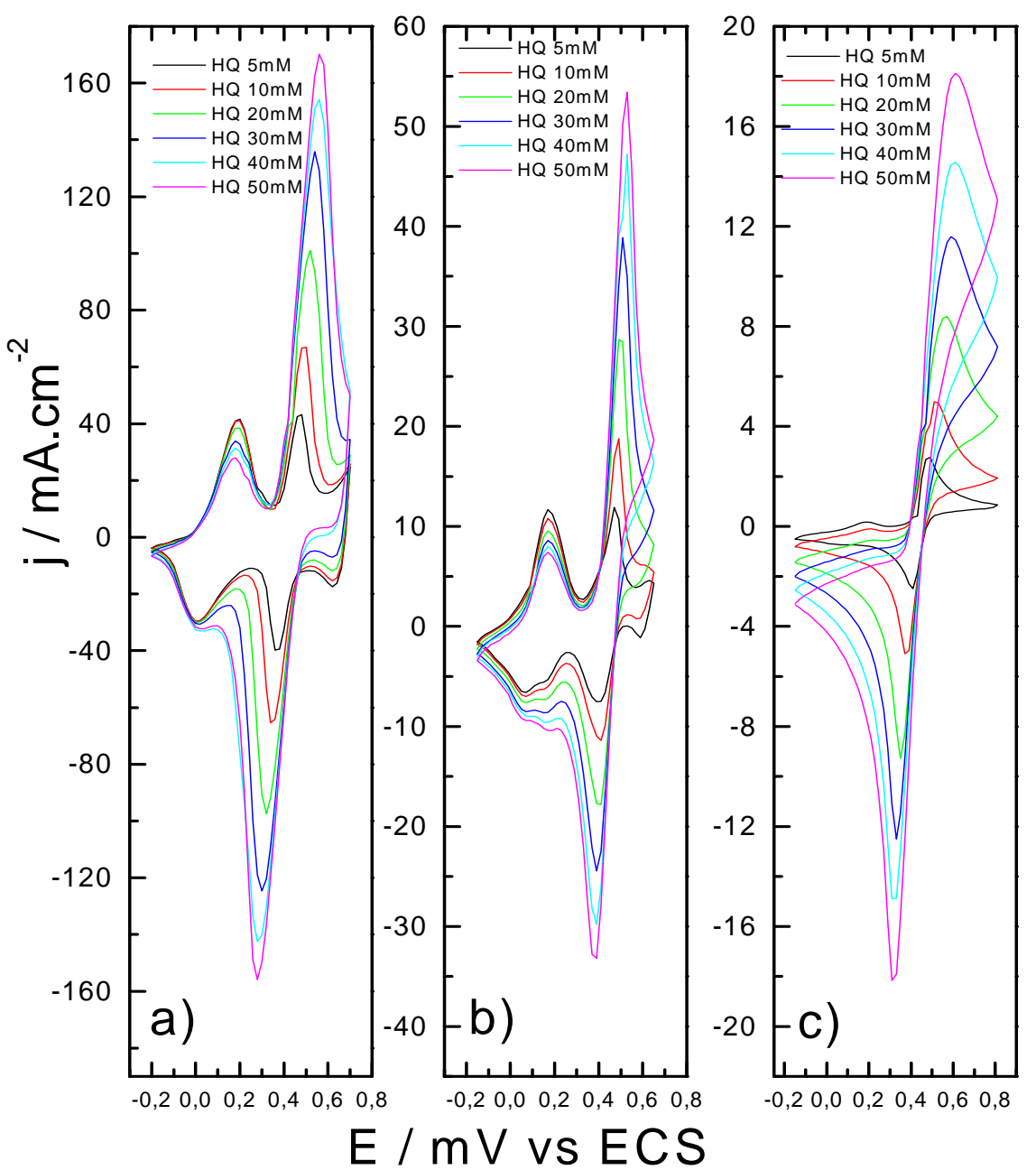

Figura 23: Resposta eletroquímica de a) PAni, b) POMA e c) PAOMA em contato com solução de $1 \mathrm{~mol} \mathrm{~L}^{-1} \mathrm{HCl}$ e 5 a $50 \mathrm{~mol} \mathrm{~L}^{-1} \mathrm{HQ}$.

O pico de oxidação de quinonas, é expressivo quando o eletrodo é submetido à respostas em meio de soluções de $\mathrm{HQ}$ em $\mathrm{HCl}$, e também mostra uma dependência da concentração de hidroquinona em solução com a intensidade da densidade de corrente do pico de oxidação na Figura 23.

Já as Figuras 24, 25 e 26 evidenciam a linearidade do crescimento da concentração de $\mathrm{HQ}$ com a densidade de corrente do pico de oxidação, além de padronizar uma reta capaz de fornecer uma concentração desconhecida de hidroquinona em solução dependendo apenas do pico de corrente de oxidação no intervalo indicado. 


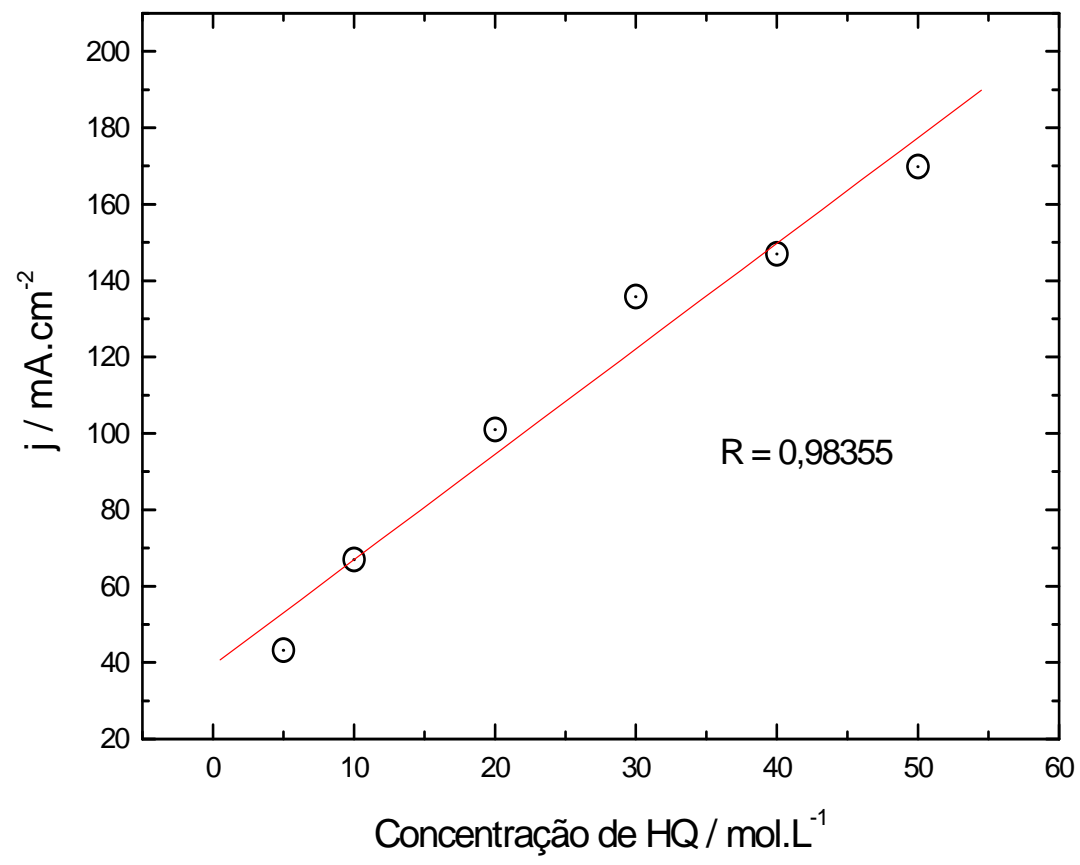

Figura 24: Curva do pico de corrente de oxidação da $\mathrm{HQ}$ pela concentração de $\mathrm{HQ}$ em solução de $\mathrm{HCl} 1 \mathrm{~mol} \mathrm{~L}^{-1}$ do filme de PAni(Cl). Coeficiente angular de 1,38142 .

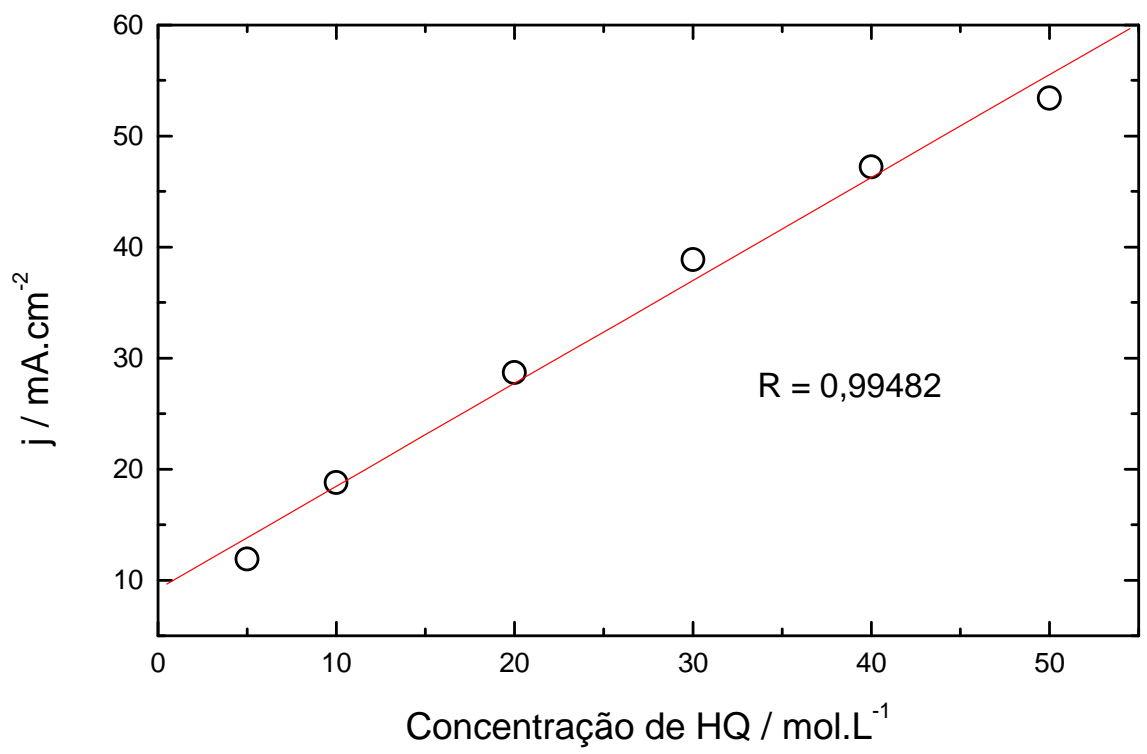

Figura 25: Curva do pico de corrente de oxidação da $H Q$ pela concentração de $\mathrm{HQ}$ em solução de $\mathrm{HCl} 1 \mathrm{~mol} \mathrm{~L}^{-1}$ do filme de $\mathrm{POMA}(\mathrm{Cl})$. Coeficiente angular de 0,46307. 


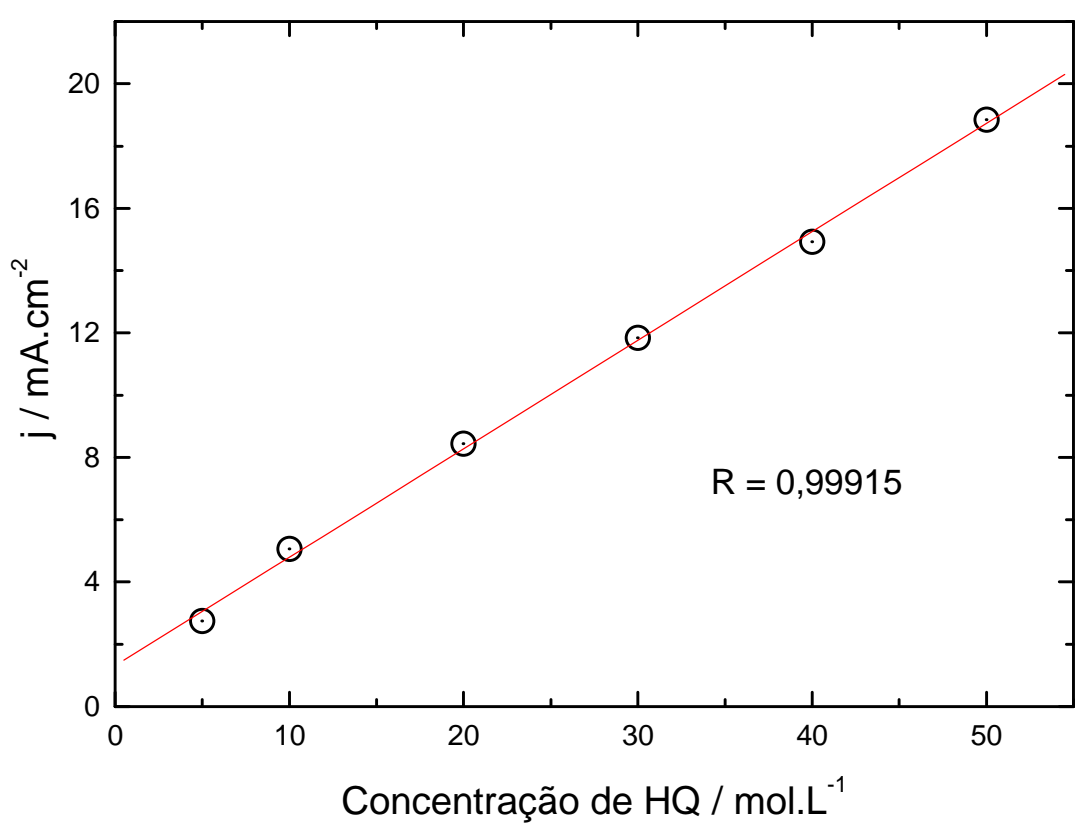

Figura 26: Curva do pico de corrente de oxidação da $H Q$ pela concentração de $\mathrm{HQ}$ em solução de $\mathrm{HCl} 1 \mathrm{~mol} \mathrm{~L}^{-1}$ do filme de PAOMA(Cl). Coeficiente angular de 0,17423 .

A espessura de filme que melhor responde à sensibilidade de hidroquinona é aquela que corresponder ao maior coeficiente angular da curva do coeficiente angular das retas da densidade de corrente do pico de oxidação pela concentração de $H Q$ vs $Q_{\text {picoA }}$ dos filmes poliméricos [48], isso pode ser observado nas Figuras 27, 28 e 29.

Então, a espessura do filme, depositado em meio de $\mathrm{HCl}$, de PAni, POMA e PAOMA que melhor responde à sensibilidade de hidroquinona é de aproximadamente $2,82,1,1$ e $0,039 \mu \mathrm{m}$, respectivamente. 


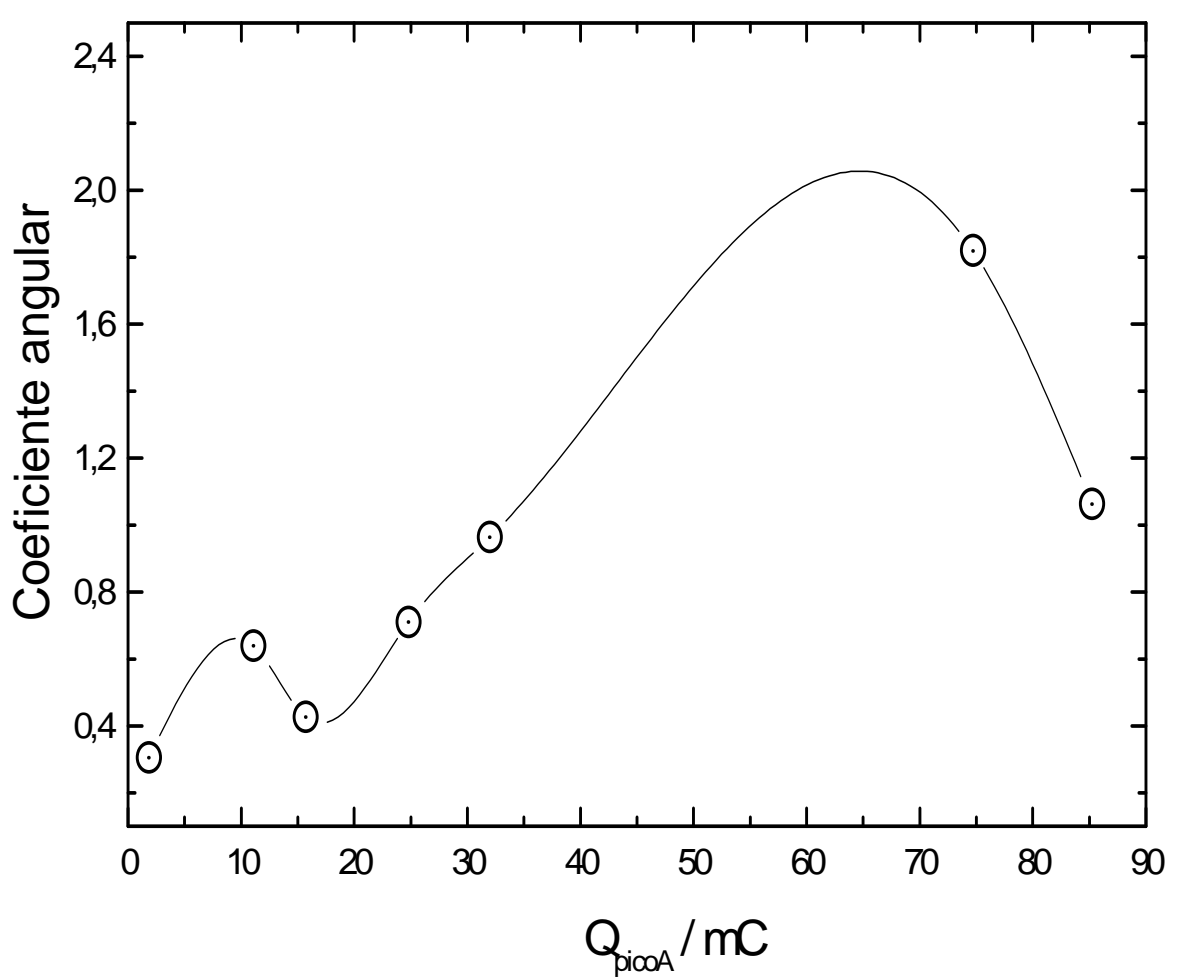

Figura 27: Curva de coeficiente angular da reta do pico de corrente de oxidação pela concentração de $\mathrm{HQ}$, pela $Q_{\text {picoA }}$ do filme de PAni(Cl).

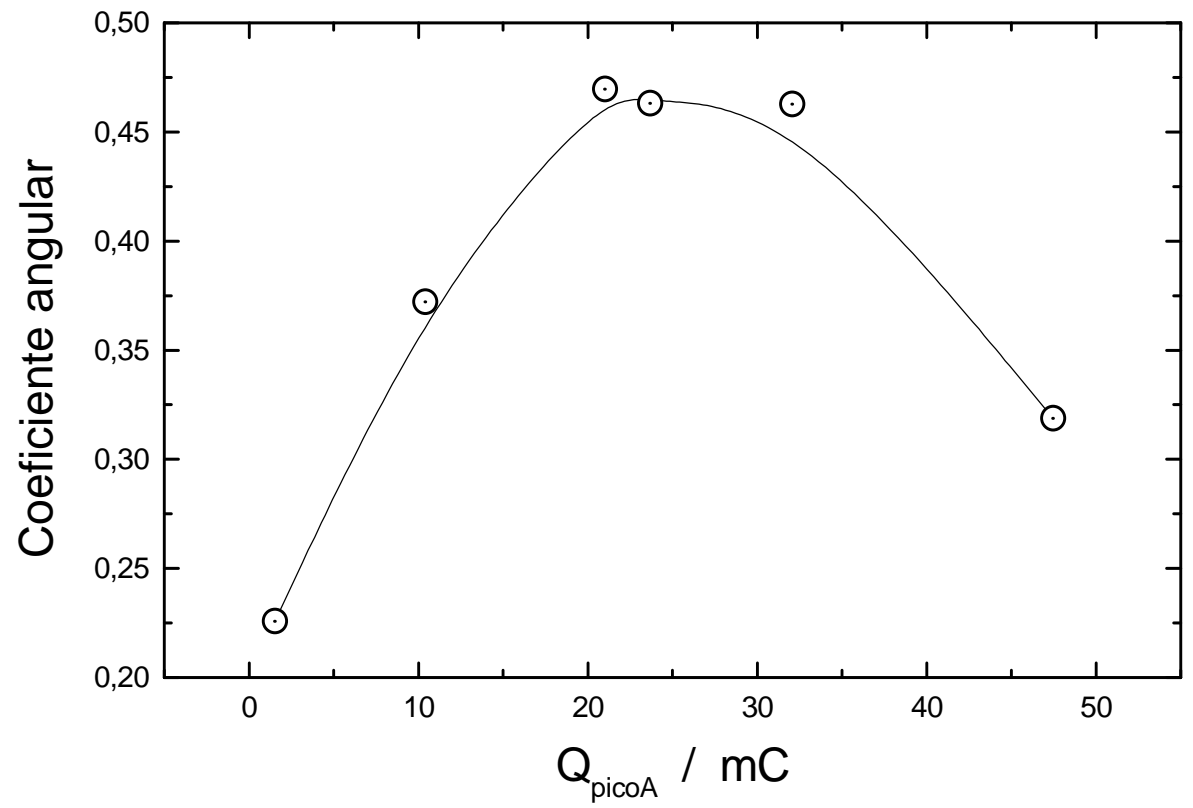

Figura 28: Curva de coeficiente angular da reta do pico de corrente de oxidação pela concentração de $\mathrm{HQ}$ pela $Q_{\text {picoA }}$ do filme de $P O M A(C l)$. 


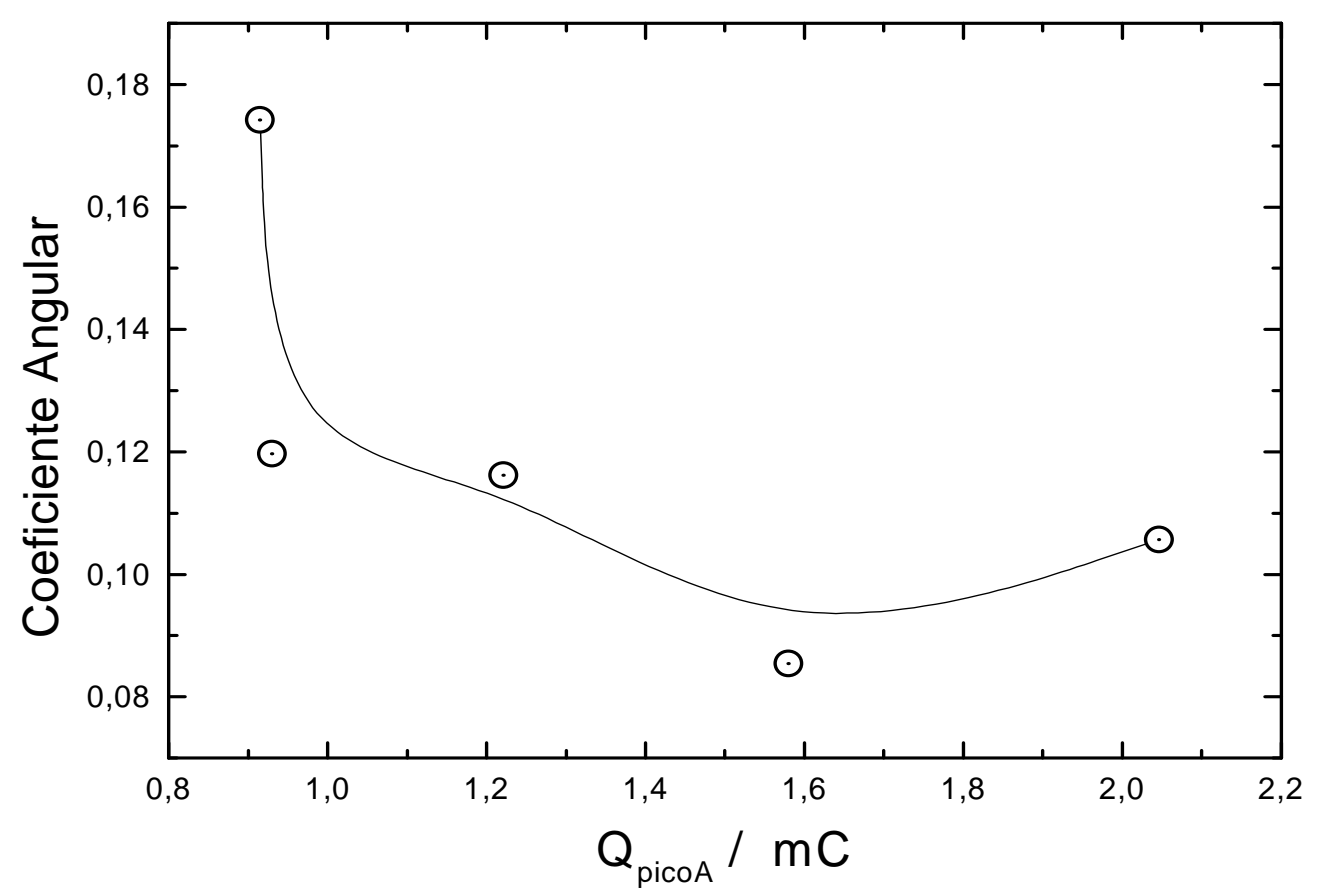

Figura 29: Curva de coeficiente angular da reta do pico de corrente de oxidação pela concentração de $H Q$ pela $Q_{\text {picoA }}$ do filme de $\operatorname{PAOMA}(\mathrm{Cl})$.

\subsubsection{Hidroquinona em meio de $\mathrm{H}_{2} \mathrm{SO}_{4}$}

A Figura 30 apresenta as respostas dos filmes de PAni, POMA e PAOMA em meio de $\mathrm{H}_{2} \mathrm{SO}_{4}$, para soluções contendo Hidroquinona, onde pode ser observado a presença do pico de oxidação das quinonas, também no potencial entre o de 0,4 e 0,45 V, como para as respostas dos filmes em meio de $\mathrm{HCl}$. 


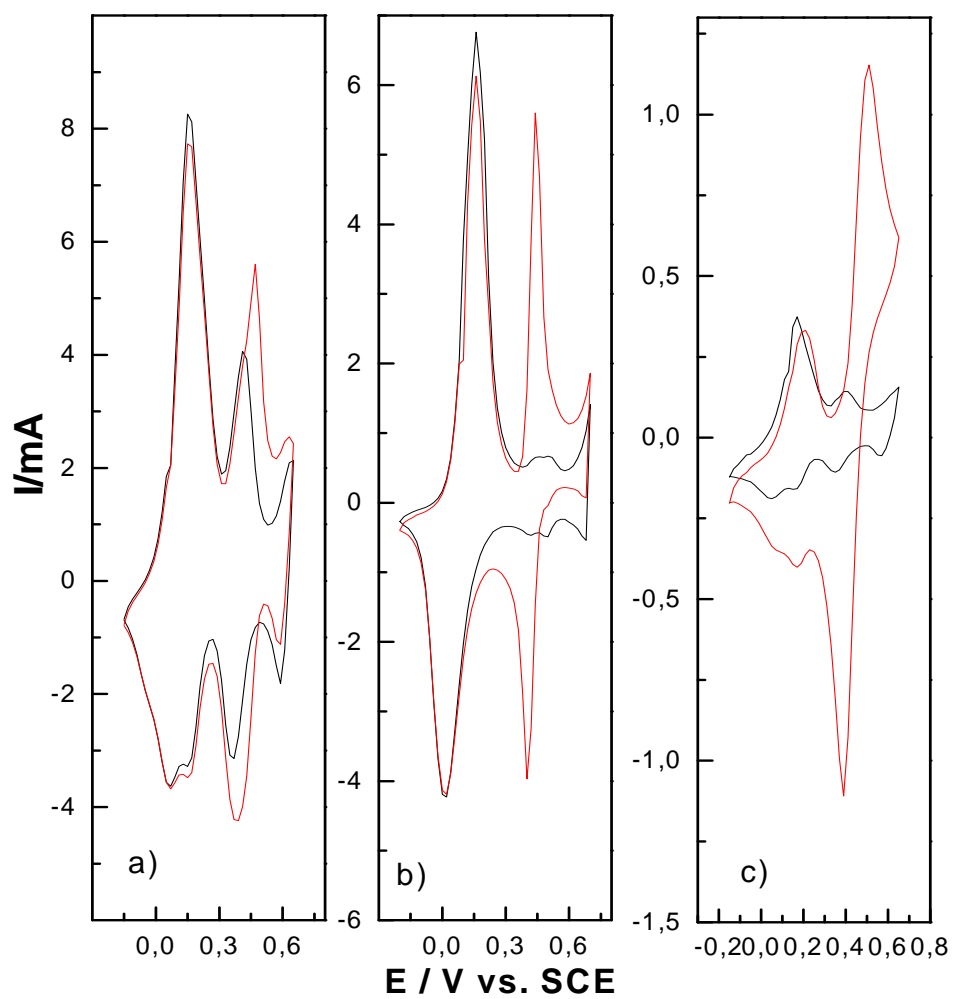

Figura 30: Respostas eletroquímicas dos filmes de a) POMA; b) PAni e c) PAOMA em $1 \mathrm{~mol} \mathrm{~L}^{-1}$ de $\mathrm{H}_{2} \mathrm{SO}_{4}(-)$ sem $\mathrm{HQ}$ e com (-) $5 \mathrm{mM} \mathrm{HQ} . \mathrm{v}=50$ $\mathrm{mV} / \mathrm{s}$.

As respostas apresentadas na Figura 31 demonstram que, assim como os filmes polimerizados em $\mathrm{HCl}$, existe uma variação crescente da concentração de $\mathrm{HQ}$ e da densidade de corrente do pico de oxidação da hidroquinona. 

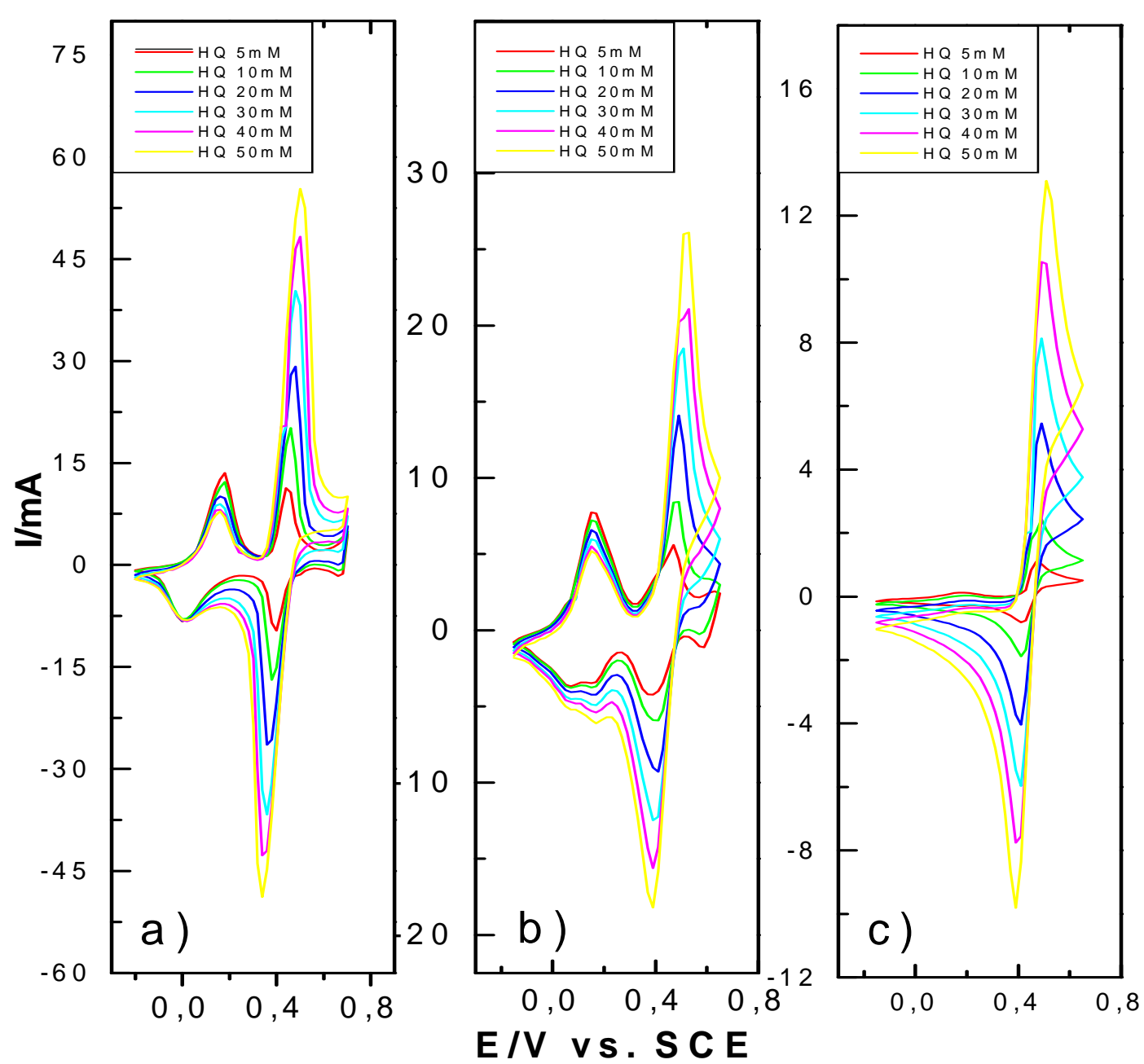

Figura 31: Resposta eletroquímica de a) PAni, b) POMA e c) PAOMA em contato com solução de $1 \mathrm{~mol} \mathrm{~L}^{-1} \mathrm{H}_{2} \mathrm{SO}_{4}$ e 5 a 50 mol. L $^{-1} \mathrm{HQ}$.

As Figuras 32, 33 e 34 mostram como obtido para $\mathrm{HCl}$ o crescimento da concentração de $\mathrm{HQ}$ com a densidade de corrente do pico de oxidação, apresentando uma reta capaz de fornecer uma concentração desconhecida de hidroquinona em solução. 


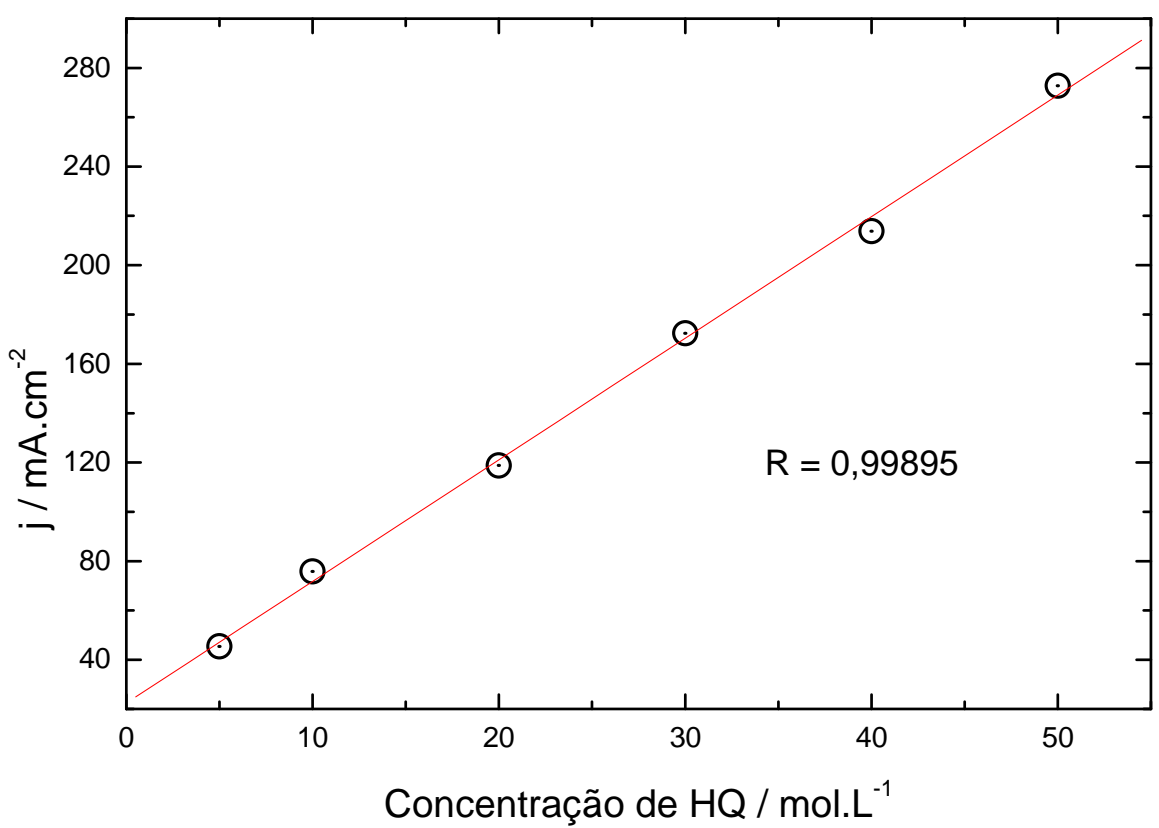

Figura 32: Curva do pico de corrente de oxidação da $\mathrm{HQ}$ pela concentração de $\mathrm{HQ}$ em solução de $\mathrm{H}_{2} \mathrm{SO}_{4} 1 \mathrm{~mol} \mathrm{~L}^{-1}$ do filme de PAni( $\left.\mathrm{SO}_{4}\right)$. Coeficiente angular de 2,46559.

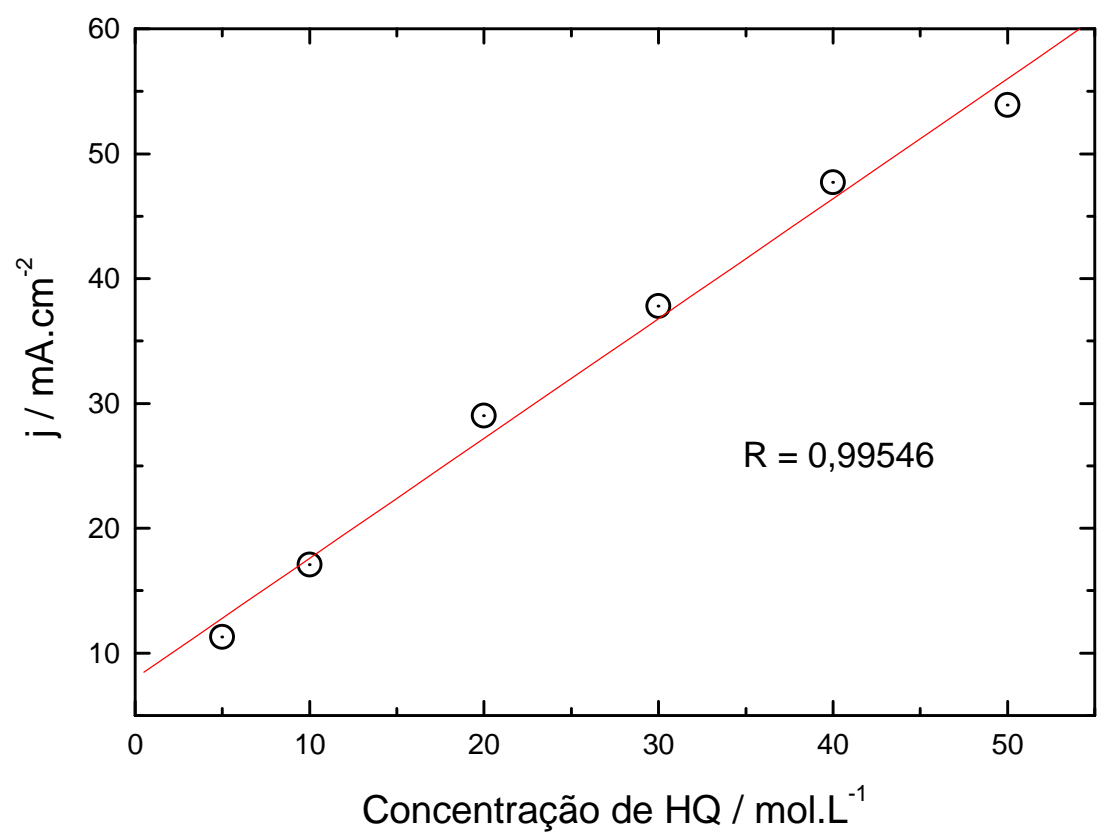

Figura 33: Curva do pico de corrente de oxidação da $H Q$ pela concentração de $\mathrm{HQ}$ em solução de $\mathrm{H}_{2} \mathrm{SO}_{4} 1 \mathrm{~mol} \mathrm{~L}^{-1}$ do filme de $\mathrm{POMA}\left(\mathrm{SO}_{4}\right)$. Coeficiente angular de 0,48005. 


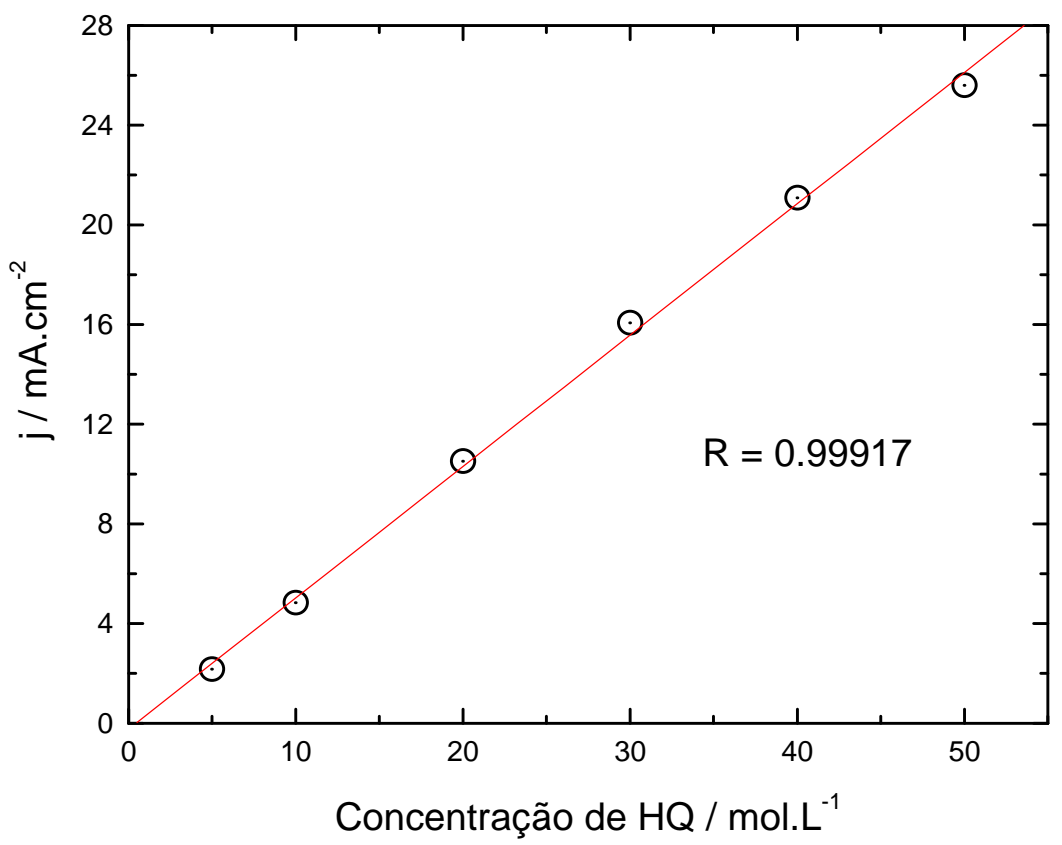

Figura 34: Curva do pico de corrente de oxidação da $\mathrm{HQ}$ pela concentração de $\mathrm{HQ}$ em solução de $\mathrm{H}_{2} \mathrm{SO}_{4} 1 \mathrm{~mol} \mathrm{~L}^{-1}$ do filme de PAOMA$\left(\mathrm{SO}_{4}\right)$. Coeficiente angular de 0,26339.

As Figuras 35, 36 e 37 mostram a relação da carga do primeiro pico (A) de oxidação dos polímeros com o coeficiente angular das retas obtidas pela concentração de $\mathrm{HQ}$ vs a densidade da corrente de pico da oxidação da HQ. O maior coeficiente angular corresponde ao filme de melhor espessura para a detecção de $\mathrm{HQ}$, pois quanto maior é a inclinação da reta, maior é a oxidação de hidroquinona nos filmes poliméricos. 


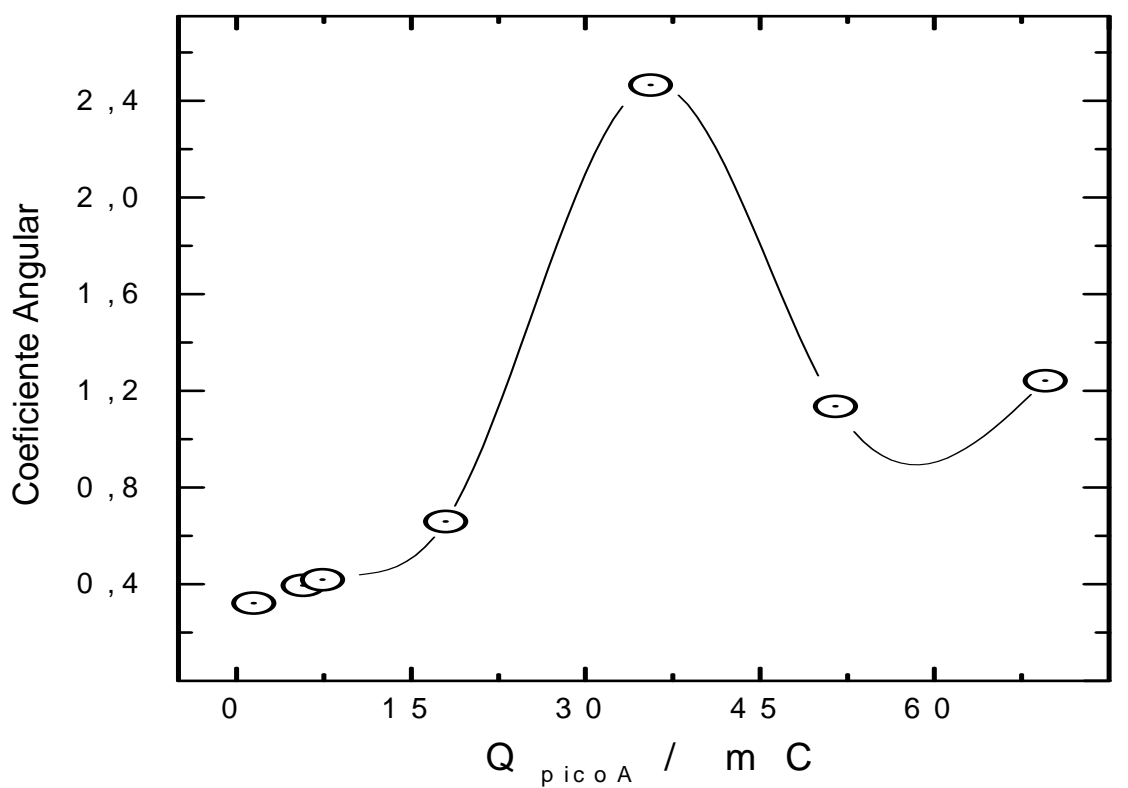

Figura 35: Curva de coeficiente angular da reta do pico de corrente de oxidação pela concentração de $\mathrm{HQ}$ pela $\mathrm{Q}_{\text {picoA }}$ do filme de $\mathrm{PAni}\left(\mathrm{SO}_{4}\right)$.

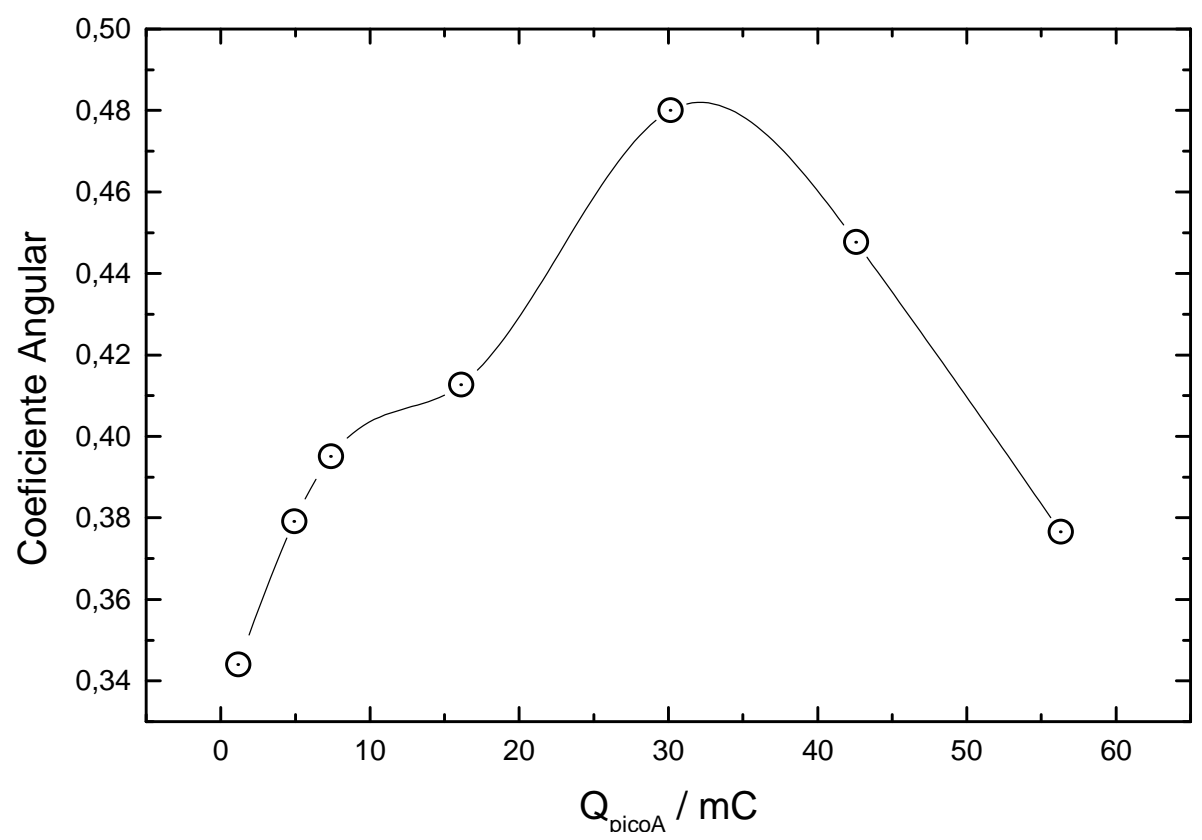

Figura 36: Curva de coeficiente angular da reta do pico de corrente de oxidação pela concentração de $\mathrm{HQ}$ pela $\mathrm{Q}_{\text {picoA }}$ do filme de $\operatorname{POMA}\left(\mathrm{SO}_{4}\right)$. 


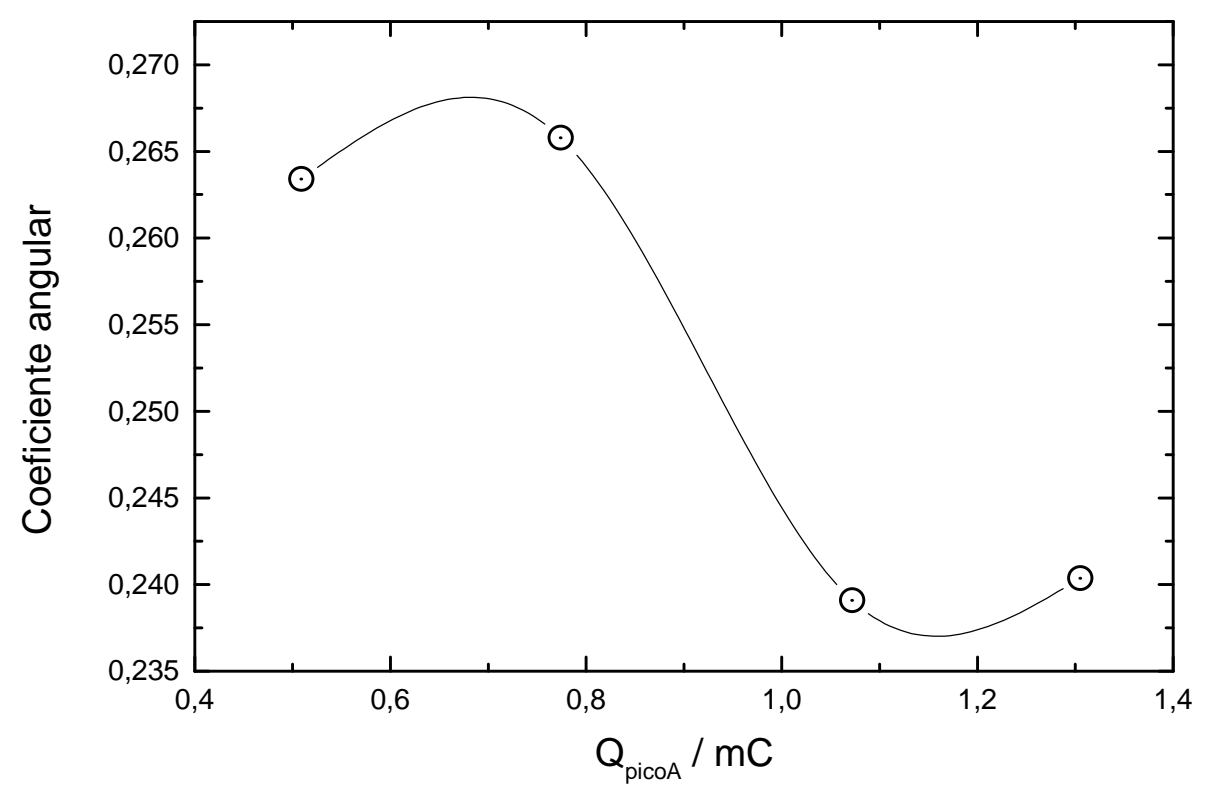

Figura 37: Curva de coeficiente angular da reta do pico de corrente de oxidação pela concentração de $\mathrm{HQ}$ pela $\mathrm{Q}_{\text {picoA }}$ do filme de $\operatorname{PAOMA}\left(\mathrm{SO}_{4}\right)$.

A espessura do filme depositado em meio de $\mathrm{H}_{2} \mathrm{SO}_{4}$ de PAni, POMA e PAOMA que melhor responde à sensibilidade de hidroquinona é de aproximadamente $1,34,1,4$ e $0,032 \mu \mathrm{m}$, respectivamente.

A interação da hidroquinona com os polímeros estudados pode ser demonstrada através de reações, onde a oxidação da $\mathrm{HQ}$ acontece na região do potencial da forma esmeraldina, essa reação pode assumir a formar da reação (1). Uma unidade esmeraldina pode transferir somente dois elétrons tanto para a forma polaron como para o bipolaron e oxidar uma molécula de $\mathrm{HQ}$, como na reação (3) [48].

Os centros esmeraldina $\left(\mathrm{EM}^{+2}\right)$ durante a polarização anódica oxidam a $\mathrm{HQ}$ de acordo com as reações (1) e (4), mas ao mesmo tempo esses centros $\mathrm{EM}^{+2}$ transformam-se em leucoesmeraldina (LE) como nas reações (2) e (4).

$$
\begin{aligned}
& \mathrm{H}_{2} \mathrm{Q} \Leftrightarrow \mathrm{Q}+2 \mathrm{H}^{+}+2 e^{-} \\
& \mathrm{EM}^{+2}+2 \mathrm{e}^{-} \Leftrightarrow \mathrm{LE}
\end{aligned}
$$


$\mathrm{EM}^{+2}+\mathrm{H}_{2} \mathrm{Q} \Leftrightarrow \mathrm{LE}+\mathrm{Q}+2 \mathrm{H}^{+}$
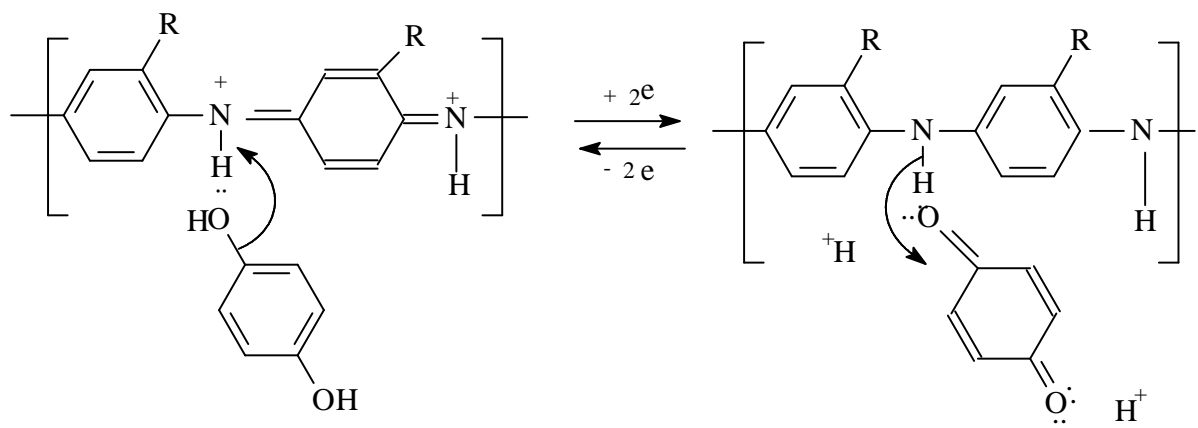

A interação dos filmes poliméricos com a hidroquinona também pode ser apresentada na forma de um diagrama como na Figura 38, onde $H Q$ : hidroquinona dissolvida em solução; $B Q$ : benzoquinona dissolvida em solução; $H Q^{P}$ : hidroquinona presente no filme polimérico; $B Q^{P}$ : benzoquinona presente no filme polimérico; $\mathrm{Ox}^{\mathrm{P}}$ : forma oxidada do filme; $\operatorname{Red}^{P}$ : forma reduzida do filme; $D_{H Q}$ e $D_{e}$ : coeficiente de difusão e $K$ : constante de velocidade. 


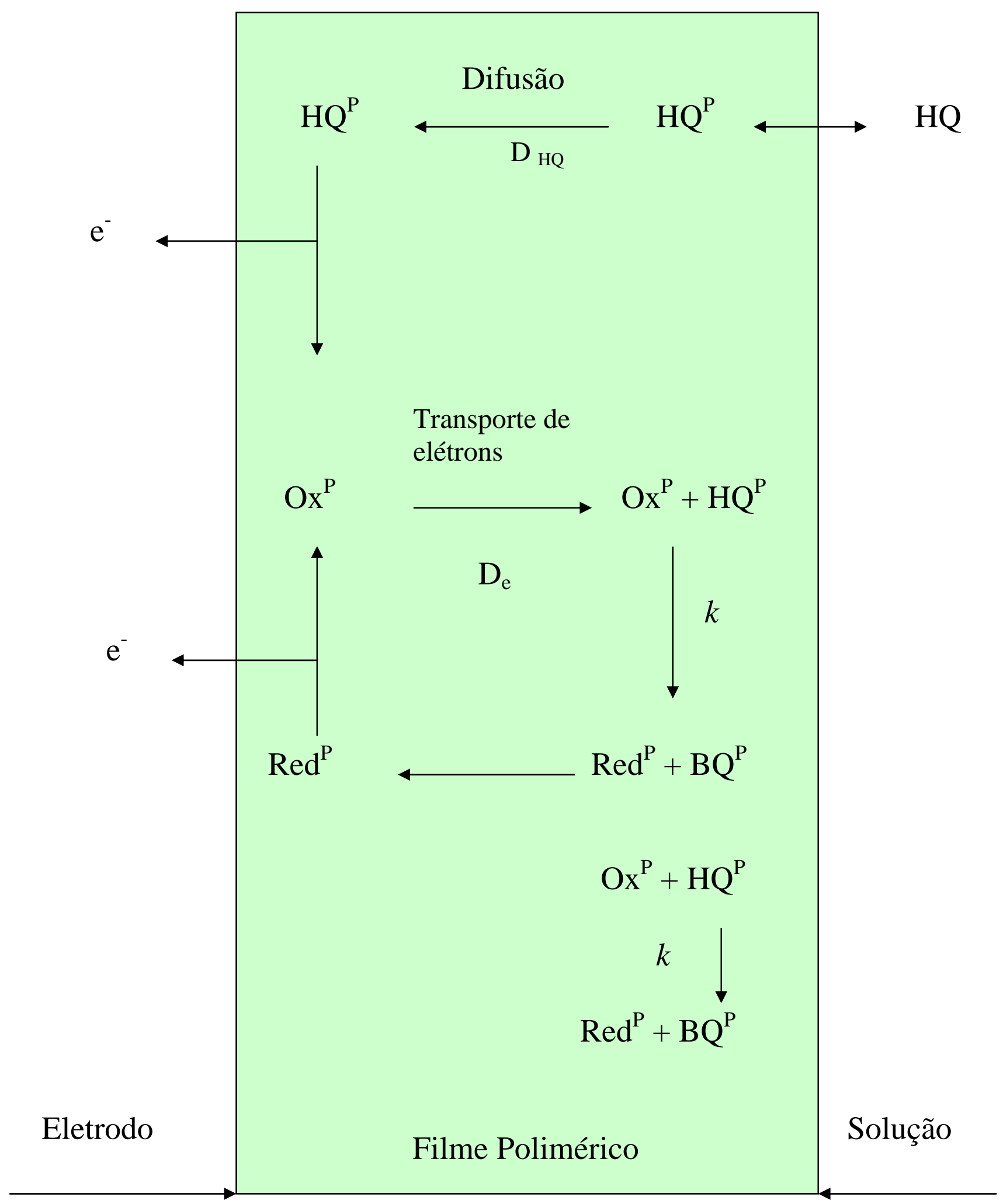

Figura 38: Diagrama da interação do filme polimérico com a Hidroquinona. 
De acordo com esse diagrama baseado na teoria de Albery e Hillman [50] a hidroquinona (HQ) presente na solução é convertida em benzoquinona (BQ) pela transferência de elétrons da forma oxidada do filme $\left(O x^{P}\right)$ correspondente a forma esmeraldina $\left(\mathrm{EM}^{+2}\right)$, que é retornada a forma reduzida do filme $\left(\operatorname{Red}^{\mathrm{P}}\right)$, forma leucoesmeraldina (LE) pela transferência de elétrons do substrato do eletrodo.

Albery e Hillman também sustentam a hipótese de que a concentração de $O x^{P}$ e de $H Q$ dentro do filme são constantes. Para obter uma evidência indireta que $\left[\mathrm{HQ}^{\mathrm{P}}\right]$ é constante nos filmes poliméricos, foi usada a equação (5):

$$
\left[\mathrm{Ox}^{\mathrm{P}}\right]=\frac{\mathrm{Q}_{\mathrm{c}}}{F \mathrm{Ad}}
$$

onde, $Q_{c}$ : carga catódica do pico de oxidação de $H Q$ no filme polimérico; F:constante de Faraday; A: área do eletrodo e d : espessura do filme polimérico.

Os filmes dos polímeros e copolímeros estudados apresentam a concentração de $\mathrm{HQ}^{\mathrm{P}}$ constantes, como pode ser visto nas Figuras 39 a 44. A concentração média de $\left[0 x^{P}\right]$ independente da espessura paras os filmes dos polímeros e copolímeros, como está apresentado na tabela 5. 


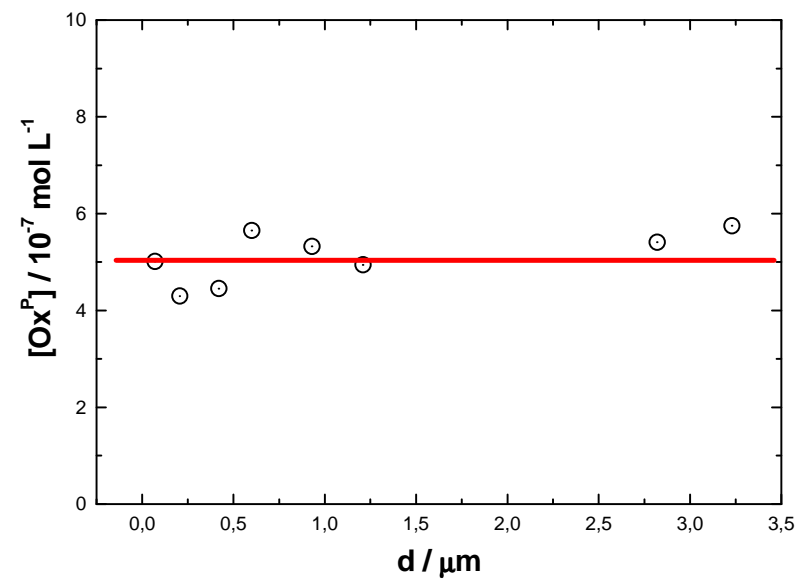

Figura 39: Efeito da espessura (d) na concentração de $H^{P}$ para o filme de PAni(Cl).

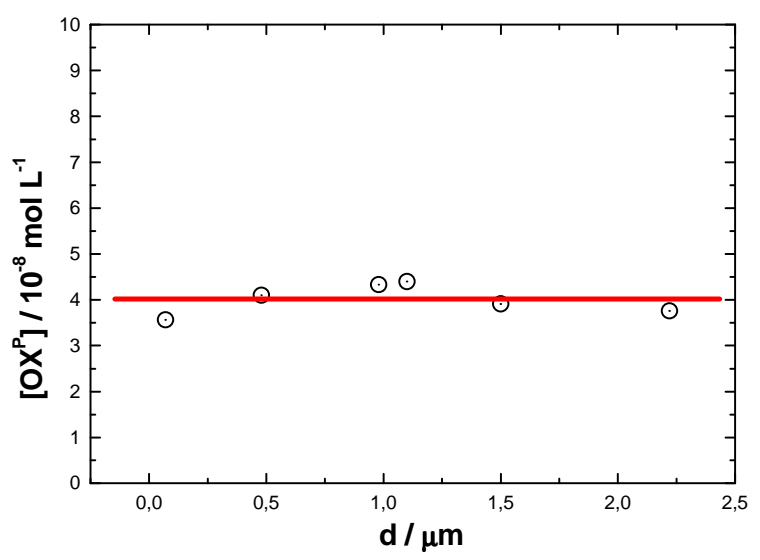

Figura 40: Efeito da espessura (d) na concentração de $\mathrm{HQ}^{\mathrm{P}}$, para o filme de $\operatorname{POMA}(\mathrm{Cl})$.

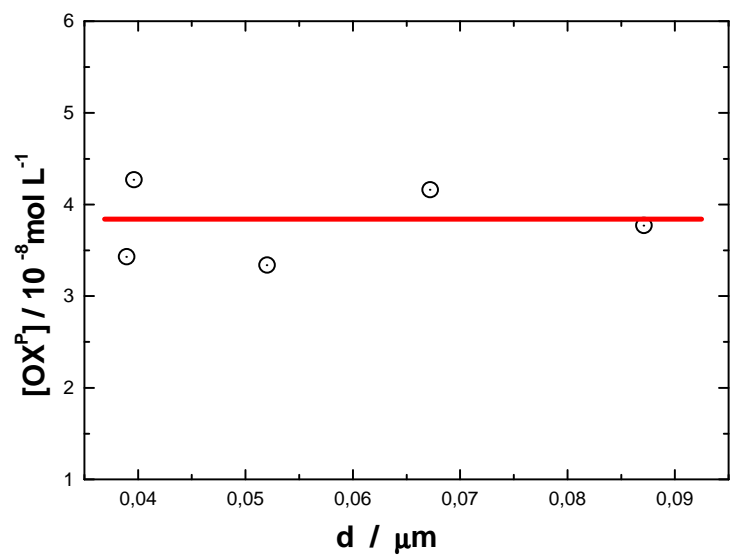

Figura 41: Efeito da espessura (d) na concentração de $\mathrm{HQ}^{\mathrm{P}}$, para o filme de $\operatorname{PAOMA}(\mathrm{Cl})$. 


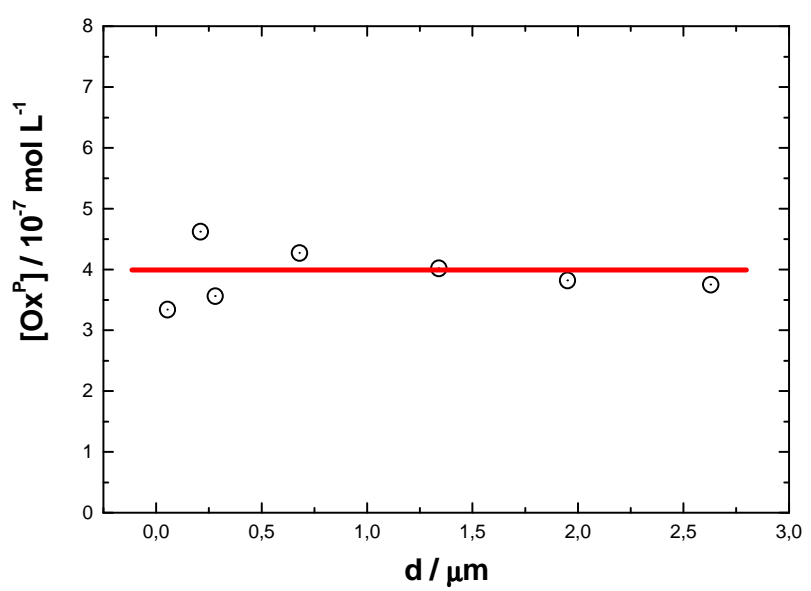

Figura 42: Efeito da espessura (d) na concentração de $\mathrm{HQ}^{\mathrm{P}}$ para o filme de PAni( $\left(\mathrm{SO}_{4}\right)$.

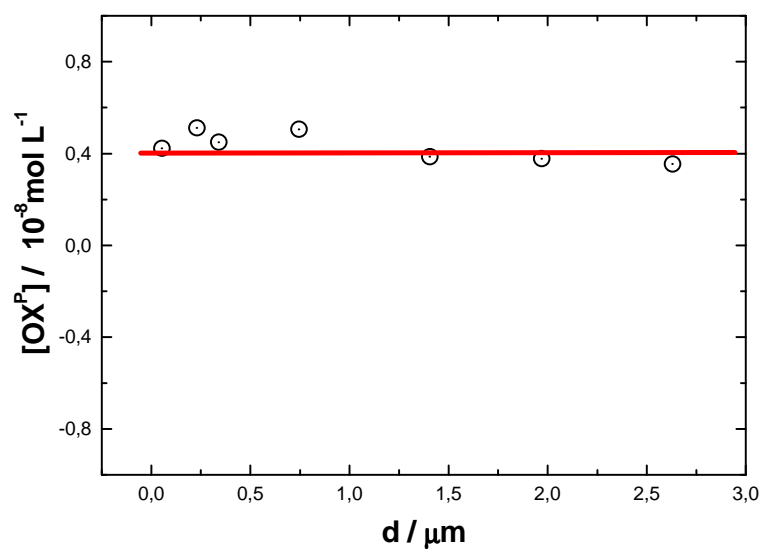

Figura 43: Efeito da espessura (d) na concentração de $\mathrm{HQ}^{\mathrm{P}}$ para o filme de $\mathrm{POMA}\left(\mathrm{SO}_{4}\right)$.

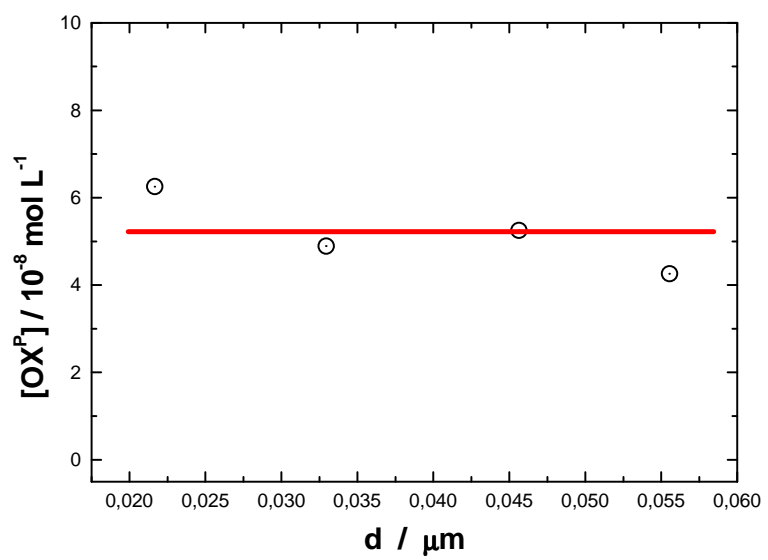

Figura 44: Efeito da espessura (d) na concentração de $\mathrm{HQ}^{P}$ para o filme de $\mathrm{PAOMA}\left(\mathrm{SO}_{4}\right)$. 
Tabela 5: Concentração Média de $\left[O x^{P}\right] / m{ }^{-1} \cdot L^{-1}$., para todos os filmes de polímeros e copolímeros.

\begin{tabular}{|c|c|}
\hline Filmes Poliméricos & $\begin{array}{l}\text { Concentração média de }\left[\mathrm{Ox}^{\mathrm{P}}\right] \\
\left(\mathrm{mol} . \mathrm{L}^{-1}\right)\end{array}$ \\
\hline PAni(Cl) & $5,0110^{-7}$ \\
\hline $\mathrm{POMA}(\mathrm{Cl})$ & $4,0110^{-8}$ \\
\hline $\mathrm{PAOMA}(\mathrm{Cl})$ & $5,1610^{-7}$ \\
\hline PAni $\left(\mathrm{SO}_{4}\right)$ & $3,9110^{-7}$ \\
\hline $\mathrm{POMA}\left(\mathrm{SO}_{4}\right)$ & $0,3610^{-9}$ \\
\hline $\mathrm{PAOMA}\left(\mathrm{SO}_{4}\right)$ & $3,7910^{-7}$ \\
\hline
\end{tabular}

Os resultados das concentrações de $\left[\mathrm{Ox}^{\mathrm{P}}\right]$ encontrados na tabela 5 , confirmam a que $\left[\mathrm{Ox}^{\mathrm{P}}\right]$ é constante independente da espessura $(\mathrm{d})$, dos filmes poliméricos [51].

A Figura 45 apresenta a variação de $E_{P}$ do par redox Quinona/Benzoquinona (Q/BQ) para todos os polímeros e copolímeros aqui estudados. A partir dos valores de $\Delta E_{P}$ pode ser discutido a reversibilidade do par redox $\mathrm{Q} / \mathrm{BQ}$ dos polímeros e também suas atividades catalíticas, quanto menor a $\Delta E_{P}$ maior é a reversibilidade do par redox $Q / B Q$ e maior é sua atividade catalítica.

Assim a ordem crescente de atividade catalítica é $\mathrm{Pt}<\mathrm{PAOMA}(\mathrm{Cl})<$ $\mathrm{PANI}(\mathrm{Cl})<\mathrm{PAni}\left(\mathrm{SO}_{4}\right)<\mathrm{POMA}(\mathrm{Cl})=\mathrm{POMA}\left(\mathrm{SO}_{4}\right)=\mathrm{PAOMA}(\mathrm{Cl})[52]$. 


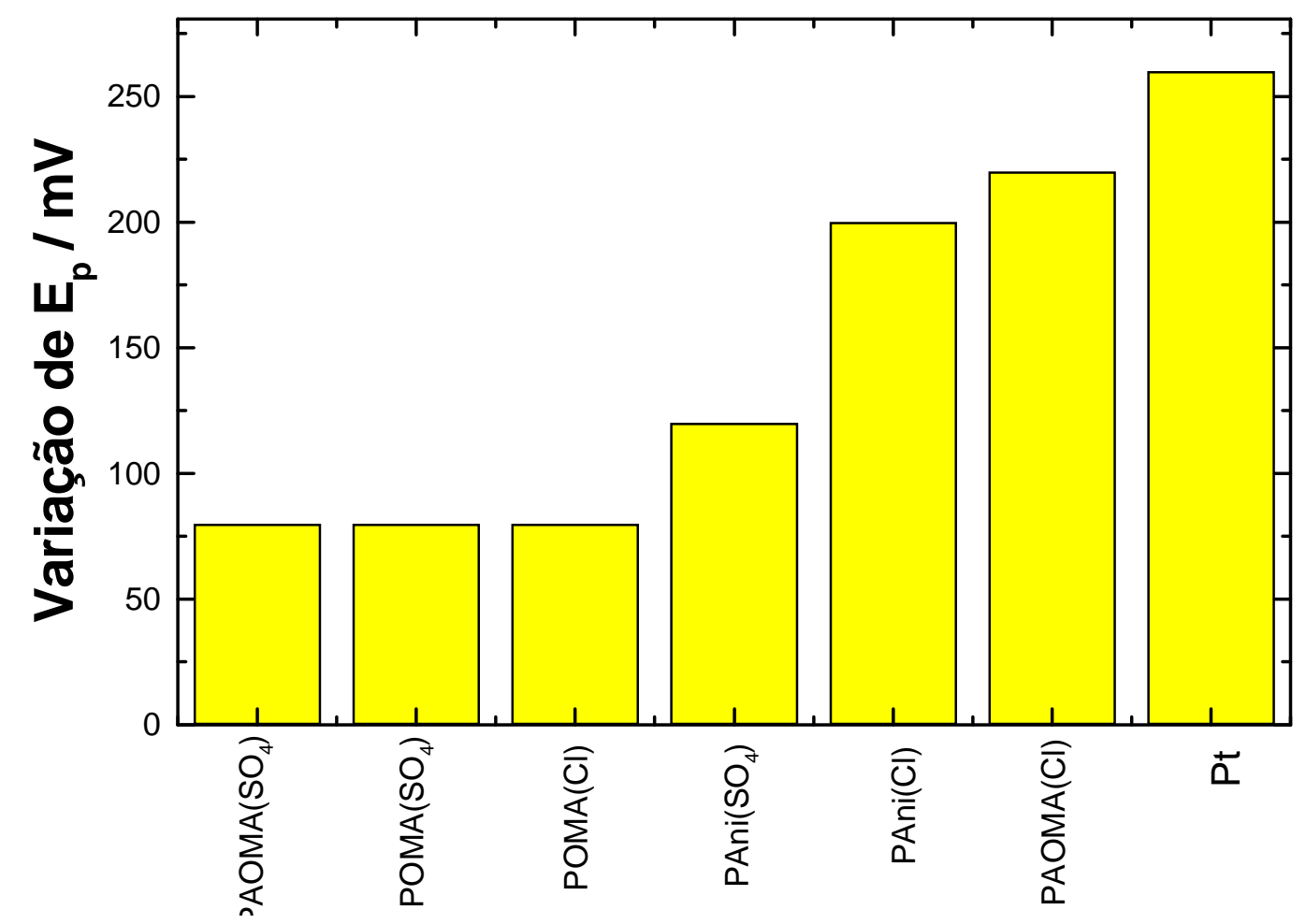

Figura 45: Valores de $\Delta E_{P}$ para o par redox Quinona/Benzoquinona para os filmes de polímeros e copolímeros. 


\section{Capítulo IV}

\section{Conclusões}

Utilizando filmes depositados com diferentes quantidades de carga (espessuras diferentes) e diferentes concentrações de $\mathrm{HQ}$, foi observado que os filmes de Pani, POMA e PAOMA possuem um comportamento eletrocatalítico na eletrooxidação da Hidroquinona.

Os filmes de PAni, POMA e PAOMA em meio de $\mathrm{HCl}$ com espessura de 2,82, 1,1 e 0,039 $\mu \mathrm{m}$ respectivamente apresentam melhor índice de detecção deste composto orgânico. Por outro lado, a comparação do desempenho dos polímeros testados mostrou que a PAni tem um limite de detecção mais elevado, por volta de 3 vezes o nível de corrente, para a POMA e 8 vezes para a PAOMA.

Já os filmes de PAni, POMA e PAOMA eletrossintetizados em meio de $\mathrm{H}_{2} \mathrm{SO}_{4}$ com espessura de $1,34,1,4$ e $0,032 \mu \mathrm{m}$, respectivamente apresentaram melhor índice de detecção para a Hidroquinona e como para os filmes eletrossintetizados em meio de $\mathrm{HCl}$ o filme de $\mathrm{PAni}\left(\mathrm{SO}_{4}\right)$ também mostrou um 
maior limite de detecção, por volta de 2 vezes o nível de corrente em comparação com a $\mathrm{POMA}\left(\mathrm{SO}_{4}\right)$ e 4 vezes para a $\mathrm{PAOMA}\left(\mathrm{SO}_{4}\right)$.

A interação da Hidroquinona, conversão da forma quinona (Q) para forma o-benzoquinona (BQ), com os filmes poliméricos se dá pela transferência de elétrons da forma oxidada do filme do polímero que está sendo retornada para a forma reduzida do mesmo.

As concentrações da forma oxidada do filme e de hidroquinona presente no filme são constantes por todo o filme polimérico.

A atividade catalítica e a reversibilidade do par redox Quinona/Benzoquinona foram obtidas a partir da variação de $E_{P}$, acompanhando a ordem crescente de atividade catalítica: $\mathrm{Pt}<\mathrm{PAOMA}(\mathrm{Cl})<$ $\operatorname{PANI}(\mathrm{Cl})<\mathrm{PAni}\left(\mathrm{SO}_{4}\right)<\mathrm{POMA}(\mathrm{Cl})=\operatorname{POMA}\left(\mathrm{SO}_{4}\right)=\mathrm{PAOMA}(\mathrm{Cl})$ 


\section{CAPITULO $V$}

\section{BIBLIOGRAFIA}

1. WESSLING, B. Dispersion on the link between basic research and commercial application of conductive polymer (polyaniline). Synthetic Metals, v. 92, p. 143-154, 1998.

2. JIN, Z..; SU, Y.; DUAN, Y. A novel method for polyaniline synsthesis whit the immobilized horseradish peroxidase enzyme Synthetic Metals, v. 122, p. 237-242, 2002.

3. SYED, A.A.; DINESAN, M.K., Polyaniline - A novel polymeric material review Talanta, v. 38, n. 8, p. 815-837, 1998.

4. MELO, C.P. Polímeros condutores. Ciência Hoje v. 6, n. 36, p.39-47, 1987.

5. CHIANG, C.K.; FINCHER Jr., C.R.; PARK, Y.W.; HEEGER, A.J.; SHIRAKAWA, H.; LOUIS, E.J.; GAU, S.C.; MACDIARMID, A.G. ElectricalConductivity in doped polyacetylene. Physical Review Letters, v. 39, n. 17, p. 1098-1101, 1977.

6. OKABAYASHI, K.; GOTO, F.; ABE, K.; YOSHIDA, T. Electrochemical studies of polyaniline and its applications Synthetic. Metals, v. 18, p. 365-370, 1987. 
7. MATTOSO, L.H.C. Polianilinas: síntese, estrutura e propriedades. Química Nova, v. 19, n. 4, p. 388-399, 1996.

8. SANTOS Jr., J.R.; MATTOSO, L.H.C.; MOTHEO, A.J. Investigation of corrosion protection of steel by polyaniline films Electrochimica Acta, v. 43, p. 309-313, 1998.

9. SCROSATI, B. Conducting polymers: advanced materials for new design, rechargeable lithium batteries. Polymer Internacional, v. 47, n. 1, p. 50-55, 1998.

10. JOSOWICZ, M.; JANATA, J. Electroactive Polymers in Chemical Sensors. In: SCROSATI, B. Applications of electroactive polymers. New York, Chapman \& Hall, 1993, p. 310-343.

11. KARIAKINA, E.E.; NEFTYAKOVA, L.V.; KARYAKIN, A.A. A high sensitive glucose amperiometric biosensor basead on Prussian-blue modified electrodes Analytical Letters, v. 27, n. 15, p. 2871-2882, 1994.

12. MORAES, S.R., Influência do Meio Reacional na eletrosíntese de Polianilina para Aplicação à corrosão de Aço, Instituto de Química de São Carlos, USP, Departamento de Físico Química, São Carlos, SP, 2001.

13. HSU, D.F.; GRATZL, M.; RILEY, A.M.; JANATA, J. Electrochemically deposited polythiophene-2 dry and wet relaxiation Journal Physical Chemistry, v. 94, p. 5982-5989, 1990.

14. HEINZE, J.; BILGER, R.; MEERHOLZ, K. BER. BUNS-GES. Electrochemically induced structural-changes in conducting polymers Physical Chemistry. v. 92, p. 1266-1271, 1998.

15. DEBARNOT, D.N.; EPAILLARD, F.P. Review: polyaniline as new sensitive layer for gas sensors. Analytica Chimica Acta, v. 475, p. 1-15, 2003.

16. SHARMA, S.; NIRKHE, C.; PETHKAR, S.; ATHAWALE, A.A. Chloroform vapour sensor based on copper/polyaniline nanocomposite. Sensors and Actuators B, v. 85, p. 131-136, 2002. 
17. LINDORFS, T.; IVASAKA, A. $\mathrm{pH}$ sensitive of polyaniline and its substituted derivates. Journal of Electroanalytical Chemistry, v. 531, p. 4352, 2002.

18. CHAN, W.H.; LEE, A.W.M.; LAM, Y.S.; WANG, K.M. Fluorescent sensor based on newly synthesized fluorescein octadecyl ether octadecyl ester (FODEE) for direct determination of phenols in aqueous solutions. Analytica Chimica Acta, v. 351, p. 197-203, 1997.

19. RUZGAS, T.; EMNÉUS. J.; GORTON, L.; MARKO-VARGA, G. The development of a peroxidase biosensor for monitoring phenol and related aromatic compounds. Analytica Chimica Acta, v. 311, p. 245-253, 1995.

20. CHANG, S.C.; RAWSON, K.; McNEIL, C.J. Disposable tyrosaneperoxidase bi-enzyme sensor for amperometric detection of phenols. Biosensors \& Bioeletronics, v. 17, p. 1015-1023, 2002.

21. SHAN, D.; MOUSTY, C.; COSNIER, S.; MU, S. A composite poly-azure B-clay-enzyme sensor for the mediated electrochemical determination of phenols. Journal of Electroanalytical Chemistry, v. 537, p. 103-109, 2002.

22. LIU, S.; YU, J.; JU, H. Renawable phenol biosensor based on tyrosinasecolloidal gold modified carbon paste electrode. Journal of Electroanalytical Chemistry, v.540, p.61-67, 2003.

23. RIUL JUINOR, A.; SOTO, A.M.G.; MELLO, S.V.; BONE, S.; TAYLOR, D.M.; MATTOSO, L.H.C. An eletronic tongue using polypirrol and polyaniline. Synthetic Metals, v. 32, p. 109-116, 2003.

24. QUAN, D.E., SHIN, WOONSUP. Sensing characteristics of tyrosinase immobilized and tyrosinase laccase co-imobilized platinum electrodes Bulletin of the Korean Chemical Society. v. 25, n. 8, p. 833, 2004.

25. PRASAD, K.R.; MUNICHANDRAIAH, N. The Chemical Educator, v. 7, n. 2, p. 84, 2002. 
26. GAZOTTI JÚNIOR., W.A.; FAEZ, R.; DE PAOLI, M.A. Electrochemical, electrochromic and photoelectrochemical behavior of a highly soluble polyaniline derivative: poly(o-methoxyaniline) doped with functionalized organic acids. Journal of Electroanalytical Chemistry, v. 415, p. 107-113, 1996.

27. CAMPBELL, D.; WHITE, J.R. Polymer caracterization-physical techniques. London: Chapman \& Hall, 2000, p. 481.

28. CHEN, Y.; KANG, E.T.; NEOH, K.G. Electroless polymerization of aniline on platinum and palladium sufaces. Applied Surface Science, v. 185, p. 267276, 2002.

29. SAZOU, D.; GEORGOLIOS, C. Formation of conducting on iron surface by electropolymerization of aniline in aqueous solutions. Journal of Electroanalytical Chemistry, v. 429, p. 81-93, 1997.

30. LIAO, C.; GU, M. Electroless deposition of polyaniline film via autocatalytic polymerization of aniline. Thin Solid Films, v. 408, p. 37-42, 2002.

31. KANATZIDIS, M.G. Conductive polymers. Chemical Engineer News, v.3, p.36-54, 1990.

32. TRIVEDI, D.C. Conductive Polymers: synthesis and electrical properties. In: NALWA, H.S. Handbook of organics conductive molecules and polymers. New York: John Wiley, 1997. v. 2, p. 505-572.

33. MATTOSO, L.H.C.; OLIVEIRA JÚNIOR, O.N.; FARIA, R.M.; MANOHAR, S.K.; EPSTEIN, A.J.; MACDIARMID, A.G. Synthesis of polyaniline/polytoluidine block copolymer via the pernigraniline oxidation state. Polymers International, v.35, n.1, p.89-93, 1994.

34. GEIBLER, U.; HALLENSLEBEN, M.L.; TOPPARE, L. Electrochemical studies on carbazole/pyrrole-copolymers. Synthetic Metals, v. 55-57, p. 14831488, 1993. 
35. GENIÈS, E.M.; LAPOKOWSKI, M. Spectroelectrochemical evidence for an intermediate in the electropolymerization of aniline. Journal Electroanalytical Chemistry, v. 236, p. 189-197, 1987.

36. GENIES, E.M.; LAPKOWSKI, M.; PENNEAU, J.F. Cyclic voltammetry of polyaniline: interpretation of the middle peak. Journal Electroanalytical Chemistry, v. 249, p. 97-107, 1998.

37. SHIM, Y. B.; WON, M.S.; PARK, S.M. Electrochemistry of conductive polymers VIII. In situ spectrochemical studies of polyaniline growth mechanisms. Journal Electrochemical Society, v. 137, n. 2, p. 538-544, 1990.

38. CATTARIN, S.; DOUBOVA, L.; MENGOLI, G.; ZOTTI, G. Electrosynthesis and properties of ring-substituted polyanilines. Electrochimica Acta, v. 33, n. 8, p. 1077-1084, 1998.

39. BÜTTNER, E.; HOLZE, R. Hydroquinone oxidation electrocatalysis at polyaniline films. Jouranl of Electroanalytical Chemistry, v. 508, p. 150-155, 2001.

40. PATIL, S.; MAHAJAN, J.R.; MORE, M.A; PATIL, P.P. Influence of supporting electolyte on the electrochemical synthesis of poly(o-methoxyaniline) thin films. Materials Letters, v. 39, p. 298-304, 1999.

41. TANG, J.; JING, X.; WANG, B.; WANG, F. Infrared spectra of soluble polyaniline. Synthetic Metals, v. 24, p. 231-238, 1988.

42. OSHAKA, T.; OHNUKI, Y.; OYAMA, N. IR absorption spectroscopic identification of electrocative and electroinative polyaniline films prepared by the electrochemical polymerization of aniline. Journal Electroanalytical Chemistry, v. 161, p. 399-405, 1984.

43. CAO, Y.; LI, S.; XUE, Z.; GUO, D. Spectrocopic and electrical characterization of some aniline oligomers and polyaniline. Synthetic Metals, v. 16, p. 305-315, 1986.

44. MATTOSO, L.H.C. Sínstese, caracterização e processamento de polianilina e seus derivados. São Carlos, 1993. p.95. Tese (Doutorado) Departamento de Materiais, Universidade Federal de São Carlos. 
45. STEJSKAL, J.; KRATOCHVÍL, P.; RADHAKRISHNAN, N. Polyaniline dispersions. 2. UV-Vis absorption spectra. Synthetic Metals, v. 61, p. 225-231, 1993.

46. MATTOSO, L.H.C.; MANOHAR, S. K.; MACDIARMID, A.G.; EPSTEIN, A.J. Studies on the chemical syntheses and on the charactheristics of polyaniline derivatives. Journal Polymer Science, Parte A: Polymer Chemistry, v. 33, p. 1227-1234, 1995.

47. SANTOS JÚNIOR., J.R. Síntese, caracterização e análise morfológica de polianilina eletropolimerizada na presença de diferentes ácidos. São Carlos, 1995, p.103, Tese (Doutorado) - Instituto de Química de São Carlos, Universidade de São Paulo.

48. DUI'C, Lj.; GRIGI'C S. The effect of polyaniline morphology on hydroquinone/quinine redox reaction Electrochimica Acta, v. 46, p. 2795-2803, 2001.

49. MOTHEO, A.J.; PANTOJA M.F.; VENANCIO, E.C. Effect of monomer ratio in the electrochemical synthesis of poly(aniline-co-o-methoxyaniline), Solid States Ionics, v. 171, p. 91-98, 2004.

50. ALBERY, W.J.; HILLMAN, A.R. Transport and Kicetics in modified electrodes. Journal Electroanalytical Chemistry, v. 170, p. 27-49, 1984.

51. YANO, J.; KOKURA, M.; OGURA, K. Electrocatalytic behavior of a poly( $N$-methylaniline) filmed electrode to hydroquinone. Journal of Applied Electrochemistry, v .24, p. 1164-1169, 1994.

52. MALINAUKAS, A.; HOLZE, R. Electrocatalysis of the Quinona/Hydroquinone system by electrodes coated with substituted polyaniline. Ber Bunsenges. Phys. Chem. , v. 100, n. 10, p. 1740-1745, 1996. 